\title{
USING A LOCAL NETWORK TO SUPPORT INTERNATIONALISATION: \\ A CASE STUDY FROM NEW ZEALAND
}

By

Vickesh Kambaran

\begin{abstract}
A thesis
submitted to the Victoria University of Wellington in partial fulfilment of the requirements for the degree of Master of Management Studies
\end{abstract}

Victoria University of Wellington 2009 


\begin{abstract}
This thesis explores how collaboration amongst a network of companies can lead to successful internationalisation. Positioned between the network and internationalisation literature, this research used a successful case study where a New Zealand company supported by a network local of companies won a \$21 million export contract to supply retail payment terminals to a Malaysian oil company. The research focused on the network formation, structure and evolution over time. In addition, the roles and performance of the network were also examined.
\end{abstract}

The research method focused on a successful case and involved in-depth interviews with senior management of four companies. This was coupled with network analysis based on data extracted from the interview transcripts. Capturing chronological data was made possible by using a historical approach.

There are several insights worth noting that surfaced from the results. First, relationally embedded ties appear to have reinforcing network effects. For example, the case shows how relationally embedded ties influence resource acquisition. Second, in examining the evolution of the network over time, the data captured shows how a closed network formed bridges across structural holes, leading to 'structural autonomy.' The third contribution of this research is the identification and integration of internationalisation theories within the case. As such, this thesis has made a series of contributions to the area of network dynamics that supports successful internationalisation. 


\section{Acknowledgements}

I would like to thank my family, Monty, Nisha, Andrisha and Jamie, who always encouraged and supported me. They provided me with the confidence and belief to pursue my goals. At times when I faltered, they were always there to guide me. I dedicate my thesis to my family and especially my parents who are my inspiration.

I am grateful to my supervisor Dr. Val Lindsay. Val provided the stimulation, guidance, knowledge and patience to take my interests and ideas and turn them into this thesis. She has supported my initiatives outside the scope of this thesis and has become a mentor and friend. Thank you.

I also would like to thank Lakshmi Narayanan, who has given me the inspiration and energy to keep going. Her love, support and encouragement has been tremendously helpful. Thank you.

I also would like to express my gratitude to my manager John Kilkenny. It helped a great deal to have his understanding and support.

Lastly, without the goodwill, interest and openness of the companies involved this research would not have been possible.

Thank You. 


\section{Contents}

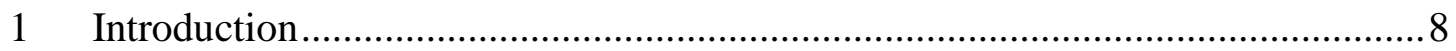

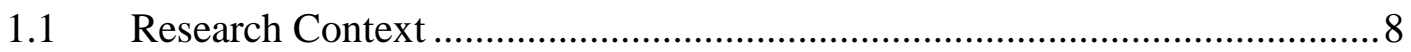

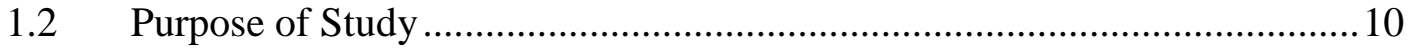

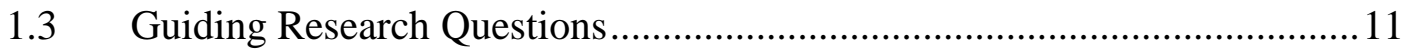

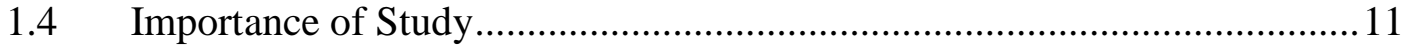

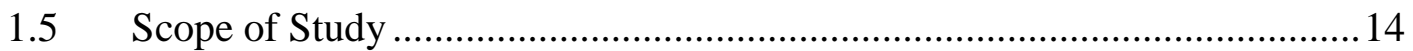

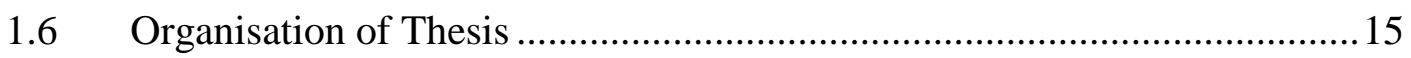

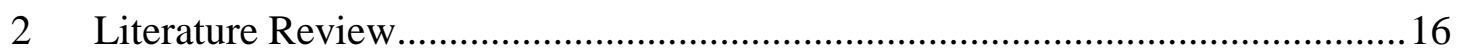

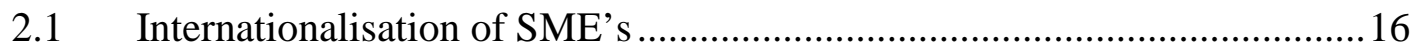

2.2 Internationalisation literature in New Zealand .........................................20

2.3 The Network Perspective .........................................................................22

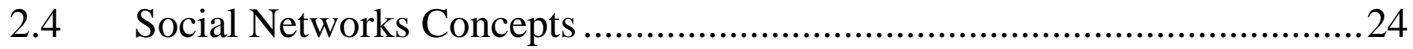

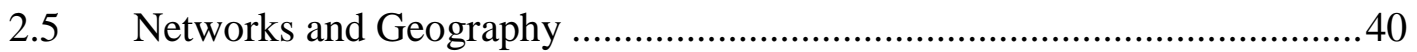

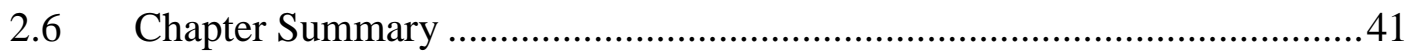

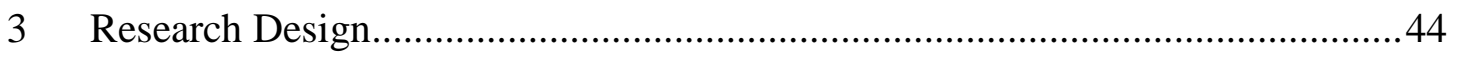

3.1 Overview of the Research Process..............................................................44

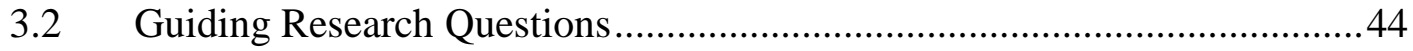

3.3 Research Perspective and Unit of Analysis .............................................45

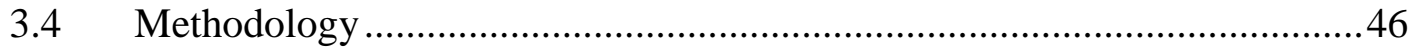

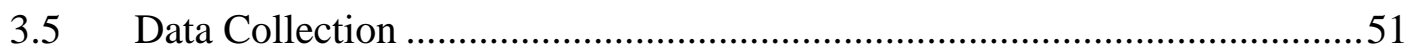

3.6 Data Preparation and Analysis ................................................................54

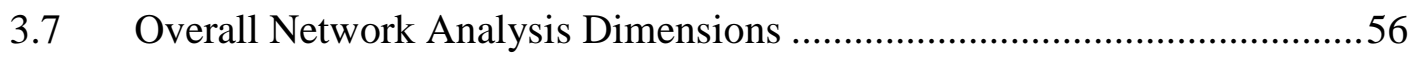

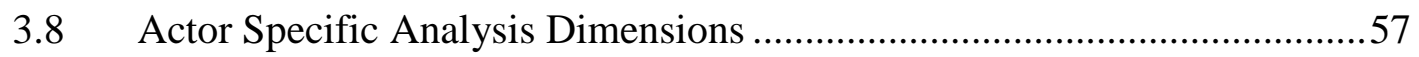

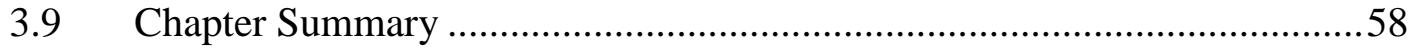

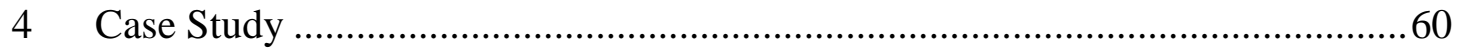

4.1 List of Companies in the Network …......................................................60

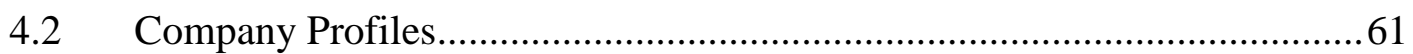

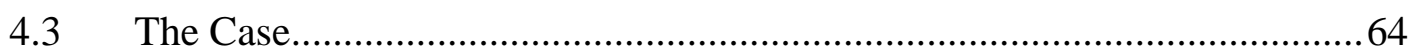

4.4 High-level Timeline of the Network ......................................................... 70

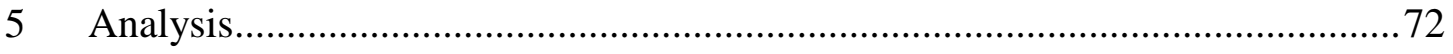

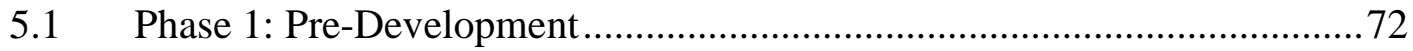




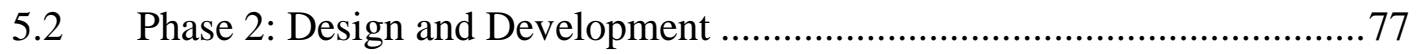

5.3 Phase 3: Production and Future Opportunities ...........................................8 84

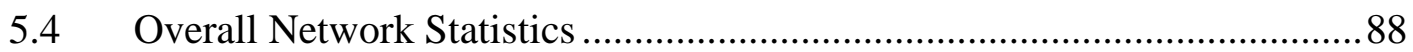

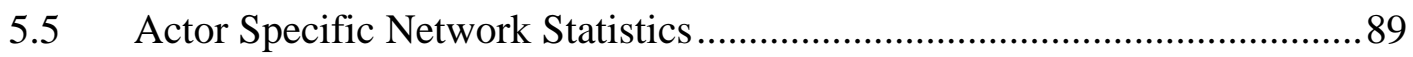

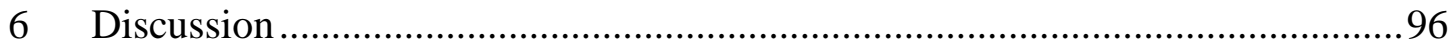

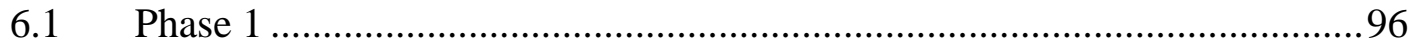

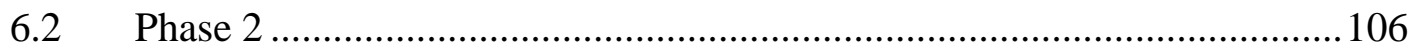

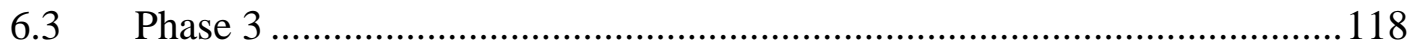

6.4 Performance Consequences of the Network ............................................ 121

6.5 Links to the Research Questions ............................................................ 122

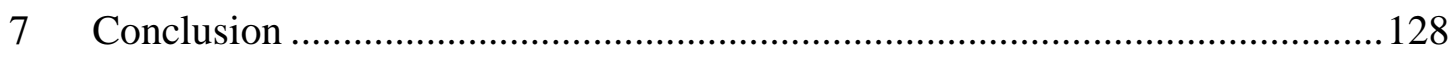

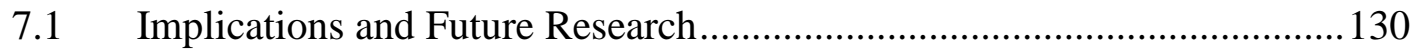

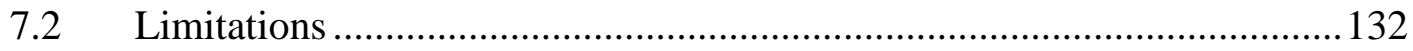

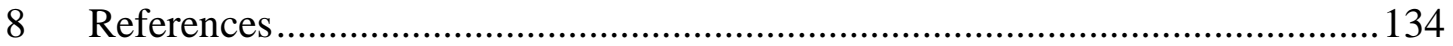




\section{List of Tables and Figures}

\section{Tables}

Table 1: Summary of Social Network Concepts

Table 2: Benefits of the Bifocal Research Lens (Coviello, 1995)

Table 3: The different dimensions of network analysis methods (Tichy, Tushman and Fombrun 1979)

Table 4: Three Phases of Network Development

Table 5: Qualitative Analysis Dimensions: Table Headings

Table 6: Example of a matrix representing network relationships for UCINET

Table 7: Overall Network Quantitative Analysis Dimensions

Table 8: Actor Specific Quantitative Analysis Dimensions

Table 9: Research Design Summary

Table 10: List of Companies in the Network

Table 11: Company Profiles

Table 12: High-level Timeline of the Case

Table 13: Phase 1 Network Features

Table 14: Phase 2 Network Features

Table 15: Phase 3 Network Features

Table 16: Overall Network Analysis Statistics by each phase

Table 17: Size and brokerage scores for each actor, across each phase

Table 18: Phase 1 Centrality Scores

Table 19: Phase 2 Centrality Scores

Table 20: Phase 3 Centrality Scores

Table 21: Phase 1 Structural Holes Measures

Table 22: Phase 2 Structural Holes Measures

Table 22: Phase 3 Structural Holes Measures 


\section{Figures}

Figure 1: Non-Redundant and Redundant Ties (Burt, 1992)

Figure 2: Weak Ties and Structural Holes (Burt, 1992)

Figure 3: Bridge across a structural hole and the broker role (Burt, 1992)

Figure 4: Phase 1 Network Map

Figure 5: Phase 2 Network Map

Figure 6: Phase 3 Network Map

Figure 7: Phase 1 Network Map

Figure 8: Phase 2 Network Map

Figure 9: Phase 3 Network Map 


\section{Introduction}

This thesis uses a case study and network analysis approach to examine a network of organisations in New Zealand. The aim is to understand how their relationships lead to the forming of an international business agreement. Of central focus to this research is the network, its structure and evolution over time.

This chapter outlines the context of the study including the phenomenon of networks in New Zealand and the role of internationalisation for New Zealand. The purpose of the research, and the questions that will guide the investigation, is then discussed. The importance and relevance of the research is presented followed by a brief discussion on the scope of the thesis. Finally, a description of the overall document structure is presented.

\subsection{Research Context}

The New Zealand business landscape provides a specific research context for two main reasons that are central to this thesis. First, New Zealand is a set of small islands in the south-western Pacific Ocean, approximately 2,000 km south-east of Australia, making it small and geographically isolated from global markets (Campbell-Hunt and Chetty, 2004, Campbell-Hunt, Chetty and Mattear, 2005, Wikipedia, accessed $14^{\text {th }}$ November 2008).

Second, the majority of businesses in New Zealand are small to medium enterprises (SME) where $89 \%$ of enterprises employ 5 or less people (SME's in New Zealand: Structure and Dynamics 2008, Ministry of Economic Development, 2008). This is significant because SME's tend to have limited resources (Oviatt and McDougall, 1999; Chetty and Holm, 2000).

Given these factors, the New Zealand Government has consistently promoted the collaboration of SME's to support the country's trading performance and international competitiveness (Chetty and Holm, 2000). 
"The lack of proximity to large markets is a key reason for this poor exporting performance...This means that many New Zealand firms remain small, constrained by the size of the New Zealand market." (The Office of the Prime Minister, 17:2002)

Collaboration between organisations typically takes the form of business networks which can be defined, in this context, as a set of two or more connected business relationships (Emerson, 1981).

The rationale is that networks facilitate market efficiencies and create business opportunities (Burt, 1977; Granovetter 1985; Coleman, 1988; Bucklin and Sengupta, 1993; Uzzi, 1997; Håkanson and Snehota 1997; Sasi and Arenius, 2008). Networks of organisations are seen as key drivers to economic growth and have become more prominent than traditional value chain structures due to their flexibility, innovation and specialisation (Roelandt and Hertog, 1998).

Over the last 10 to 15 years research on how organisational networks evolve has developed into a new research field (Coviello, 2005). This allows a better understanding of how businesses can access international markets. Previous research has shown that there is limited explanation as to how companies develop international contracts (Chetty and Holm, 2000) and little is known about firm conduct in a network context (Gulati, Nohria and Zheer, 2000; Hendry, Brown and DeFillippi, 2000). Insights from this research may contribute to this relatively new research field.

The distance from large markets is a constraint on New Zealand's international competitiveness. New Zealand depends on international markets to drive economic activity and access to these markets also allows New Zealand to keep pace with market changes. A New Zealand government report called 'Growing an innovative New Zealand' confirms the importance of these international linkages which they term 'economic integration': 
“...economic integration with the rest of the world to expand our potential market is critical...New Zealand's ability to integrate with the rest of the world and to keep pace with technological change is made more difficult by its distance from major markets...Great integration will not only assist the exchange of good and services it will also increase our access to skilled people, capital, ideas and knowledge." (The Office of the Prime Minister, 44:2002)

Thus, New Zealand's integration with global markets is important because it allows New Zealand to keep pace with technological change, access skilled people, capital, ideas and knowledge. My research interest is aligned to that of the New Zealand government (outlined above) and the private sector; to better understand how New Zealand can integrate with global markets.

An example of international economic integration is a single customer-supplier between New Zealand and another country. If the majority of New Zealand companies are SME's, how can they collaborate as networks to develop international relationships? In an attempt to address this question the following research aims to understand how a network of companies develop a successful international relationship.

\subsection{Purpose of Study}

Within the research interest outlined above, the purpose of this thesis is to examine a network of organisations in New Zealand to understand how their relationships lead to the forming of an international business agreement.

By focusing on a successful international transaction, this research captures qualitative and quantitative network data to map the business relationships over time. 


\subsection{Guiding Research Questions}

Based on the New Zealand context and interest in networks and internationalisation introduced earlier, the research questions presented below are intended to guide the research process. Research questions provide specific areas to investigate.

In a case of an organisation achieving international success, how does the supporting network structure evolve?

Specifically,

1. How does the network form?

2. How is it organised and structured?

3. How does the network change and evolve over time?

4. How distinctive are the firm roles within these relationships?

5. What are the performance consequences for companies in the network?

These questions have been used to provide direction in researching the literature, collecting data and also the analysis of the data.

\subsection{Importance of Study}

Addressing these research questions will provide insights across three areas of research. First, there is limited research and understanding on how a network changes over time and the role they play in the internationalisation of member companies. Internationalisation refers to the process of increasing international involvement in terms of increasing foreign market knowledge and resource commitment (Johansson and Vahlne, 1990).

Second, economic development policy has a strong interest in promoting international business and this research provides an account of how a group of companies collaborate over time to develop world-class capabilities. 
Finally, using a historic case methodology, coupled with network analysis, provides a unique research perspective that captures time, quantitative and qualitative network data. This research will test the practical use of this methodology. The following sections explain these three areas in more detail.

\subsubsection{Contribution to Organisational Network Research}

Studying networks of organisations as a phenomenon is a relatively new area of research particularly in regard to network initialisation and evolution (Kosa and Lewin, 1999, Gulati, 1998). Examining the literature on organisational networks shows a consistent interest and demand for a more dynamic view that captures network evolution (Aldrich, Reese and Dubini, 1990; Hite and Hesterly, 2001; Human and Provan, 2000; Larson and Starr, 1993). By taking a historic perspective and triangulating several data sources, this thesis is able to show how a network changes over a fixed period of time.

Uppsala University has driven a major area of research into networks and internationalisation (Turnbull and Valla, 1987, Holm and Johanson, 1997) and have noted there is "...little research on the international linkages and relationships between firms that accompany international business operations in network configurations” (Todeva, 2001). In light of this, New Zealand has delivered pockets of network research that focus on internationalisation and innovation.

This thesis builds on network analysis studies (Burt 1982, 1992, Nohria and Eccles, eds. 1992) and the relational approach to internationalisation of the Uppsala University (Johansson and Mattson, 1988, 1992; Hakansson and Snehota, 1995; Hakansson and Johanson, 1993). In terms of the methodology, it largely follows Coviello's (1995) work which relies on the case study method to drive both qualitative and quantitative analysis of networks. 
Previous research has shown how network positions can influence organisational learning (Powell, Koput and Smith-Doerr, 1996) and similar to work by Ahuja (2000), this thesis provides an account on how effective communication flows within a network can result in innovation. While not a direct focus of this research, there has been little work using analysis of networks to investigate the development of innovative products and the role it plays in organisational learning (Ahuja, 2000). In this case, product innovation is central to competing in the international marketplace and the networks success. As such, this research will contribute to the network literature providing quantitative and qualitative case evidence of social network concepts within an internationalisation context.

\subsubsection{Networks and International Business}

Access to international markets is driven by access to international customers. Using a network of organisations to access customers is vital (Johansson and Wiedersheim Paul 1975, Johanson and Vahlne, 1977). As mentioned previously, New Zealand's economic development policy, at both local and national levels, promotes collaboration and networking to support internationalisation (Ministry of Economic Development, 2008, Available: http://www.med.govt.nz/templates/Page_16234.aspx, Accessed: 18 December 2008). The interest of New Zealand's Ministry of Economic Development lies in stimulating economic activity in New Zealand, creating jobs and driving innovation.

The competitiveness of New Zealand business is of considerable concern, on a number of measures because the New Zealand economy has under-performed (Crocombe, Enright and Porter 1991). The weaknesses of the New Zealand economy have been attributed to a number of factors, including size (Simmons 2001), location (McCann 2003) and economic structure (Crocombe, Enright and Porter 1991).

Understanding how businesses organically form networks that meet international market demands will give economic development policy makers a clearer 
indication of the role government can play in supporting network development and harnessing its positive effects (Solberg and Durrieu, 2004).

\subsubsection{Combining Network Analysis and Case Study Approaches to Organisational Research}

Although Coviello's (1995) research method is now over 14 years old, developing quantitative data for network analysis from a case study is still relatively new. It provides a holistic account of network dynamics by the application of qualitative and quantitative network data that is generated from analysis of interview data (Coviello, 1995). Although not a central focus, in addressing the research questions this thesis will provide feedback on this research methodology in addressing network evolution.

\subsection{Scope of Study}

This thesis will examine a single case study that tracks the design and manufacture of a product that primarily involves four organisations based in New Zealand. The case study and network analysis integrates qualitative and quantitative approaches as set out by Coviello (1995) and spans the product development from design to delivery.

Primary research involved in-depth interviews with senior leadership in each of the four companies. Secondary research was captured from news articles and company websites. Further information on the research methodology can be found in Chapter 3: Research Design. 


\subsection{Organisation of Thesis}

Chapter 2 will discuss in-depth the internationalisation and network literature. The internationalisation literature provides the context for research and the network analysis literature provides the approach and tools for the investigation.

Having established an understanding of the phenomenon, Chapter 3 outlines the research design. This means, given this research topic, what methods are most suitable to answer the research questions posed in Chapter 2. Chapter 3 also discusses the preparation of the data and the approach to analysis.

A narrative of the case is then presented and this captures a rich and holistic account of the actors, decisions, activities and outcomes of the network. The case study in Chapter 4 also sets the scene for the analysis presented in Chapter 5, which presents both a qualitative and quantitative analysis.

A discussion of the results takes place in Chapter 6, which is structured into the 3 phases of the network development. This chapter will link the results of the qualitative and quantitative analysis with references back to concepts discussed in the literature review. The last section of Chapter 6 revisits and addresses the research questions.

Finally, the conclusion will discuss the contribution of this research and implications are drawn out for managers, policy makers and researchers. This is then followed by a discussion on the limitations of the thesis. 


\section{Literature Review}

As described in Chapter 1, this thesis examines a network of organisations which collaboratively develops a product that results in an international contract. Given that the context of research is the internationalisation of SME's, a review of the internationalisation literature is presented followed by briefly looking at similar network-oriented internationalisation studies in New Zealand.

As part of the internationalisation literature, a network model of how organisations internationalise, developed by Johanson and Mattson (1988), will be explored. This model provides a foundation to understanding how organisations use networks to develop international opportunities. While it is not the only network model that addresses internationalisation, it has pioneered the theory on the role of networks in the internationalisation process.

Shifting focus to the network and network processes, the rest of the Chapter will provide a review of the literature concerning social networks, as they relate to organisations, beginning with an introduction of the social network perspective.

Specific network concepts will then be explained as these provide the basic constructs for analysis. In developing a technical understanding of networks, the literature will then conclude with a discussion on organisational networks and their externalities or role in a wider economic context.

\subsection{Internationalisation of SME's}

Through the reduction of tariffs and decreases in the cost of travel and information access, globalisation has led to a decrease in the resources required for organisations to enter foreign markets. This has increased competition levels globally, but also allowed smaller companies with less scale and resources to compete in global markets (Etemad, 2004; Coviello and McAuley, 1999). 
Initial research on the international activities of SME's focused on characteristics such as export performance, size and behaviour (Coviello and McAuley, 1999). More recently however, this research focus has shifted to understanding the processes that drive the internationalisation of SME's (Coviello and McAuley, 1999).

Internationalisation refers to the process of increasing awareness of international activities and the establishment of transactions with foreign countries (Beamish, 1990). The research interest has resulted in three main bodies of research which examine how SME's internationalise. They are the Foreign Direct Investment (FDI) model, the Stage models and the Network model of internationalisation (Johanson and Mattson, 1988).

After describing the FDI and Stage models, a detailed account of the Network model is presented due to its relevance to the research question.

\subsubsection{The Foreign Direct Investment (FDI) Model of Internationalisation}

The FDI model views the internationalisation process as a series of investment decisions based on organisational structure and location. For example, a firm may choose to locate an operation in a foreign country if the overall economic costs are lower or minimised. This model has been criticized for its emphasis on investment patterns and decision making by managers (Coviello and McAuley, 1999). As such, it is largely an economic model based on transaction costs.

\subsubsection{The Stage Models of Internationalisation}

In contrast, the Stage models of internationalisation are behavioural and refer to an incremental step-wise process based on learning through experience. This model highlights learning about international markets from low risk activities, such as exporting to similar markets, and using these experiences to drive further economic commitment to more distance markets (Coviello and McAuley, 1999). 
Each 'stage' represents higher levels of commitment and changes in firm orientation toward international markets. The most popular version of this model was pioneered by Johanson and Vahlne (1997) from the Uppsala University in Sweden and is referred to as the Uppsala model.

\subsubsection{The Network Model of Internationalisation}

By examining the internationalisation process through a network lens, Johanson and Mattson (1988) acknowledge that long-term relationships facilitate economic transactions. Furthermore, relationships are time-consuming and they can take years to establish requiring trust and resources to overcome distance and resource requirements (Johansson and Mattson, 1998; Scholl, 2006).

"These relationships influence the decision for market strategies as well as they ensure the functioning of the market in general." (Scholl, 2006:11)

Entry into a new market is thought to be dependent on network position as it provides access to social capital or resources, information and opportunities (Johansson and Mattson, 1988). Social capital refers to the benefits a person or organisation receives through relationships with friends, colleagues and other contacts (Burt, 1992, 2000).

Recognising the concept of social capital, the network model of internationalisation assumes firms are dependent on the resources controlled by others and can access them through positions within the network. It is interesting to note the emphasis the authors Johansson and Mattson (1988) put on the cost of achieving this position. The network position is then synonymous with the traditional market asset concept.

Along with financial and human capital, social capital refers to the relationships a person or organisation has through friends, colleagues and other contacts (Burt, 1992). Social capital refers to opportunities that can arise from these relationships, 
such as job offers, inclusion in special projects and so on. As with all forms of capital it is viewed as an investment with expected returns (Lin, 2001).

In summary, Scholl (2006) notes:

\begin{abstract}
"The Network Approach considers internationalization to be the attempt of a firm to establish and develop its position in the network through international extension, penetration, and international integration. This model determines the degree of internationalization by the extent to which the company holds certain positions in different national nets, and the degree of relevance and integration of those positions. Internationalization means an increase in the number and strength of relationships between different parts of the global network." (Scholl, 2006:12)
\end{abstract}

A key assumption behind the network approach, when internationalising, is that specific relationships may lead to information about international business opportunities or potential partners and introductions to these potential partners (Scholl, 2006). Similarly, Ellis (2000) finds that awareness of opportunities in foreign markets are acquired from existing social ties. Knowledge of entrepreneurial opportunities depends on the informational benefits of the actors network. Their study finds that the formal mechanisms to explore international opportunities are hardly ever used in practice, as most are facilitated through relationships (Ellis, 2000). International markets do not appear anonymous as they can be identified as social networks. Todeva (2001) identifies a need for further research on the networks that support international relationships:

\footnotetext{
"There is very little research on the international linkages and relationships between firms that accompany international business operations in network configuration... The bulk of the literature on international business networks has not recognised yet the rich conceptual apparatus of network analysis...” (Todeva, 2001)
}

Using a longitudinal case study approach, Bohmanm, Boter and Tesar (2003) explore how a group of companies network to meet the demand of large 
customers. They find that actors play different role models at various stages of network development. These roles drive processes such as environmental scanning, strengthening ties and identification/exploitation of opportunities, thus highlighting the role of key entrepreneurs exploiting the network intentionally (Bohmanm, Boter and Tesar, 2003).

This thesis takes a similar longitudinal case-study approach to Bohmanm, Boter and Tesar (2003). However, the emphasis is on how the network contributes to the establishment of an international contract and hence, focuses on internationalisation as opposed to the entrepreneurship of the local companies. Fletcher (2008) has also taken a longitudinal approach in examining internationalisation from a network perspective. However, Fletcher's (2008) unit of analysis is the life-cycle of an Australian company in contrast to this thesis, where the unit of analysis is the network and a particular contractual outcome.

In relation to the internationalisation literature, it specifically addresses how a local network supports internationalisation.

\subsection{Internationalisation literature in New Zealand}

The following section highlights internationalisation literature in New Zealand that specifically focuses on networks. The aim here is to identify research gaps and outstanding issues within this area.

Using a case study and resource-based view of the firm, Chetty and Wilson (2002) explore how companies in New Zealand internationalise in comparison to the Uppsala stage model and the International New Venture (INV) model. An INV is a business that from inception maintains its competitive advantage through participation and commitment to international markets (Oviatt and McDougall, 1994, Coviello, 2006). In relating the network internationalisation model to New Zealand, Chetty and Wilson (2002) have found that SME's need to collaborate with competitors in order to build the capability to internationalise whereas prior 
research has tended to examine only vertical links. However, the authors are not able to pinpoint if this was a New Zealand specific phenomenon, given their physical distance from global markets and small scale economy (Chetty and Wilson, 2002). The findings highlight the significance of horizontal relationships for local competitors in acquiring resources to support internationalisation.

In 2000, Chetty and Holm (2000) use the four profiles of Johanson and Mattson's internationalisation model to examine the networks of four companies using a case study methodology. The four profiles represent various stages of internationalisation for the firm and industry. The paper provides insight into specific firm and market characteristics as they relate to the four profiles of the model. In addition, the role of the key decision maker in identifying international opportunities is underscored.

In researching the impact of networks on New Zealand firms, Chetty and Sadler (2004) develop a conceptual model from literature to explore how firms use networks to reduce barriers to exporting. Using a postal survey, findings show that networks influence market selection for potential exporters, and network actors are comprised of customers and their suppliers.

Using qualitative and quantitative approaches of social network and analysis and case data, Coviello (2006) examines how the network of an International New Venture (INV) changes over time. Several propositions are developed that relate network characteristics to the firms' stage of internationalisation (these propositions are outside the scope of this thesis). While offering insight to nuances of INV's, the networks are found to be dynamic and unpredictable.

This thesis complements the research outlined above by focusing on qualitative approaches to understanding network dynamics in New Zealand. It is set apart by examining the network in relation to a specific outcome, namely the multi-million dollar international contract and the local network structure and dynamics that support successful internationalisation. 


\subsection{The Network Perspective}

Within the internationalisation context as discussed above, the preceding discussion focuses on networks beginning with an introduction to the network perspective. In a general sense, the network perspective draws attention to the relationships, interdependence, linkages, transactions or flows between actors. Within the context of organisational theory, actors take the form of individuals, suppliers, competitors, customers, distributors, government, venture capitalist etc. In the remaining sections of this document the terms nodes and ties and used interchangeably with the terms actors and relationships as these represent generic network terminology.

Literature employing a network perspective is increasing, with a mix of methodologies, theories and empirical studies stemming from its multidisciplinary nature (Borgatti and Foster, 2003). In saying that, the network approach has developed from three main disciplines (Tichy, Tushman and Fombrun, 1979). The first is sociology that emphasised patterns of interaction and communication as essential to understanding social behaviour (ibid). The second was anthropology and this developed what is known as exchange theory with a focus on the bond (or relationship) between individuals and its evolution (ibid). The third school of thought is role theory which takes the perspective that an individual's action is driven by the roles or expectations of others (ibid). These three dimensions are captured by the network approach to organisational research.

Social networks are a branch of network theory that perceives any social organisation as a network. The main tenet behind social network theory is to explain behaviour/action and organisational performance through network structure, dynamics and position.

Organisations can be thought of groups of people with patterns of interactions over time. Mitchell (1969), defined a social network as a specific set of links among a defined group of persons, such that the characteristics of linkages as a whole can be used to interpret behaviour of the actors within the network. These 
internal networks facilitate social links (representing conversations, advice, friendship, neighbours etc), communication, coordination, and production activities and thus make up the organisation (Mitchell, 1969).

Applying this concept to organisations, Nohria (1992) developed five premises of the social network perspective. Broadly speaking, Nohria (1992) defines a network as a set of actors that maintain a defined set of relationships between them.

The following five points are central to the social network perspective (Nohria, 1992).

1. View all organisations as a social network. This point applies equally for any level of analysis, i.e. individuals, departments within an organisation, whole organisations, industries, and so on. This includes formal networks, such as reporting lines but also the less tangible, informal or emergent relationships.

2. The social network perspective views the environment as a network and this stands in contrast to systems thinking perspective that typically identifies the environment as a black box. Instead the network perspective highlights specific nodes and relationships - suppliers, consumers, regulatory bodies, competitors etc.

3. Action, attitude and behaviour can be explained by actor position in the network. This premise highlights the contrast with traditional organisational management theory as it reduces the importance placed on traditional attributes and capabilities of the firm for predicting behaviour. Instead, the network approach assumes firm behaviour is driven by its network position and structure.

It is important to note here that authors such as Blau (1982) view actor attributes as complementary data to the network while others see it as superfluous. 
Concepts and tools to measure and define the structure and position of networks will be discussed below. An exemplar theory is that of Ronald Burt (1992), who outlines concepts of cohesion, equivalence, prominence, range and brokerage. These will be explored in the upcoming section.

4. Networks constrain action and in turn are shaped by them. Thus the network is constantly changing and is therefore, both a process and a structure at the same time.

5. Any comparison of organisations should include network data including structure, position and relations etc.

These premises are adopted as the research paradigm of this thesis. The next section draws on this discussion of the network perspective by describing specific network concepts from the literature, which are relevant to this thesis.

\subsection{Social Networks Concepts}

This section reviews the social network concepts that will be used as a lens to examine the case data. Please refer to Table 1 at the end of this chapter for a summary of these concepts.

\subsubsection{Embeddedness}

The notion of embeddedness stems from the idea that people seek non-economic (or social) and economic goals simultaneously. The two goals are inseparable as economic activity occurs through personal relations and also people pursue noneconomic goals through economic activity, such as social status (Granovetter in Nohria and Eccles, 1992). This is not a new idea. Throughout history prominent 
economists such as Adam Smith have accommodated this notion by referring to 'the rational /economic actor' and treating them as separate issues.

By adopting the social network approach this thesis accepts an underlying premise that economic and non-economic motives can be pursued in parallel. This draws out the question: How do social relations affect individual and institutional behaviour?

In their book Networks and Organisations, Nohria and Eccles (1992) identify two polar extremes as a result of this question. On one hand, economic and social behaviours are treated separately and on the other, the so-called 'Strong embeddedness position,' economic activity is seen to be a result of social pursuits - put more explicitly everything is done in pursuit of individual gain (Granovetter in Nohria and Eccles, 1992). As a result, the authors develop the 'weak embeddedness position,' neatly summarised as follows:

"Actors do not behave or decide as atoms outside a social context, nor do they adhere slavishly to a script written for them by the particular intersection of socio-cultural categories they happen to occupy. Their attempts at purposive action are instead embedded in concrete, ongoing systems of social relations." (Nohria and Eccles, 1992:32)

Thus, Granovetter argues that "Embeddedness refers to the fact that economic action and outcomes, like all social action and outcomes, are affected by actors dyadic (pair-wise) relations and by the structure of the overall network of relations" (Nohria and Eccles, 1992:32)

This is a fundamental aspect of the social network approach. Embeddedness is a critical aspect to acknowledge because it is easy to slip to a simple onedimensional perspective of ties when explaining behaviour. In addition, identifying and understanding embedded relations requires recognition of the history of their relationships (Nohria and Eccles, 1992). 


\subsubsection{Relational and Structural Embeddedness}

Taking this concept further, there are two different types of embeddedness; relational and structural. Relational embeddedness refers to the kind of relations an actor has developed and their direct effects on individual action. Choosing to conduct business with a friend is an example of how a relation influences individual actions directly. Relational embeddedness is associated with tie strength or intensity (Easterby-Smith and Lyles 2003).

Structural embeddedness is more subtle and less direct. Instead of influence stemming from direct relations, structural embeddedness refers to entire network (or a surrounding region in a network) (Van Wijk et al 2003 in Handbook of Org learning and KM, Easterby-Smith and Lyles 2003). Structural embeddedness is based on the idea that information, norms and cultures are more efficiently transmitted within dense or cohesive networks thereby creating homogenous groups relative to the rest of the network. Conversely, the fragmentation of the network will reduce the homogeneity of behaviour (Nohria and Eccles, 36:1992)

Some authors have noted that the positive benefits of embedded positions are increasing access to information and higher levels of trust and note that both are often hard to replicate. For example:

Uzzi (1997) maintains that embedded relationships (in networks) are rational through positive effects like trust, fine-grained information transfer and joint problem solving arrangements. He furthermore asserts that: "embeddedness creates economic opportunities that are difficult to replicate via markets, contracts, or vertical integration." (Solberg and Durrieu, 2004:37)

Embeddedness can apply to an individual, department or whole organisation. In their paper on strategic alliances, Gulati and Garguilo (1999) propose a model of the formation of inter-organisational networks. Taking organisations as socially 
embedded, they show how networks emerge and how the structure of the network influences behaviour. They find this to be a two-way link where:

On the one hand, the emerging social structure progressively shapes organizational decisions about whether and with whom to create new ties. On the other hand, this social structure is produced and reproduced by the (structurally shaped) decisions of individual organizations to establish relations with one another. (Gulati and Garguilo, 1999:42)

Similarly to Johanson and Mattson (1988), Gulati and Garguilo (1999) show how firms access critical ties for resources. They emphasise that the selection of relationships stem from the network itself and its embedded features.

Over time, these embedded relationships (Granovetter, 1985) accumulate into a network that becomes a growing repository of information on the availability, competencies, and reliability of prospective partners (Kogut, Shan \& Walker 1992; Gulati 1995b; Powell, Koput \& Smith-Doerr 1996).

Embeddedness theory is central to social network analysis and strongly influences trust and information flows. How relationships become embedded, and the impact of embedded ties, will be explored in the case study.

\subsubsection{Social capital}

In discussing the role of networks in the internationalisation process, we introduced the concept of social capital as an asset that signifies the resources made available from a particular network position. Social capital is the benefit a person or organization receives through relationships with friends, colleagues and other contacts (Burt, 1992, 2000). Social capital also refers to the opportunities that can arise from these relationships, such as job offers, inclusion in special projects etc. As with all forms of capital, it can be viewed as an investment with expected returns (Lin, 2001). 
Social capital is a critical factor in competition. For example, acknowledging actor behaviour, as a result of social relations, partially explains the imperfection of economics. As a result, who you know is a deciding factor in how effective you are in achieving your goals. Social capital represents both the structure of relations and also the resources it gives access to (Bourdiue, 1980; Burt, 1992).

A node within a network directly and indirectly provides potential access to other actors. Resources embedded in these nodes become the ego's social capital (Lin, 2001). Lin (2001) highlights the fact that these potential exchanges are not only centred on one particular shared interest, they also bring their personal and positional resources, such as jobs, friends, affiliations, religious beliefs etc. As a result, when examining resource interactions we should analyse and understand interaction and networking structure (Burt, 2000).

Burt (2000) emphasises that location in the network structure determines social capital. Thus, actors are constrained by their resources and network resource heterogeneity, but also by their social structure (Lin, 2001).

Lin (2001) helps understand why social capital enhances outcomes and cites the following four reasons; influence the flow of information, decision makers, can act as social credentials and reinforce identity and recognition. Information diffusion is a key variable to understand how social capital can have these effects (Burt, 1992). Actors within a network benefit from social capital (in relation to peers) by being more aware of and having the ability to access opportunities. As information-based benefits, these can be further categorised as access, timing and referrals (Burt, 1992 in Nohria and Eccles, 1992). In conclusion, understanding social capital can provide insight on the level of information flow, actor influence and status. 


\subsubsection{Social Capital and Social Structure}

Social capital is largely dependent on information flows within the network. Burt (1992) describes two requirements needed to receive information benefits. First, the actor requires contacts in places where useful information is likely to be found and second, they are able to provide a reliable flow of information, to and from those places (Burt, 1992). Thus, we draw attention to the importance of network structure.

Added to this complexity is the idea that some players in the network can chose whether to withhold or release information. Therefore, trust and reliability also play a significant role in the effectiveness of a network's structure (Burt, 1992). In addressing Burt's first point, the assumption behind having contacts in useful places is having a large and diverse network (Burt, 1992:64).

In regard to a network comprised of ties and nodes, as discussed above, what does large and diverse mean? First, size can be both positive and negative. Actors have cognitive and resource limitations (their time and energy) on the information they can process, filter and communicate (Burt, 1992). So, large quantities of information are not necessarily a good thing. Furthermore, information doesn't travel evenly or instantaneously through networks. Each actor has a limited amount of time and energy they can spend building, maintaining and processing information from links. After a certain size the actor can be overwhelmed with information making it difficult to sort what is important and what is not (Burt, 1992).

Therefore, Burt (1992) has found upon closer examination that actors need to discriminate against certain relations if they are to build an efficient and effective network. One way to discriminate against duplicate information sources is through identification of redundant nodes. Redundant nodes are contacts that you can already reach through an existing relationship, meaning the ego, or central actor, already has access to that information flow (Burt, 1992). This is viewed as an opportunity cost as the actor can be conducting more effective communication 
with that time and energy. As such, Burt (1992) found the solution to provide information benefits was to add non-redundant contacts. Figure 1 shows nonredundant ties in network $\mathrm{A}$, however while network $\mathrm{B}$ appears to have more relationships these are redundant because the ego can access them via the existing relationship in network A. Therefore, there are minimal information benefits derived from network B in comparison to network A. In addition, the extra relationship the ego now maintains requires time, effort and resources (Burt, 1992).

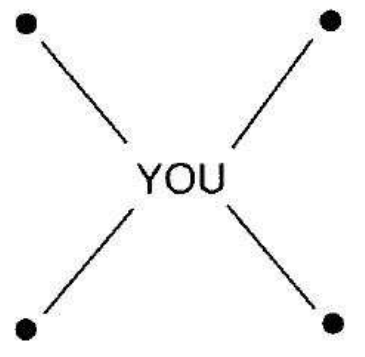

Network A

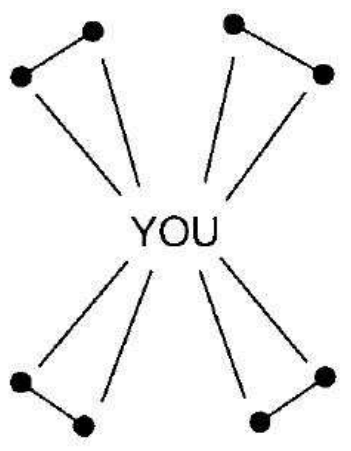

Network B

Figure 1: Non-Redundant and Redundant Ties (Burt, 1992).

To understand social capital benefits in regard to non-redundant links, we require an idea of the overall network structure. Similarity amongst network actors means groups of actors coalesce together, forming dense groups with less ties between the groups and a higher number of ties within them (Burt, 2005). For example, these groups can represent an after-work social sport group. Figure 2 shows 3 dense groups, 2 of which are linked by weak ties. 


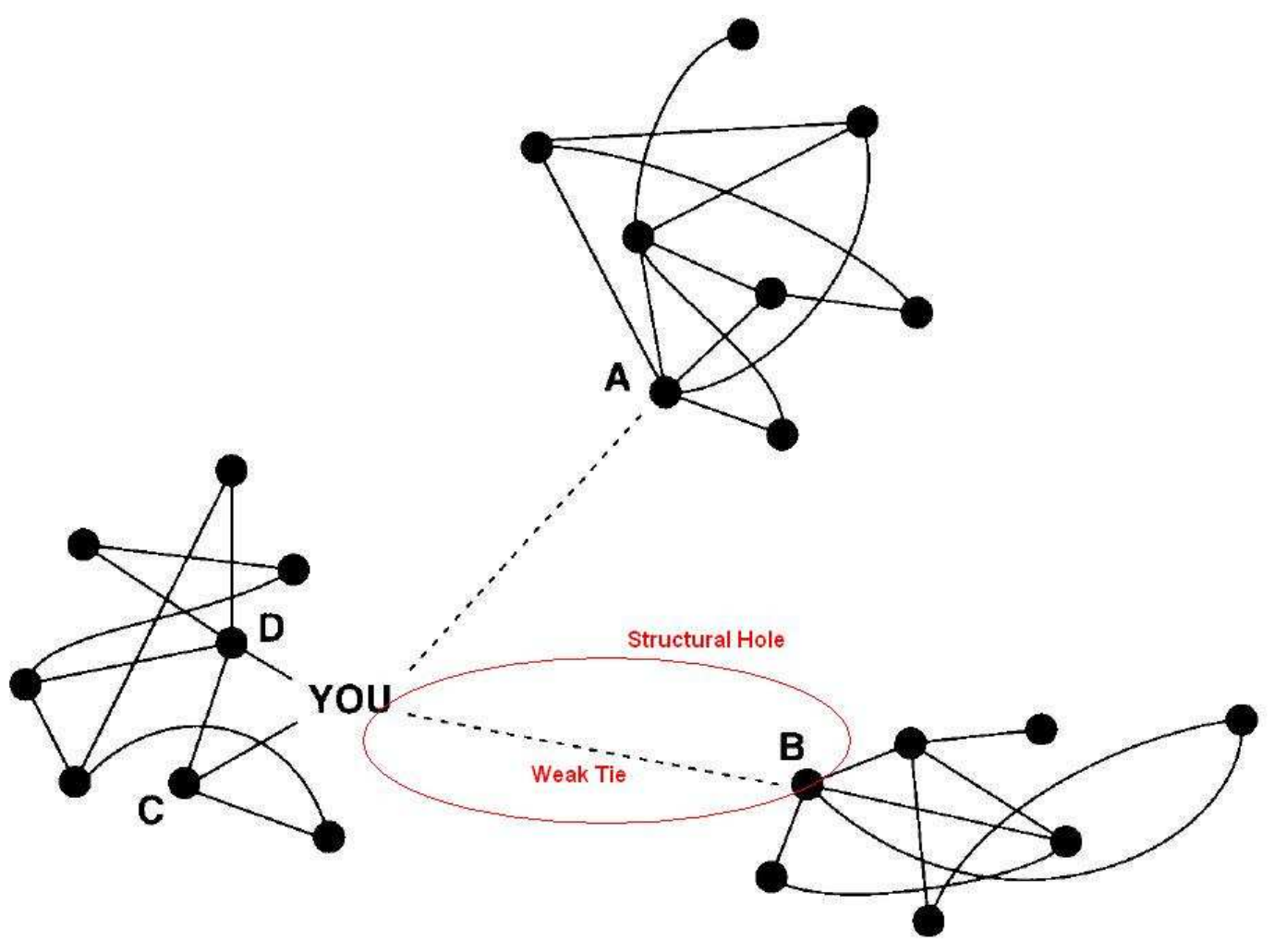

Figure 2: Weak Ties and Structural Holes (Burt, 1992)

However, the implication of these cohesive groups is that within each group, information, opinion and behaviour are relatively homogeneous (Burt, 2005). Therefore, Burt describes the gap between the groups as 'structural holes,' referring to a hole in the structure of information flows. This is shown in Figure 2 as the dotted lines or weak ties span the structural holes.

\subsubsection{Structural Holes}

Structural holes are holes in the structure of information flow, typically formed between groups (Burt, 2005). Thus a structural hole is “... a term for the separation between non-redundant contacts" (Burt, 2005). Individuals may be aware of the other groups, but will tend to focus on their own group activities and be caught in different information flows. 
The importance of structural holes is that they separate non-redundant sources of information. The tie that spans a structural hole is referred to as a network bridge (Burt, 2005). Burt (2005) takes this further by defining the coordinating activities over a bridge as the activity of brokerage.

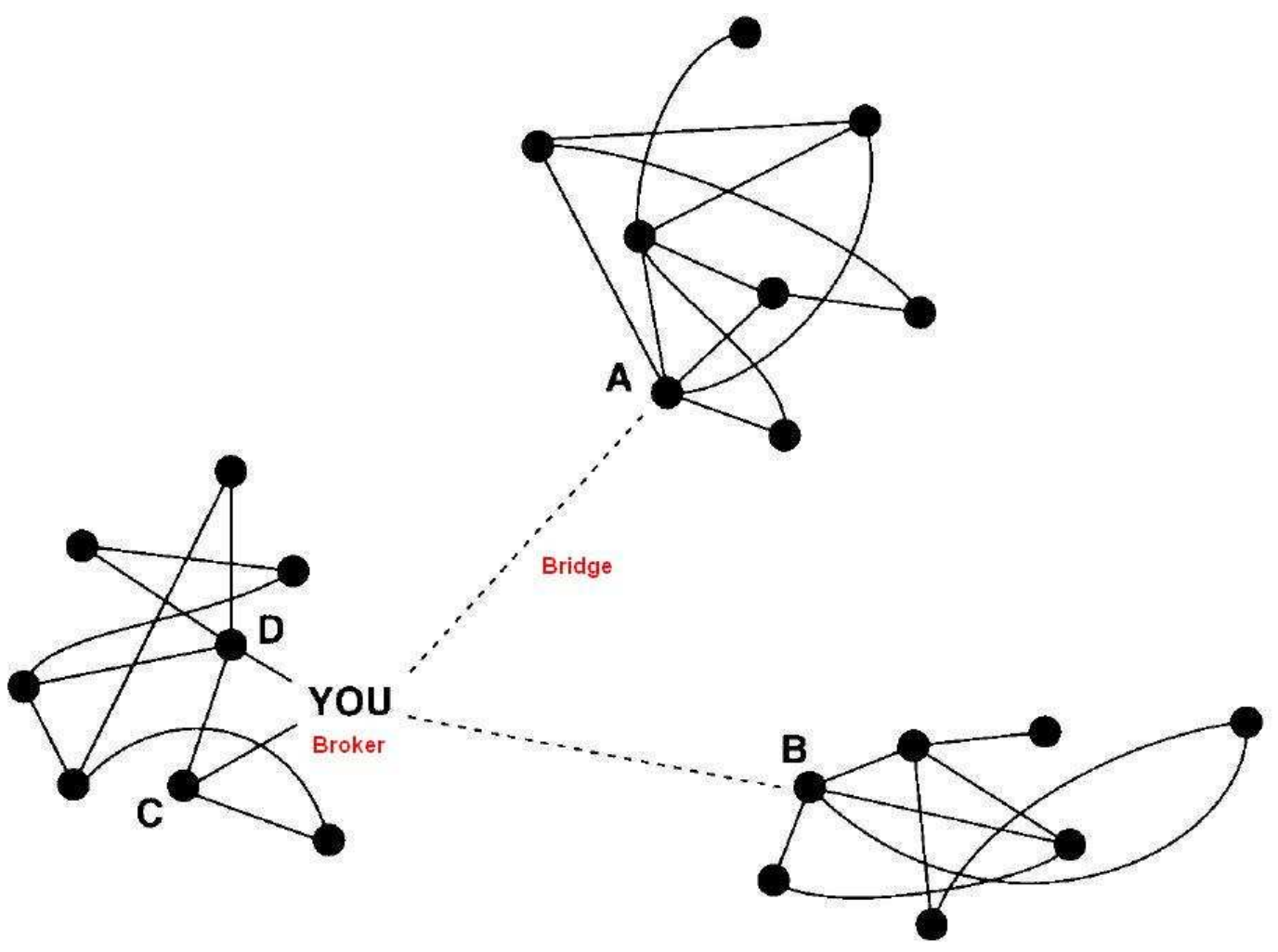

Figure 3: Bridge across a structural hole and the broker role (Burt, 1992)

Linking concepts described earlier, social capital is then seen as the opportunities that stem from the hole to the broker, providing flow of information and bringing people together across the hole or bridge.

The advantages of the position of a broker are summarised as follows:

1. Access to less redundant information,

2. Awareness and learning of the activities in both groups. It is assumed that the broker is included in activities due to their diverse set of contacts (increasing his attractiveness as an asset), 
3. The broker is more likely to know when to bring people together, allowing a disproportionate say of whose interests are served. This is neatly summarised as Tertius Gaudens - or 'the third that benefits.'

(Burt, 2005)

In complement to the concept of a bridge, Burt uses the term bond to define a strong relationship between people in a closed network (Burt, 2005). Thus, bridges are useful for creating information variation and bonds are effective at reducing variation and protecting people from inconsistent information.

Brokerage theory stems from work by Simmel (1922) and implies that if two actors are after the same resource, a third player can benefit. The third player will need to be aware of their needs and can then play each against the other. For example, a single customer may solicit quotes from two direct competitors. Adding to this argument, the competition can be artificially created and does not necessarily have to emerge organically (Nohria and Eccles, 1992).

This behaviour is referred to as structural autonomy, where structural holes lead to entrepreneurial activities that then turn into information and control benefits (Nohria and Eccles 1992).

Burt offers the following four themes through his book, Brokerage and Closure (2005) and provides a summary of the implications on social capital.

1. People whose networks bridge the holes are brokers rewarded for their integrated work...Brokers do better,

2. Information is more homogenous within groups such that people who bridge the holes between groups are at great risk of having creative ideas and more likely to see a way to implement ideas,

3. Closure reinforces status quo (i.e. punished if different etc), 
4. Facilitating the trust and collaborative alignment needed to deliver the value of brokerage, closure is a complement to brokerage such that the two together define social capital in a general way in terms of closure within a group an brokerage beyond the group.

(Burt, 2005:7)

Social capital is a key variable that influences the success of action and actors who form or are near bridges will have better social capital than others. Therefore the next section will focus on developing the concept of social capital further

\subsubsection{Content of Ties}

As mentioned in the introduction of this chapter, a social network is comprised of node and ties, where nodes represent actors and ties represent their relationships. These ties can facilitate a wide variety of exchanges.

Tichy et al. (1979) identify four types of transactional content; exchange of affect, exchange of influence or power, exchange of information, and exchange of goods and services. These can be thought of as separate networks, although in practice they tend to overlap in the same set of relations (ibid, 1979).

We are interested in the network exchanges and resulting effects of those exchanges on the network structure. The various concepts explored in this chapter are influencing factors to what is exchanged, between whom and why.

\subsubsection{Characteristics of Network Ties}

Ties can be characterised in terms of their strength, intensity, reciprocity etc, with some overlap between the terms. The following section is by no means an exhaustive list of relationship dimensions, but does present the most widely adopted ones. 


\subsubsection{Strength or Weakness of a Tie}

Some of the measurements of tie strength include recency of contact (Lin, Dayton and Greenwald 1978), frequency, references to labels such as "friend" (Granovetter, 1982) and others, which include a combination of measures such as Granovetter's (1973) described below. Burt (1990) and Marsden and Hurlbert, (1988) measure two independent variables; frequency of contact and emotional closeness (Burt, 1992).

We will focus on Granovetter's (1973) developments on the strength of ties as it has sparked several debates and research papers regarding its influence on the network (for example see Krackhardt, 1992 in Nohria and Eccles, 1992).

According to Granovetter (1973), the strength of a tie is a combination of the time spent, emotional intensity, intimacy and reciprocal services (Granovetter, 1973). The linearity of strength is still debated and researchers have focused on this aspect to various degress (Granovetter 1973, Krackhardt, 1992). For our purposes it is sufficient to acknowledge the arguments being made.

A weak tie is described generally as a tie with very few interactions, and inversely, a strong tie is characterised by high levels of intensity, intimacy, contact frequency, acknowledged obligations, and provision of reciprocal services (Granovetter, 1992).

\subsubsection{Strong Ties}

Strong and weak ties are crucial to understanding networks because they provide access to different types of resources (Krackhardt, 1992; Granovetter, 1982; Marsden \& Campbell, 1984; Uzzi, 1996). The assumption is that strong ties result in (and are result of) similar people being connected, leading to the formation of a group as they are mutually connected, they maintain redundant information (Krackhardt, 1992). This is largely based on Milgrams (1967) work on the Small World Theory and the concept of homophily. Homophily is the tendency of 
individuals to associate and bond with others in a similar situation. If individuals required different information they would need to access a different social circle (Granovetter, 1982; Burt, 1992).

After reviewing his initial paper the Strength of Weak Ties (Granovetter, 1983), Granovetter (1983) made note of the importance of strong ties. Granovetter finds that when people are in insecure, high risk positions or turbulent change they will seek strong ties for protection and uncertainty reduction (Krackhardt and Stern, 1988). Additionally, strong ties are more likely to assist in action and mobilisation of resources, and also be more readily available (Krackhardt, 1992; Granovetter 1983).

\subsubsection{Weak ties}

Weak ties on the other hand are often, but not always, 'bridges' that join and integrates otherwise disconnected social structures and are more likely to access new information (Granovetter, 1973; Lin, 2001). The ties between different social groups are termed bridges. By definition, without the linkage the two groups would be independent.

This tie between the two individuals is called 'weaker' because they participate in different social circles thus making it more difficult to foster high levels of intensity, interaction, intimacy, and provision of reciprocal services (Burt, 2005). As a result, the chances of gaining better information are enhanced if the individual explores weak ties, and thus Granovetter called this strategy and benefit the 'strength of weak ties' (Lin, 2001).

Krackhardt's (1992) paper in Network and Organisations provides a critique of the Granovetter's (1982) Strength of Weak Tie theory. One of his main concerns is with the measurement of tie strength and the impact it has on information returns (Krackhardt, 1992). This is assumed to be a curvilinear relationship, where with no tie, you receive no information, with a weak tie you receive a lot of useful information and lastly with a strong tie you receive little useful information 
(Krackhardt, 1992). The term 'useful' refers to receiving heterogeneous information. Related to this, is the question of how the four individual measurements contribute to strength.

Following Krackardt's empirical study of an information systems company, as it developed an employee union, he found that with change, one experiences resistance and to overcome resistance, one requires trust stemming from strong, affective and time honoured relationships (Krackhardt, 1992:238). Thus linking the complementary natures of both strong and weak ties, where weak ties provide opportunities for changes but at the same time, managing change requires strong relationships.

\subsubsection{Centrality and Power}

The idea of the most central position within a network or centrality, is one of the earliest concepts of network theory. However, there has been much debate in its different conceptualisations and measurement (Freeman, 1979, Burt, 1991). A central position within a network is thought to provide better access to resources, information (Raider and Krackhardt, 2002 in Companion to Organizations, Baum, 1992) and power (Brass and Burkhardt, 1992).

Calculating centrality in an isolated (or abstract) network is fairly straight forward. However, as Granovetter (1992) finds, once this network is embedded within a larger network this becomes much more difficult. For example, degree measurements, which counts the number of relationships an actor has, do not consider the larger network.

Granovetter follows Freeman's (1979) line of thinking, stating that a node's centrality is influenced by the centrality of its neighbours. Freeman (1979) addresses this by developing the following measurements.

Centrality can be defined by three attributes, degree, betweenness and closeness. 
1. Degree refers to the direct links in and out of an actor (Freeman, 1979).

2. Betweeness is high for an actor if they are between a high number of other actors (Freeman, 1979).

3. Closeness is high for actors who have the shortest steps to all other actors (Freeman, 1979). The closeness measure can be interpreted to efficiency to reach all other networks.

\subsubsection{Degree or Local Centrality}

Local centrality is defined as the degree of a node, which is the number of direct links in and out of an actor.

\subsubsection{Betweeness}

The idea of betweenness is also important as it help identify nodes sitting between other points. Thus a node can have low centrality/degree but sit in-between two groups (as a bridge for example). The concept of betweenness then alludes to dependencies as actors in the network depend on middlemen (i.e. the people inbetween) to transfer information etc. Thus it is seen as a position of power in communication networks (Freeman, 1979). This measure of centrality developed by Freeman (1979) will be used in our analysis.

\subsubsection{Closeness}

The closeness measure can be interpreted as the efficiency to reach all other networks. Closeness or global centrality is expressed in terms of the distances among the various points (Freeman, 1979, Nohria and Eccles, 1992). This is calculated using the 'sum distance' - the distances to all other points on the graph. Low sum distance would be interpreted as being close to other points. 


\subsubsection{Power}

One possible definition of power, which is particularly relevant here, is that power is the inverse of dependency, and derives from the control of resources (Hickson et al 1971) in Nohria and Eccles (1992). Brass and Barkhardt (1992) find that centrality and power are positively correlated but require more evidence to clarify whether one causes the other. Granovetter's (1973) study finds that centrality is positively and significantly related to power across three different types of networks; workflow, communication and friendship.

\subsubsection{Network Structure Measures}

The following section provides a brief description of each method that will be used to analyse the network structure.

\subsubsection{Cliques}

A clique is a group within a network that maintains a close set of relationships to each other. Common examples of cliques include a group of close friends or a team at work. Technically, a clique is a network where each actor has relationships with all other actors. This is also called a maximal graph or network closure (Burt, 2000).

Identification of cliques is useful to understand dense areas in the network, where actors are close and have strong ties, thereby, sharing information and norms (Granovetter, 1973).

\subsubsection{Density}

Density is the proportion of ties in a network relative to the total number possible. Dense networks are a common form of social capital and are thought to facilitate fine-grained communication, trust and norms (Lin, 2003). As such, the measure is used to identify sparse or dense networks. 


\subsubsection{Network Size}

Network size refers to the number of actors in the network.

\subsubsection{Average Distance}

This is an overall measure of distance between all actors. It is calculated by averaging the shortest distance between every pair of actors. The average distance provides an indication of how many steps, on average, it takes to reach a given actor within a network.

\subsubsection{Cohesion}

Cohesion refers to how strongly connected actors are and Burt (2000) argues that these actors will have similar information. Cohesive bonds can often be found in cliques as they share strong relationships.

\subsection{Networks and Geography}

Networks are spatial entities in that they have specific locations and thus rely on infrastructure for information and transport transfer systems (Granovetter, 1983). So in addition to transaction costs, networks possess a strong spatial element due to the costs related to communication and transport (Johansson and Karlsson, 2001).

Different activities have different distance sensitivities. For example, product development is often highly distant sensitive, sometimes requiring frequent faceto-face contact with clients. This leads to regional specialisation leading to interregion trade. Following this logic firms with highly distance sensitive input 
requirements will have incentives to co-locate with their suppliers. Leading to external economies of scale.

Upon closer inspection it is easy to see that distance is closely related to softer aspects, such as trust, that informs decision making etc. Thus networks don't necessarily need to be geographically clustered but do require effective mechanisms to foster trust (Johansson and Karlsson, 2001).

Geography is important because trust can be built more readily when actors are in close proximity allowing for face-to face interaction and higher potential for a common language, culture, values and social norms (Johansson and Karlsson, 2001).

\subsection{Chapter Summary}

With regard to the internationalisation theory, this chapter focused on the Network Model of internationalisation and positioned this research within this domain. The research area here specifically focuses on a local network supporting internationalisation which is an area of interest for the internationalisation theory and also local New Zealand network practitioners. As previously acknowledged, there is clear evidence of interest in New Zealand network research.

The second half this of this chapter introduced the network analysis paradigm and some of the core concepts relevant to this thesis. For ease of reference a summary of these concepts are present in Table 1. 
Table 1: Summary of Social Network Concepts

\begin{tabular}{|c|c|c|}
\hline Concept & Key points & $\begin{array}{l}\text { Relevance to research } \\
\text { questions }\end{array}$ \\
\hline Embeddedness & $\begin{array}{l}\text { There are multiple and over- } \\
\text { lapping layers to an actor's } \\
\text { position and their actions are } \\
\text { influenced by these } \\
\text { embedded positions. }\end{array}$ & $\begin{array}{l}\text { Helps explain actor and } \\
\text { network behaviour } \\
\text { (Granovetter, 1985). }\end{array}$ \\
\hline Social Capital & $\begin{array}{l}\text { The actual or potential } \\
\text { resources access through an } \\
\text { actor's network. }\end{array}$ & $\begin{array}{l}\text { Helps explain actor and } \\
\text { network behaviour - “a } \\
\text { resource for action" (Coleman, } \\
\text { 1988). }\end{array}$ \\
\hline Structural Holes & $\begin{array}{l}\text { A gap in information flow } \\
\text { between two groups. }\end{array}$ & $\begin{array}{l}\text { Provides insight into the } \\
\text { structure of the network and } \\
\text { potential for social capital and } \\
\text { the role of brokers (Burt, } \\
\text { 1982). }\end{array}$ \\
\hline Brokerage & $\begin{array}{l}\text { Linking otherwise } \\
\text { disconnected groups } \\
\text { provides social capital, new } \\
\text { ideas, more options etc. }\end{array}$ & $\begin{array}{l}\text { Provides insight into the } \\
\text { structure of the network and } \\
\text { potential for social capital and } \\
\text { the role of brokers (Burt, } \\
\text { 1982), }\end{array}$ \\
\hline Tie Content & $\begin{array}{l}\text { Describes what was } \\
\text { exchanged between two } \\
\text { actors, e.g. affect, influence, } \\
\text { information, or goods and } \\
\text { services. }\end{array}$ & $\begin{array}{l}\text { Identifies exactly what was } \\
\text { exchanged between actors - } \\
\text { not just physical exchanges. }\end{array}$ \\
\hline Strong Tie & $\begin{array}{l}\text { Relationship with a } \\
\text { relatively high level of time, } \\
\text { reciprocity, emotional }\end{array}$ & $\begin{array}{l}\text { Fundamental network concept } \\
\text { that gives rise to network } \\
\text { structure and information or }\end{array}$ \\
\hline
\end{tabular}




\begin{tabular}{|c|c|c|}
\hline & $\begin{array}{l}\text { intensity and intimacy } \\
\text { (Granovetter, 1973). }\end{array}$ & $\begin{array}{l}\text { communication flows } \\
\text { (Granovetter, 1973). }\end{array}$ \\
\hline Weak Tie & $\begin{array}{l}\text { Relationship with a } \\
\text { relatively low level of time, } \\
\text { reciprocity, emotional } \\
\text { intensity and intimacy } \\
\text { (Granovetter, 1973). }\end{array}$ & $\begin{array}{l}\text { Fundamental network concept } \\
\text { that gives rise to network } \\
\text { structure and information or } \\
\text { communication flows } \\
\text { (Granovetter, 1973). }\end{array}$ \\
\hline $\begin{array}{l}\text { Centrality } \\
\text { (betweenness) }\end{array}$ & $\begin{array}{l}\text { An indication of the power } \\
\text { an individual based on their } \\
\text { location within network } \\
\text { (Freeman, 1977). }\end{array}$ & $\begin{array}{l}\text { Identifies the power of actors } \\
\text { in the network providing } \\
\text { insight into their role and } \\
\text { influence. }\end{array}$ \\
\hline Cliques & $\begin{array}{l}\text { A group with a complete set } \\
\text { of relations. }\end{array}$ & $\begin{array}{l}\text { Identifies close groups with } \\
\text { strong relationships. }\end{array}$ \\
\hline Density & $\begin{array}{l}\text { Number of ties divided by } \\
\text { the number of actors. }\end{array}$ & $\begin{array}{l}\text { Shows how well connected the } \\
\text { network is. }\end{array}$ \\
\hline Network Size & $\begin{array}{l}\text { Number of actors in the } \\
\text { network. }\end{array}$ & $\begin{array}{l}\text { How does the network size } \\
\text { change over time? }\end{array}$ \\
\hline $\begin{array}{l}\text { Average } \\
\text { Distance }\end{array}$ & $\begin{array}{l}\text { An average of all the paths } \\
\text { between actors. }\end{array}$ & $\begin{array}{l}\text { Provides an indication of the } \\
\text { distance needed to access } \\
\text { resources across the network. }\end{array}$ \\
\hline Cohesion & $\begin{array}{l}\text { How strongly connected is a } \\
\text { particular relationship of } \\
\text { group }\end{array}$ & $\begin{array}{l}\text { Identifies close groups with } \\
\text { strong relationships. }\end{array}$ \\
\hline
\end{tabular}

These measures and concepts provide insight into three different network areas, the actors, the relationships and the overall the network structure. Together these are used to probe the case data in the discussion chapter. Chapter 3 will present the research design outlining data collection and the methods used to ensure data validity. 


\section{Research Design}

The purpose of this chapter is to translate the research questions, as outlined on page 10, into a robust and pragmatic research plan. Supporting the paradigm and context of this research are three specific methodology issues; capturing organisational network data; capturing historical data, and social network analysis. This will be concluded by a description of the data collection process and analysis.

\subsection{Overview of the Research Process}

The following steps outline the high level research process:

1. Identification of themes from literature,

2. Selection of case,

3. Data gathered from secondary sources,

4. Data collected from managers and others involved in the network using semi-structured interviews,

5. Interviews transcribed and analysed using qualitative techniques,

6. Networks mapped using both manual techniques and specialised network analysis software, such as UCINET.

\subsection{Guiding Research Questions}

The following statements represent the problem definition that arose from the literature covered in Chapter 2.

In a case of a local organisation reaching international success, how does the supporting network structure evolve? 


\section{Specifically}

1. How does the network form?

2. How is it organised and structured?

3. How does the network change and evolve over time?

4. How distinctive are the firm roles within these relationships?

5. What are the performance consequences for companies in the network?

The purpose of this research is to describe the evolution of the network and understand structural characteristics of the network in this particular situation. It will achieve this by taking a descriptive research approach using a case-study methodology. As such it is not designed to produce new theory, but will provide insights into the role of networks in internationalisation.

\subsection{Research Perspective and Unit of Analysis}

As Cavana et al. (2001) noted, in undertaking any research it is important for the researcher to acknowledge and understand his/her world-view or paradigm, referring to their values and beliefs (Cavana, Delahaye, Sekaran, 2001).

The social network perspective highlights the embeddedness of social and economic interaction and, therefore, this research will take an interpretivist perspective. Thus, it seeks to understand behaviour (at the individual, organisation and network level) and recognises the social interaction and different social constructions of each actor (Cavana, Delahaye, Sekaran, 2001).

The unit of analysis is the network that is comprised of a set of organisations. 


\subsection{Methodology}

The research question requires a method that can a) capture network data and b) capture it over time.

Network data are comprised of a wide range of data. As described in Chapter 2, this includes data on power, position in the network, network size, tie content, strength, direction, cohesion, structural holes, information flows, embeddedness and so on.

In summary, research methods need to track the parallel evolution of both network structure and interactions, through the firm's development (Coviello, 1995). It requires a holistic, social approach that includes observation, in-depth interviews within their environments and also captures the chronological data (Coviello, 1995).

The combination of structural and interaction-based data requires both qualitative and quantitative approaches. Following O’Donnell, Gilmore and Cummins (1999) and Coviello's (1995) guidance the qualitative approach to data collection is found to be most appropriate for two key reasons. First, it captures the multiple layers of information required for network analysis. Second, it is possible to induct quantitative network data (Coviello, 1995). This approach is termed the 'bifocal lens' as it integrates quantitative and qualitative approaches. The benefits of the bifocal research lens are presented in Table 2.

Table 2: Benefits of the Bifocal Research Lens (Coviello, 1995)

\begin{tabular}{|l|l|}
\hline $\begin{array}{l}\text { 1. Trace the deeper aspects of the } \\
\text { network in its social context. }\end{array}$ & 2. Address the network as a whole. \\
\hline $\begin{array}{l}\text { 3. Capture important dynamic } \\
\text { dimension of the network. }\end{array}$ & $\begin{array}{l}\text { 4. Encompass both structural (hard) } \\
\text { and interactional (soft) network } \\
\text { dimension. }\end{array}$ \\
\hline
\end{tabular}


This approach has also been tested in similar research undertaken by Chetty and Campbell-Hunt (2004) that uses an in-depth historiographic case to illustrate international business success. The research here follows these recommendations by using a case study comprised of in-depth interviews and secondary data.

\subsubsection{Case Study Method}

This section explores the case study methodology and justifies its appropriateness to address the research objectives.

The case study approach involves gathering in-depth information using a range of methodologies about a specific entity, whether it is an individual, organization or region etc (Eisenhardt, 1989; Cavana, Delahaye, Sekaran, 2001). Yin (1993:59) defines a case study as an empirical investigation that examines an issue within its natural environment, typically where the area of interest and the context are hard to separate. Additionally, the case study method provides for situations where data are required from more than one data set and can therefore rely on multiple sources resulting in triangulation (Yin, 1994).

The key difference to other approaches is that the case method is open to the methods that guide the research and analysis (Meyer, 2001). Typically, cases combine qualitative and quantitative data collection methods (Eisenhardt, 1989).

Indeed, this is both the strength and weakness of the case method. On one hand, having no predefined theory can lead to meaningless data, on the other hand, a rigid framework limits the representation of the phenomenon (Meyer, 2001). Meyer (2001) cites Gummesson's (1988) idea of maintaining a fine balance between having preconceived ideas to give direction, while also maintaining an open mind. The use of the social network perspective acts as a guide within the case study approach and therefore, mitigates against a lack of direction. 


\subsubsection{Single Case Study}

In selecting a case the first step is to consider selecting single or multiples cases. Multiple cases allow for replication and contrasting data (Lin, 2003), while single cases tend to limit generalizability and introduce the chances of biases in information gathering (Eisenhardt, 1989). However, the unit of analysis here is an inter-organizational network and, as such provides sub-units that can be analysed as separate entities negating against respondents' bias (Yin, 1993).

While there are benefits of including multiple cases, it can limit the depth of information collected, given limits on time and resources (Meyer, 2001). The case here represents several companies, each acting as sub-cases.

\subsubsection{Purposeful and Judgement Sampling}

Researching specific target groups is referred to as purposeful sampling and is typically pursued because they are the only groups who are able to provide the information or data needed (Cavana, Delahaye, Sekaran, 2001). Taking this further, judgement sampling chooses subjects who can best provide the information (Cavana, Delahaye, Sekaran, 2001).

The case study presented in this thesis was chosen because of its success in developing an international contract. Instead of statistical sampling, the case method involved theoretical sampling that provides a clear success story (Eisenhardt, 1989). Therefore, a purposeful sampling method was used.

During the time of research four potential cases were identified. The cases were the Kumara network (Kaipara), the wood processing network (Hawkes Bay), electronics network (Canterbury), and a engineering network (Taranaki). This then represented the target population. A single case was then chosen based on the following criteria: 
1. Recency of the contract.

2. Success of international contract.

3. Access to key stakeholders.

4. Level of cluster/network collaboration.

Yin (1994) outlines several tactics to test the validity of the case study approach that have been followed (Yin, 1994). This includes using multiple sources for data collection, time series analysis for internal validity and structured approaches to the management of case data to improve reliability (Yin, 1994).

In conclusion, selection of a single case was done with purposeful sampling and the network analysis method will be used to guide data collection and analysis.

\subsubsection{Historical Method}

The focus of this research is the activities and structure of actions prior to an international contract being formed. A potential and suitable method to analyse this outcome, is to work backwards from the point of contract formation in attempt to uncover what happened historically. Goodman and Kruger (1989) recommend a historiographic approach when focusing on the evolution of a given phenomenon; in this case a network.

The historiographic approach is sometimes considered as an alternative research methodology. However, it has significant benefits and has been developed into a formal and credible research method. This section will address the main limitations of the historical method and highlights the strengths it offers this research design.

Primarily the historical method helps understand how an event came to being, having the ability to describe characteristics as they unfold over time, particularly culture specific characteristics in organisations (Kieser, 1994; Mason, McKenney and Copeland, 1997). This is especially significant when trying to understand 
polarised examples of performance. In this case the performance manifests as an international contract.

Historical knowledge attempts to capture the complexity and context of a situation and thus includes several dimensions of social, political, organisational, individual etc, information (Mason, McKenney and Copeland, 1997). Described as an idiographic rather than nomothetic approach it aims to produce a complete picture of the past (Mason, McKenney and Copeland, 1997).

\begin{abstract}
"Historical analyses teach us to interpret existing organisational structures not as determined laws but as the result of decision in past choice opportunities, some of which were made intentionally and other more implicitly" (Kieser, 1994)
\end{abstract}

Historical information can also be treated as data allowing for inductive reasoning, such as pattern analysis (Mason, McKenney and Copeland, 1997). Case studies often employ the historical method, and Yin (1984) also talks about inductive extrapolation from case studies.

In terms of organisational theory, the historical method helps understand current phenomena by looking at the development of the trajectory by which it evolved. It can thus, highlight key decision points in the organisation's history that led to the current state (Kieser, 1994; Mason, McKenney and Copeland, 1997).

As a result, the historical case study methodology allows for focus on the outcome of the network, analysis of its evolution and sufficient flexibility to capture hard and soft data. The next section will describe the data collection method and analysis used. 


\subsection{Data Collection}

The unit of analysis is the network. Data collection involved in-depth, semistructured interviews within a case study methodology as described by Eisenhardt (1989) and Yin (1989).

Interviews were held with key stakeholders of the project, in most cases the chief executive officers of each organisation or the marketing manager of the larger firms. A snow balling method was used (Laumann and Pappi, 1976), where an initial contact was asked to identify peers in each organisation who were instrumental in the development of the project. This was repeated for validity with other participants until the list was exhausted. Each participant was provided with an information sheet prior to the interview, which described the objective of the research, purpose and outcomes of the interview.

Interviews ranged between 1-2 hours and were open-ended focusing on the evolution of the network. Each candidate were asked for a historical, time-based account of the project which spanned four years. In addition, candidates were asked to provide a brief overview of the organisation's history and a description of their current operations.

Factual triggers sourced from secondary material were used to assist memory recall (Chetty and Campbell-Hunt, 1994). Interviews were held in company offices where possible with one held via teleconference due to time constraints. All interviews were tape recorded and later transcribed verbatim.

The data collection approach required several iterations of clarification and probing of the participant's knowledge. This was achieved by using open-ended questions and key decisions were highlighted for dates and outcomes providing a backbone to construct the case (Chetty and Campbell-Hunt, 1994).

Triangulation is critical when capturing personal perspectives of a given activity particularly when it spans a period of years. This was addressed by developing a 
dataset of factual information from the public domain that included company websites and news articles on their success. These data provided enough information to sketch a high level time frame and highlight key actors and decisions. This was then utilised in the interviews to clarify and validate data to iteratively build the case.

With the collection of transcripts and case data, the analysis involved identification of themes and matching of events across the different participant accounts. Analysis was shaped at a high-level by the network constructs discussed in Chapter 2. The chronology of events was constructed through analysis of the interview transcripts and this was validated by secondary data.

By taking a case study approach that capture rich qualitative data, the analysis is able to accommodate for a range of traditional network analysis methods as summarised below. A multi-method approach provides the most comprehensive view of the network (Tichy, Tushman and Fombrun 1979).

Table 3: The different dimensions of network analysis methods (Tichy, Tushman and Fombrun, 1979)

\begin{tabular}{|l|l|l|}
\hline Type of Analysis & Description & $\begin{array}{l}\text { Addressed in this research } \\
\text { from }\end{array}$ \\
\hline Positional Analysis & $\begin{array}{l}\text { Formal organisation data. } \\
\text { E.g. organisational charts. }\end{array}$ & Secondary case data. \\
\hline $\begin{array}{l}\text { Reputational / } \\
\text { Attributional }\end{array}$ & $\begin{array}{l}\text { Focus on actors perception of } \\
\text { power and relationships. }\end{array}$ & $\begin{array}{l}\text { Captured from in-depth } \\
\text { semi-structured interviews. }\end{array}$ \\
\hline Decision Analysis & $\begin{array}{l}\text { Highlights the process, roles } \\
\text { and power of decisions. }\end{array}$ & $\begin{array}{l}\text { Captured in primary and } \\
\text { secondary data collection. }\end{array}$ \\
\hline Interactional Analysis & $\begin{array}{l}\text { Flows of interaction or } \\
\text { communication: direction, } \\
\text { constraints etc. }\end{array}$ & $\begin{array}{l}\text { Captured from in-depth } \\
\text { semi-structured interviews. }\end{array}$ \\
\hline
\end{tabular}


Aligned to the three network areas discussed in the literature review, Tichy, Tushman and Fombrun (1979) identify three types of network data for analysis; transactional content, nature of links (intensity, reciprocity, clarity of expectations and multiplexity) and structural characteristics.

Transactional content and the nature of the relationships are analysed from the qualitative data and summarised in Tables 13, 14, 15 and represent the chronology of network evolution grouped into stages.

Structural network data are also elucidated from the qualitative data set and captured in matrices (see Section 3.6). The network data are then analysed using a range of measures that are outlined in Section 3.6. This approach follows the network analysis approach described by Coviello (1995).

\subsubsection{Network Attributes}

An attribute network is where actors are linked with a shared commonality (Fombrun, 1982). For example, a network of friends may be identified based on attending a common high school. In this case, the school is an attribute of each network member. This is distinguished from transactional networks that are identified on the type of exchange (Fombrun, 1982). For example, a transactional network may be identified based on the exchange of computer data.

The implications are critical. As Fombrun (1982) points out, beginning with network attributes, exchanges are seen as the consequences of the attributes (Fombrun, 1982). However, starting with a transactional network, the attributes become explanations or causes of the transactions (Fombrun, 1982). Most social network research to date has focused on transactional networks for conceptual and practical reasons, as there are more causal attributes than types of transactions (Fombrun, 1982). The transactional approach is adopted here for developing the initial network map. 


\subsection{Data Preparation and Analysis}

The analysis of the individual interview transcripts began by grouping the data by particular events or themes from the literature. This allowed the researcher to identify what events occurred at a particular time and, as such, develop a chronological account of the data for each actor.

Taking guidance from the participant's account of the networks development, the data for all actors were then split into 3 phases that aligned to the 3 phases of the network's developments. Each phase is captured in Table 4 below.

Table 4: Three Phases of Network Development

\begin{tabular}{|l|l|l|}
\hline Phase 1 & Pre-Development & 1999 to 2001 \\
\hline Phase 2 & Design and Development & 2002 to 2003 \\
\hline Phase 3 & Production and Future Opportunities & 2004 to 2005 \\
\hline
\end{tabular}

Using a phased approached to data analysis allows for identification of how the network structure and specific relationships changed over time.

Focusing on each individual relationship, data from individual transcripts were integrated into a single description of each relationship across the three phases. Further analysis of the interview data provided several dimensions of each relationship that together provided a rich source of relational data. Tables 5 and 6 (below) capture information for each unique set of relationships across the three phases. These tables provide a basis for further qualitative analysis. While there are several other organisations in the network, our analysis and emphasis will be on the four companies that data were collected from, all critical actors in the network. Table 5 describes each dimension of the relationship analysis and why it is important to the analysis. 
Table 5: Qualitative Analysis Dimensions: Table Headings

\begin{tabular}{|c|c|}
\hline Actors & Describes what actors are involved in the relationship. \\
\hline Context & $\begin{array}{l}\text { Captures a qualitative description of the means and motivation of the } \\
\text { relationship. The context provides insight into the social capital } \\
\text { involved in the relationship and its embeddedness. }\end{array}$ \\
\hline Content & $\begin{array}{l}\text { Describes exactly what was exchanged in the relationship and } \\
\text { explains the meaning of the relationship for the actor. Was it specific } \\
\text { technical knowledge, financing a contract etc. }\end{array}$ \\
\hline $\begin{array}{l}\text { Strength of } \\
\text { the } \\
\text { Relationship }\end{array}$ & $\begin{array}{l}\text { Describes the strength of the relationship in terms of the reciprocity, } \\
\text { emotional intensity, frequency and trust (Granovetter, 1979). From a } \\
\text { network perspective identifying the strength can highlight what actors } \\
\text { are core and which ones are periphery in terms of their bonds. }\end{array}$ \\
\hline History & $\begin{array}{l}\text { Identifies what relationships are new and what relationships are built } \\
\text { on previous interactions. It can also provide insight to the durability } \\
\text { of a relationship by identifying what actors continue to have } \\
\text { relationships across the three phases. }\end{array}$ \\
\hline Distance & $\begin{array}{l}\text { Qualitatively describes the physical distance of each actor. Local } \\
\text { refers to actors in the same city or region, national refers to actors in } \\
\text { the same country and international refers to actors in different } \\
\text { countries. This allows the identification of international relationships } \\
\text { and also highlights the impact of national distances on actor } \\
\text { relationships. }\end{array}$ \\
\hline
\end{tabular}

This is developed for each phase of the network and summarised in Tables 13, 14 and 15 .

Using the relationships tables, simple matrices that represent each relationship were developed for input into a network analysis software package called UCINET (Borgatti, Everett and Freeman, 2002). UCINET is a Microsoft windows based software program that takes network data in the form of matrices (described below) and provides the capability to analyse and visualise the network. While 
UCINET provides a wide range of analysis, the research focuses on the concepts described in Chapter 2. Each dimension is explained in detail in Section 3.11 and 3.12 .

To develop the matrices required for UCINET the relationships between actors were noted with a 1 or 0 representing whether the relationship was present or not respectively. This was done for each of the 3 phases. In addition, relationships were also analysed for the actor who initiated the relationship. As such, the matrices are not symmetrical as they capture directional relationships. For example, a relationship initiated by A to B is represented as follows:

Table 6: Example of a matrix representing network relationships for UCINET

\begin{tabular}{|l|l|l|}
\hline & A & B \\
\hline A & 0 & 1 \\
\hline B & 0 & 0 \\
\hline
\end{tabular}

In Table 6 above, reading from row 1, actor A has initiated a relationship to B. This is the only relationship between the two actors, A and B. Capturing who initiated a relationship is important to understanding how the network develops as it show what new actors were brought into the network and by whom. Using these matrices, UCINET is able to graphically display the network in each phase. Visualising the network is a powerful way to communicate and analyse network phenomenon. Together with the relationship tables, these data sets provide a basis for qualitative and quantitative analysis.

\subsection{Overall Network Analysis Dimensions}

The matrices described above will be used to represent the quantitative perspective of each network phase. This allow for quantitative analysis on the overall network and also specific actors. Table 7 below describes the quantitative network analysis dimensions by providing a description of each calculation. 
Table 7: Overall Network Quantitative Analysis Dimensions

\begin{tabular}{|l|l|}
\hline Name & Description and Relevance \\
\hline Number of Ties & The number of relationships in the network. \\
\hline Density & $\begin{array}{l}\text { The number of relationships divided by the total number of } \\
\text { pairs. }\end{array}$ \\
\hline Average Distance & $\begin{array}{l}\text { The average distance between actors provides insight into how } \\
\text { accessible resources are across the network. }\end{array}$ \\
\hline Clique identification & $\begin{array}{l}\text { An exclusive group that shares relations across all actors. } \\
\text { Technically, a clique is a maximally complete sub-graph. } \\
\text { Cliques can be identified for any size and in this case a cliques } \\
\text { are identified for } 3 \text { actors in a complete sub-graph. }\end{array}$ \\
\hline
\end{tabular}

\subsection{Actor Specific Analysis Dimensions}

In addition to the overall network measure, Table 8 below outlines a description of the analysis that will be carried out for each actor. The information will provide an indication of how well positioned an actor is within a network based on the following measures: 
Table 8: Actor Specific Quantitative Analysis Dimensions

\begin{tabular}{|l|l|}
\hline Name & Description and Relevance \\
\hline Size & How many relationships does this actor have? \\
\hline Effective Size & $\begin{array}{l}\text { This measure counts the number of pairs that are not directly } \\
\text { connected to each other. Actors with a high brokerage score } \\
\text { are likely to be positioned next to a structural hole. }\end{array}$ \\
\hline $\begin{array}{l}\text { Number of ties, less the average number of ties amongst the } \\
\text { neighbours. This measures shows the size of the ego's } \\
\text { networks less the redundant ties. }\end{array}$ \\
\hline $\begin{array}{l}\text { Constraint } \\
\text { Betweeness } \\
\text { Centrality }\end{array}$ & $\begin{array}{l}\text { involve only one actor (Borgatti and Foster, 2003). This is an } \\
\text { inverse measure of social capital, where the lower the } \\
\text { constraint the higher the ego's social capital. }\end{array}$ \\
\hline $\begin{array}{l}\text { Normalised } \\
\text { creating opportunities for controlling information flows. }\end{array}$ \\
\hline
\end{tabular}

The framework described above provides a means to examine the evolution of the overall network and also specific actor networks.

\subsection{Chapter Summary}

In summary, the research design is based on a combination of network analysis and case study methods. Themes from the social network analysis literature have been used to guide data collection and analysis. Primary data has been collected from in-depth interviews with senior management of four companies. Issues using the historical approach to capture data from participants have been acknowledged and mitigated through secondary data triangulation and cross-interview validation. 
This thesis has taken guidance from Coviello's (1995) bifocal approach that incorporates both quantitative and qualitative network data into the case method. This approach analyses the interview transcripts for key events and research themes. Finally, quantitative network data are developed from the qualitative data and analysed using UCINET, a social network analysis software package (Borgatti, Everett and Freeman, 1999). Further information on the quantitative data is presented in Chapter 5. Table 4 summarises the research design approach adopted for this thesis.

Table 4: Research Design Summary

\begin{tabular}{|l|l|l|l|l|}
\hline \multicolumn{1}{|c|}{ Themes } & $\begin{array}{c}\text { Research } \\
\text { Methods }\end{array}$ & \multicolumn{1}{c|}{$\begin{array}{c}\text { Data } \\
\text { Collection }\end{array}$} & $\begin{array}{c}\text { Qualitative } \\
\text { Analysis } \\
\text { Techniques }\end{array}$ & $\begin{array}{c}\text { Quantitative } \\
\text { Analysis } \\
\text { Techniques }\end{array}$ \\
\hline Internationalisation & Case Study & $\begin{array}{l}\text { Semi- } \\
\text { structured } \\
\text { interviews }\end{array}$ & $\begin{array}{l}\text { Interview } \\
\text { analysis }\end{array}$ & $\begin{array}{l}\text { Network } \\
\text { analysis using } \\
\text { UCINET }\end{array}$ \\
\hline Network Analysis & Historical & $\begin{array}{l}\text { Secondary } \\
\text { research }\end{array}$ & $\begin{array}{l}\text { Time series } \\
\text { analysis }\end{array}$ & \\
\hline & Network & & \\
\hline Data validation through triangulation between each individual's accounts and also \\
factual secondary data.
\end{tabular}




\section{Case Study}

This chapter introduces the qualitative aspects of the case. First, a list of the companies is provided followed by a narrative summarising the case. This was written by the researcher primarily based on interview data and then supplemented with secondary data from news articles and company websites. It is followed by a high-level timeline and profiles of the companies that were involved in the network.

\subsection{List of Companies in the Network}

While the research directly captured data from four companies, Table 10 shows the actors involved in the network as identified by their peers. The first 4 actors in Table 10, highlighted in italics were directly involved in providing data.

Table 10: List of Companies in the Network

\begin{tabular}{|l|l|l|}
\hline Name/Alias & Location or Headquarter & Function \\
\hline ManufactureCo & Christchurch, New Zealand & Contract Manufacturer \\
\hline DesignCo & Christchurch, New Zealand & Industrial Designer \\
\hline PaymentSolutionCo & Auckland, New Zealand & Retail Payment Solutions \\
\hline PlasticCo & Christchurch, New Zealand & $\begin{array}{l}\text { Plastic Injection Moulder } \\
\text { and Supplier }\end{array}$ \\
\hline WoodCo & Auckland, New Zealand & Wood and Paper supplier \\
\hline SheetMetalCo & Christchurch, New Zealand & Engineer of sheet metal \\
\hline GlobalPlasticCo & Saudi Arabia & $\begin{array}{l}\text { Supplier of raw plastic } \\
\text { materials }\end{array}$ \\
\hline SoftwareCo & Christchurch, New Zealand & Software developer \\
\hline
\end{tabular}




\begin{tabular}{|l|l|l|}
\hline MalaysianGov & Malaysia & Government \\
\hline GlobalOilCo1 & Malaysia & $\begin{array}{l}\text { Global Petroleum } \\
\text { Supplier }\end{array}$ \\
\hline FuelPumpCo & New Zealand & Pump Manufacturer \\
\hline $\begin{array}{l}\text { MalayOilCo } \\
\text { (represents multiple } \\
\text { companies) }\end{array}$ & Malaysia & $\begin{array}{l}\text { Global Petroleum } \\
\text { Supplier }\end{array}$ \\
\hline $\begin{array}{l}\text { NZGovtGrant } \\
\text { PrinterCutterCo } \\
\text { (represents 3 } \\
\text { companies) }\end{array}$ & Auckland, New Zealand & $\begin{array}{l}\text { Global Petroleum } \\
\text { Supplier }\end{array}$ \\
\hline
\end{tabular}

\subsection{Company Profiles}

The following section provides background to the central actors in the network. Specifically, it outlines their core services or products, the industry they participate in, their location and size in terms of employee numbers. The tables below represent the four companies involved in data collection and the customer in Malaysia. 
Table 11: Company Profiles

\begin{tabular}{|c|c|}
\hline \multicolumn{2}{|l|}{ MalayOilCo } \\
\hline Description & $\begin{array}{l}\text { MalayOilCo is an international petroleum and gas company based } \\
\text { in Malaysia. }\end{array}$ \\
\hline Industry & Oil \\
\hline Headquarters & Kuala Lumpur, Malaysia \\
\hline Size (employee) & 33,944 \\
\hline Services & $\begin{array}{l}\text { Oil } \\
\text { Natural gas } \\
\text { Petrochemical manufacturing } \\
\text { Shipping services }\end{array}$ \\
\hline
\end{tabular}

\section{PaymentSolutionCo}

\begin{tabular}{|c|c|}
\hline Description & $\begin{array}{l}\text { An enterprise that designs, builds, distributes and services some of } \\
\text { the world's most innovative payment and transaction solutions. } \\
\text { Globally, PaymentSolutionCo is heir to } 30 \text { years experience } \\
\text { supplying solutions to the retail oil industry. This includes } \\
\text { developing and installing the world's first EMV compliant } \\
\text { forecourt payment system. PaymentSolutionCo offers complete } \\
\text { end-to-end, integrated petrol station solutions consisting of } \\
\text { payment, point of sale, back office and head office systems as well } \\
\text { as forecourt controllers. }\end{array}$ \\
\hline Industry & Payment and transaction solutions \\
\hline Headquarters & Auckland, New Zealand \\
\hline Size (employee) & 300 \\
\hline Services & $\begin{array}{l}\text { Petroleum \& C-Store - Smart automation technology for the retail } \\
\text { and commercial fuelling environment. }\end{array}$ \\
\hline
\end{tabular}




\begin{tabular}{|l|l|}
\hline Point of sale. Back office. Head office. Forecourt control. Outdoor \\
payment terminals. \\
Unattended Components \\
PINpad. Encrypting PINpad
\end{tabular}

\begin{tabular}{|c|c|}
\hline \multicolumn{2}{|l|}{ ManufactureCo } \\
\hline Description & $\begin{array}{l}\text { ManufactureCo is a contract electronics manufacturer. Most } \\
\text { production is exported - to over } 40 \text { countries. }\end{array}$ \\
\hline Industry & Manufacturing, Electronics \\
\hline Headquarters & Sydney, Australia and Christchurch, New Zealand \\
\hline Size (employee) & 130 Christchurch, 570 in Sydney \\
\hline Services & $\begin{array}{l}\text { A Contract Electronics Manufacturer (CEM). They provide high- } \\
\text { level technical and management resources to manage the } \\
\text { introduction, manufacture, and support of technically complex } \\
\text { products such as: Microwave Radio systems, Optical } \\
\text { Communications products Medical Electronics equipment, } \\
\text { Products that are commercially complex. }\end{array}$ \\
\hline
\end{tabular}

\begin{tabular}{|c|c|}
\hline \multicolumn{2}{|l|}{ PlasticCo } \\
\hline Description & $\begin{array}{l}\text { Custom plastic injection moulder, tool and die-maker first } \\
\text { established in } 1972 \text { to provide a manufacturing services. Situated } \\
\text { in a modern manufacturing facility they employ over } 100 \text { people } \\
\text { and operate } 28 \text { moulding machines ranging from } 22 \text { to } 680 \text { tonnes. }\end{array}$ \\
\hline Industry & Plastic Moulding \\
\hline Headquarters & Christchurch, New Zealand \\
\hline Size (employee) & 105 \\
\hline Services & $\begin{array}{l}\text { - } \quad \text { Ultrasonic and Hot Plate Welding. } \\
\text { - } \quad \text { Cinpres Gas Assisted Injection. } \\
\text { - } \quad \text { In-Mould Decoration and Labelling (IMD). }\end{array}$ \\
\hline
\end{tabular}




\begin{tabular}{|l|l|}
\hline & - Printing and Electroplating of Plastics. \\
- & Multi-Component Two Shot Injection. \\
- & Encapsulation and Insert Moulding. \\
- & Transfer Co-Moulding. \\
- & Post Moulding Assembly. \\
- & Class 2 Clean Room. \\
- & Mould Design and Toolmaking. \\
\hline
\end{tabular}

\begin{tabular}{|l|l|}
\hline \multicolumn{2}{|l|}{ DesignCo } \\
\hline Description & $\begin{array}{l}\text { A design company that takes initial ideas and develops to } \\
\text { engineered products ready to manufacture. }\end{array}$ \\
\hline Industry & Industrial Design \\
\hline Headquarters & Christchurch, New Zealand \\
\hline Services & $\begin{array}{l}\text { New Product Creation - NPC Validating that the product } \\
\text { specification defines customer need. } \\
\text { New Product Development - NPD Smart design process creating } \\
\text { smart products. } \\
\text { New Product Implementation - NPI Ready-to-ship product from } \\
\text { world-class suppliers. }\end{array}$ \\
\hline
\end{tabular}

\subsection{The Case}

As mentioned, the following case is intended to be a summary of the network as it develops. This summary has been written by the researcher based on interview and secondary data. 
Within the electronics cluster of the Canterbury region in New Zealand, the chief executives of three complementary firms decided to offer a complete manufacturing solution and hence, search for work together.

The companies represented were PlasticCo, ManufactureCo and SheetMetalCo. In 1999 the three entities got together for the first time and decided to meet once a month. Coming out of these meetings were tasks such as bringing new opportunities to the table taking advantage of their compleimentary services.

“...trying to create a solution where we came in and said leave all manufacturing solutions to us, we've got between us electronics, plastics and metal work... you know once you've got software development, we can do the rest. And it seemed to have quite an appeal to the people we targeted" (PlasticCo)

This resulted in several pockets of work that required fluid structures in terms of who was involved. For example, projects often demanded two of the three companies and therefore the group couldn't and didn't want a rigid structure. The three executives recognised their natural fit and enjoyed working with each other.

Parallel to this, in 1999 an industrial design company was founded in Christchurch. DesignCo started small with 2-3 staff initially, although the founder already had considerable experience with a large white-ware manufacturer in New Zealand and also experience in London.

DesignCo's exploration of opportunities led them to a cold call meeting with PaymentSolutionCo. PaymentSolutionCo had just purchased the payment terminal business from FuelPumpCo. Initially, they did not know what to do with it, but saw it as a potential extension of their business.

PaymentSolutionCo began researching and developing concepts with DesignCo for one to two years. The tipping point came when the Malaysian Government announced their intentions to embrace the new EMV (Europay, Mastercard and VISA) requirement for credit card transactions. This new standard meant credit 
card fraud was reduced dramatically and Malaysia wanted to be the first country to lead the way. Only then did DesignCo and PaymentSolutionCo become aware that all the old credit card terminals would have to be replaced and this opportunity triggered and drove product development in 2002.

Representatives from PaymentSolutionCo spoke to DesignCo and realised MalayOilCo wanted to look at some rendering and a total cost of ownership model. DesignCo then went away to begin investigating how this would be achieved.

As a result, in September 2002 DesignCo pulled together PaymentSolutionCo, PlasticCo, GlobalPlasticCo and DesignCo for a meeting. They spoke about the intended concept and wanted to explore opportunities of in-mould decoration (IMD) and the plastic technologies. PlasticCo had previously done some work using IMD and GlobalPlasticCo were there to talk and discuss their capabilities. Thus, this meeting acted as preliminary feedback for DesignCo as the product designers (and also as project managers). However, the whole team was generally naïve about the project and product.

IMD meant huge risks for all involved but also tremendous upsides in terms of longevity and appearance of the product.

"There's no other material in the market which could sustain what we were looking at doing with the IMD” (DesignCo)

Three people represented GlobalPlasticCo; an IMD expert from Pittsburgh, USA, and two sales representatives from Australia.

DesignCo were primarily driving the discussion as they were tasked with designing the terminal by PaymentSolutionCo, and so it was DesignCo who brought the other players together. PlasticCo were there because they had used the IMD technology in a camera case they produced, and GlobalPlasticCo, because there are only two IMD suppliers in the world and GlobalPlasticCo were the ones 
who could produce a clear sheet that was resistant to the chemicals typically found in the petroleum environment.

Following this meeting, DesignCo, now grown with considerable projects, went away and designed the mechanical and electronic aspects in the form of a digital design. At that stage the other suppliers and the manufacturer had limited information about the project and were only contacted specifically for understanding the possibilities to design.

DesignCo took the role of project managers and took advantage of existing relationships between SheetMetalCo, ManufactureCo and PlasticCo. As a result, DesignCo were facilitating and coordinating all activities under the watch of PaymentSolutionCo. It was a conscious decision of PaymentSolutionCo's that the companies all be co-located in the same region increasing the likelihood of them knowing each other.

A marketing prototype was hand built by DesignCo to win the bid put out by MalayOilCo in Malaysia. The New Zealand team took specifications, drawings and cost models over several iterations. The eventual result was that a rendering was drawn up of the look, feel and assembly.

Around mid 2003 PaymentSolutionCo went to visit the prospect with the fully developed prototype. However, even though there was increasing commitment from the New Zealand companies, sign off did not occur until early 2004. This was because there was an intimate sales process working closely with MalayOilCo mechanical teams to understand the integration and advantages of the New Zealand approach.

Between August 2003 and February 2004 a pilot of 50-100 units were made. This was eventually ramped up to 5,000 units for full production.

“5,000 units don't sound like many units to produce but it proved to be quite a task because we were pioneering it and hadn't done it before." (PlasticCo) 
PlasticCo expected support from the expert GlobalPlasticCo in the US, but it turned out that what the New Zealand network wanted to do, pushed the envelop beyond GlobalPlasticCo's current capabilities. As a result, they ended up going through endless trial runs and huge amount of prototyping and trial and error learning. Massive efforts were needed to research thermoforming, printing and distortion printing - all requiring long hours.

Three processes were subcontracted by PlasticCo; printing, thermoforming and cutting. Essentially PlasticCo learnt as much about each process as the subcontractors because every process was new and no one could tell them how to do it.

PlasticCo carefully picked these partners and the three Christchurch firms collectively went through a learning and capability development process. Working together to develop capability meant that any work that required these services were shared amongst the group.

“...it became an ongoing brainstorm between us and the printer and occasionally the thermoformer..." (PlasticCo)

Finding partners was a trial and error process:

“We used another printer and found they weren't as capable and opted for the current one" (PlasticCo)

As a result development costs were significantly higher than what PaymentSolutionCo expected, due to the depth of issues that needed to be addressed. Not only in the plastics area, but also in the security around EMV, from a software perspective to integrate with banks in Malaysia, and from an electronic hardware perspective, building a secure encryption system that allowed for electronic tampers. 
With such a large development process, and so many unforeseen obstacles, the pressure to deliver meant that, as a group, they were always behind their targets and playing catch up. It was considered a tumultuous project that was to be expected with any leading edge development - or 'bleeding edge' as some of the participants joked.

The implication on how the set of companies worked together meant that they couldn't be clinical or definitive about their collaboration. Instead of relationships being strained, as a result they were strengthened:

“...[its] a credit to all these companies involved in the fact that everyone treated it like a true partnership and treated very much as a joint development and I think everyone understood that we were pioneering and [that] pioneering comes with a price...” (PlasticCo)

The process took a huge cost to all involved in terms of time, money and stress. But over time they've made their margins. Furthermore, the research and development has put them in a unique position, creating potential work for years to come.

These process were facilitated by the team of engineers going back and forth between these organisations and also while other projects were on the go. The dependency on each other meant they became intimately tied to each other, risking their companies' viability if the project failed. This was also layered upon formal processes that are required when developing a product for manufacturing as this involves engineering change notices (ECN's), orders, forecasts, several consultations and joint meetings. For instance, a production manager, the purchasing manager, the project manager at ManufactureCo, the project manager at PaymentSolutionCo and the project team from DesignCo get together weekly.

At the senior level, executives met once a month over the period of the project. The forces binding the different layers wasn't so much the right personality combination, but the desire to be respective leaders in the their fields. They were all ready to be innovative risk takers for high returns. 
It was PaymentSolutionCo who had the ultimate contract with MalayOilCo. It was their strong presence in Malaysia, their comprehensive knowledge of the oil industry needs, their software and their approach to development in terms of offering a customised solution.

At the end of the day, the customer was blissfully unaware of the scale of collaboration between multiple firms in New Zealand and the painful, but rewarding, development process.

Results of the collaboration:

- \$21 million contract.

- New technology that can be sold around the world.

- Awards for plastics and exporting.

- Further sales to GlobalOilCo1 in Malaysia.

- And options to sell to Shell and other large oil companies.

\subsection{High-level Timeline of the Network}

Table 12 below highlights the key events that occurred over the five year period of the case. The purpose of the Table is to provide the key milestones driven by particular actors before and after the specific opportunity. 
Table 12: High-level Timeline of the Case

\begin{tabular}{|l|l|l|}
\hline \multirow{4}{*}{ Phase 1 } & 1999 & $\begin{array}{l}\text { Initial networking sessions in Christchurch: SheetMetalCo, ManufactureCo } \\
\text { and PlasticCo. }\end{array}$ \\
\cline { 2 - 3 } & 1999 & $\begin{array}{l}\text { PaymentSolutionCo bought electronic pump management from } \\
\text { FuelPumpCo. }\end{array}$ \\
\cline { 2 - 3 } & 2000 & DesignCo develop relationship with PaymentSolutionCo. \\
\cline { 2 - 3 } & 2001 & Malaysian Government sets target on EMV standard. \\
\hline \multirow{3}{*}{ Phase 2 } & 2002 & $\begin{array}{l}\text { DesignCo assembles team: SheetMetalCo, ManufactureCo and PlasticCo, } \\
\text { GlobalPlasticCo, PaymentSolutionCo. }\end{array}$ \\
\cline { 2 - 3 } & 2003 & Fully developed prototype taken to client in Malaysia. \\
\hline \multirow{3}{*}{ Phase 3 } & 2004 & Commitment gained for production of 5,000 units. \\
\cline { 2 - 3 } & 2005 & New customers gained with existing product. \\
\hline
\end{tabular}

Where this chapter summarised the case, Chapter 5 will provide detailed analysis of the data for each of the three phases in Table 12. 


\section{Analysis}

This chapter presents the data and resulting analysis. This section will introduce each phase and then outline the qualitative data, presented as tables and visual maps for each phase. Table 12 shows the three phases of the network. The network maps are developed from UCINET as described in Chapter 3 and the geographic markings have been manually added by the author. This is then followed by quantitative data for each phase. Detailed explanations of the table structures have been provided in Chapter 3.

\subsection{Phase 1: Pre-Development}

Phase 1 captures the events that occurred before the opportunity to supply a retail automation product to MalayOilCo was recognised. Table 13 presented below, identifies the relationships that occurred during this Phase.

As discussed earlier, for each relationship, data are presented on the context, content, strength, history and geography of the relationship. Relationships that have multiple partners for a single event, or purpose, have been captured as a single relationship. For example, the first row shows three actors who collaborated to identify and share joint opportunities. Visual representation of the relationships can be found as a network map in Figure 4. This provides a complementary perspective of the network and additionally, highlights the international relationships that are implicit in the table.

There are 3 separate sub-networks in the Phase 1 network map (Figure 4). The largest sub-network, located on the bottom left of Figure 4, represents two important activities. First, row 1 in Table 13 explains that in 1999 three companies in Christchurch initiated collaborative meetings to identify and share opportunities with each other based on their complimentary services. This included ManufactureCo, PlasticCo and SheetMetalCo. The second activity, in this subnetwork, is the development of a new product for WoodCo. WoodCo contacted 
DesignCo to design the product and relied on all actors in the sub-network to support the product's manufacture. The inputs for the product included software, electronics, plastics and sheet metal. Both these activities occurred over a period of several months and their impact will be discussed in Chapter 6 .

The sub-network that spans the international boundary involves actors FuelPumpCo, PaymentSolutionCo and GlobalOilCo1. The second row in Table 13 describes the relationship between PaymentSolutionCo and FuelPumpCo and explains that PaymentSolutionCo had no prior history with FuelPumpCo and acquired the retail automation software in 1999. The other relationship from PaymentSolutionCo is to a global oil company (GlobalOilCo1) based in Malaysia. This relationship (row 4) shows that PaymentSolutionCo maintains a supplier relationship to this market with a previous product.

The last sub-network is based in Malaysia and shows how the Malaysian government announced a new standard for electronic transactions. This standard was then adopted as a goal for MalayOilCo to achieve by 2004. Together these relationships represent the network in Phase 1 and show the elements that support the opportunity developing. 
Table 13: Phase 1 Network Features

\begin{tabular}{|c|c|c|c|c|c|}
\hline $\begin{array}{l}\text { Actors (dyadic and } \\
\text { triadic) }\end{array}$ & $\begin{array}{l}\text { Context } \\
\text { (Description of Relationship) }\end{array}$ & $\begin{array}{l}\text { Content } \\
\text { (power, information, } \\
\text { goods \& services, } \\
\text { influence) }\end{array}$ & $\begin{array}{l}\text { Strength } \\
\text { (reciprocity, } \\
\text { intensity, trust, } \\
\text { time) }\end{array}$ & History & Geographic distance \\
\hline $\begin{array}{l}\text { PlasticCo, SheetMetalCo } \\
\text { and ManufactureCo }\end{array}$ & $\begin{array}{l}\text { In } 1999 \text { the } 3 \text { CEO's were looking for } \\
\text { joint opportunities. They met over } \\
\text { lunch every month. Worked well and } \\
\text { required flexibility based on each } \\
\text { opportunity. As a group they had more } \\
\text { power. }\end{array}$ & $\begin{array}{l}\text { Information, Goods } \\
\text { and Services. }\end{array}$ & $\begin{array}{l}\text { Strong relationships } \\
\text { between the three } \\
\text { based on the trust, } \\
\text { dependence on each } \\
\text { to deliver and time } \\
\text { spent. }\end{array}$ & $\begin{array}{l}\text { None prior to } \\
1999\end{array}$ & $\begin{array}{l}\text { All three companies and } \\
\text { CEO's located in } \\
\text { Christchurch }\end{array}$ \\
\hline $\begin{array}{l}\text { PaymentSolutionCo and } \\
\text { FuelPumpCo }\end{array}$ & $\begin{array}{l}\text { During } 1999 \text { PaymentSolutionCo } \\
\text { bought the fuel pump technology from } \\
\text { FuelPumpCo }\end{array}$ & Goods and services & Weak & $\begin{array}{l}\text { None prior to } \\
1999\end{array}$ & $\begin{array}{l}\text { PaymentSolutionCo and } \\
\text { FuelPumpCo are based in } \\
\text { New Zealand }\end{array}$ \\
\hline $\begin{array}{l}\text { DesignCo ManufactureCo, } \\
\text { SheetMetalCo, SoftwareCo } \\
\text { PlasticCo and WoodCo }\end{array}$ & $\begin{array}{l}\text { Previous collaboration to deliver the } \\
\text { HM } 200 \text { for WoodCo in } 2002 \text { Provided } \\
\text { credibility for DesignCo and their } \\
\text { network }\end{array}$ & $\begin{array}{l}\text { Goods and Services, } \\
\text { information, influence }\end{array}$ & Strong & $\begin{array}{l}\text { None prior to } \\
1999\end{array}$ & All Christchurch based \\
\hline $\begin{array}{l}\text { PaymentSolutionCo and } \\
\text { GlobalOilCo1 }\end{array}$ & $\begin{array}{l}\text { PaymentSolutionCo has sold previous } \\
\text { models to the oil industry and } \\
\text { maintains these relationships with } \\
\text { customers. There are } 17,000 \text { units in }\end{array}$ & $\begin{array}{l}\text { Information, goods and } \\
\text { services }\end{array}$ & Strong & 5-10 years & Malaysia to New Zealand \\
\hline
\end{tabular}




\begin{tabular}{|l|l|l|l|l|l|}
\hline & field. & & & \\
\hline Malaysian Government and & $\begin{array}{l}\text { Malaysian government announces } \\
\text { intention to be the world first to adopt } \\
\text { the new EMV standard in payment } \\
\text { MalayOilCo }\end{array}$ & & & & \\
& $\begin{array}{l}\text { Oechnology. Trigger of opportunity. The } \\
\text { name EMV comes from the initial } \\
\text { letters of Europay, MasterCard and } \\
\text { VISA, the three companies which } \\
\text { originally cooperated to develop the } \\
\text { standard. }\end{array}$ & Information, influence & Weak & Both entities in Malaysia \\
\hline
\end{tabular}




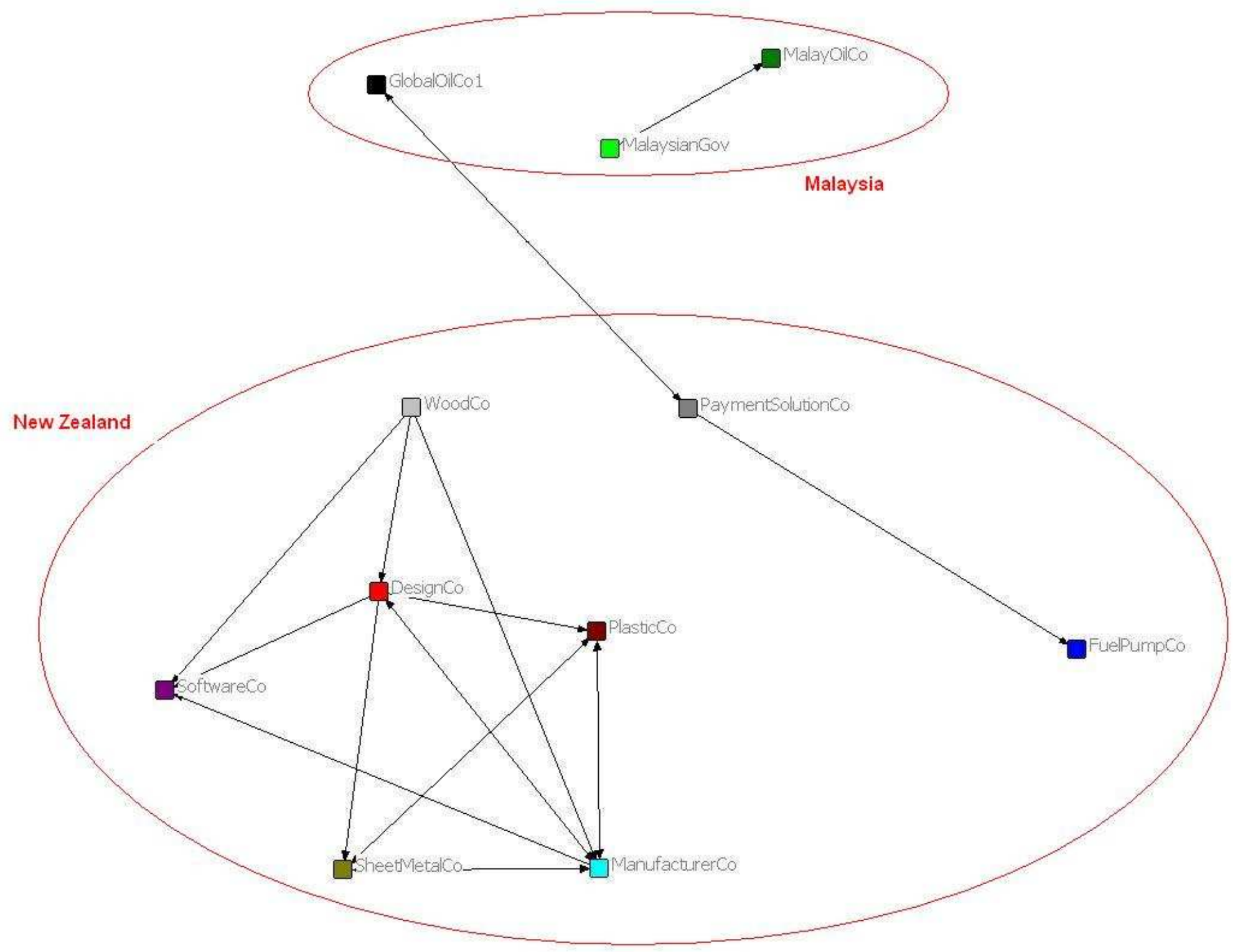

Figure 4: Phase 1 Network Map 


\subsection{Phase 2: Design and Development}

Phase 2 begins when PaymentSolutionCo becomes aware of the opportunity to supply MalayOilCo with new payment terminals that meet the new standard set by Easypay, Mastercard and Visa (EMV). This is described in the first row of Table 14. Triggered by the opportunity, Phase 2 represents the network dynamics that support the design and development of the product. The following paragraphs will describe what is presented in the relationship tables and network map for Phase 2.

Table 14 on page 79 illustrates four relationships that all involve PaymentSolutionCo based in Auckland, New Zealand. PaymentSolutionCo's first relationship develops from market intelligence in Malaysia, where MalayOilCo seeks to meet the new EMV standard as such, requires new payment terminals throughout Malaysia.

The second row of Table 14 shows PaymentSolutionCo developing a new relationship with DesignCo. An interesting point about this relationship is that it occurred by chance. The Discussion chapter will show why this relationship developed into a strong and intimate relation, formalised by a contract for design services. The initial meeting and supplier contract are shown as two separate relationships in Table 14 because they occurred at different times (over a 12 month gap).

In pursuing the design contract for PaymentSolutionCo, DesignCo began to explore the requirements and options for the casing of the product. This led to a meeting with leading plastic experts both, locally and globally, from PlasticCo and GlobalPlasticCo respectively. The purpose of the meeting was to identify the capabilities available and the potential benefits for the customer in Malaysia. It was felt that with this information, DesignCo could better design the prototype needed to win the tender.

PaymentSolutionCo and DesignCo were jointly scoping the product development. DesignCo's prior relationship with ManufactureCo, led to the introduction 
between ManufactureCo and PaymentSolutionCo. This is shown in the first row on page 80 (Table 14). These data show that both DesignCo and ManufactureCo were located in Christchurch and had prior relationships, while PaymentSolutionCo was based in Auckland and had no prior relationship with ManufactureCo.

DesignCo took a lead in the project management. To develop a sound understanding of the product's requirements and the integration required on-site in Malaysia, a selected number of DesignCo flew to Malaysia and met with MalayOilCo, accompanied by PaymentSolutionCo. PaymentSolutionCo were not able to fulfil this function because they did not have the technical expertise possessed by DesignCo. Furthermore, DesignCo maintained close relationships with suppliers in Christchurch and therefore, could better understand their requirements.

The result of DesignCo and PaymentSolutionCo making several trips to MalayOilCo, and their presentation of a prototype was that PaymentSolutionCo won the tender to supply 5,000 units. This contractual relationship has been captured in Table 14, row 1, page 81. This agreement is worth \$21 million and represented a significant win for PaymentSolutionCo.

In formalising the contract, PaymentSolutionCo then formalised a relationship with ManufactureCo. This is captured in row 2 of the table on page 81 . ManufactureCo were responsible for purchasing all supplies, manufacture, delivery and product servicing. The relationship between ManufactureCo in Christchurch and MalayOilCo is shown in the last row of Table 14 and also in Figure 5, the network map of Phase 2.

Figure 5 (page 82) shows the network map of Phase 2. It shows a yellow node (NZGovtGrant) with a relationship to PaymentSolutionCo and this signifies PaymentSolutionCo receiving a government grant to subsidise their research and development costs. The value of this was $\$ 400,000$. This information is also presented in Table 14 on page 80. 
As mentioned earlier, the plastic technology provided unique benefits to MalayOilCo. PlasticCo were responsible for pioneering new processes and material to develop the product moulds. Table 14 (row 4 on page 81 ), shows PlasticCo developing new relationships with three local companies who are all sub-contractors. These relationships involved developing new capability as a group. The data also show that their relationships were strong based on their technical learning, frequent contact, a partnership approach and sharing of risks. Figure 5, provides a visual summary of the relationships in Phase 2. 
Table 14: Phase 2 Network Features

\begin{tabular}{|c|c|c|c|c|c|}
\hline Actors & $\begin{array}{l}\text { Context } \\
\text { (Description of Relationship) }\end{array}$ & 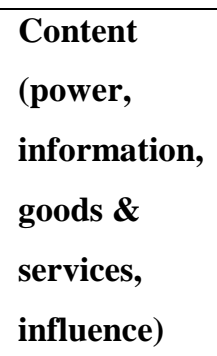 & $\begin{array}{l}\text { Strength } \\
\text { (reciprocity, } \\
\text { intensity, } \\
\text { trust, time) }\end{array}$ & History & $\begin{array}{l}\text { Geographic } \\
\text { distance }\end{array}$ \\
\hline $\begin{array}{l}\text { PaymentSolutionCo } \\
\text { and MalayOilCo }\end{array}$ & $\begin{array}{l}\text { PaymentSolutionCo have existing relationships with other } \\
\text { companies in Malaysia and learn about the new standard } \\
\text { requirements. The result is realising that all existing terminals in } \\
\text { the field will need to be replaced - presenting an opportunity for } \\
\text { PaymentSolutionCo to step up. This occurred in early } 2002 \text {. }\end{array}$ & Information & Weak & None & $\begin{array}{l}\text { Malaysia to } \\
\text { Auckland, New } \\
\text { Zealand }\end{array}$ \\
\hline $\begin{array}{l}\text { DesignCo and } \\
\text { PaymentSolutionCo }\end{array}$ & $\begin{array}{l}\text { Cold call where PaymentSolutionCo and DesignCo met in } \\
\text { Wanganui in 2001. At this stage PaymentSolutionCo were doing } \\
\text { market research into the opportunity. They did not know each } \\
\text { other prior to this. PaymentSolutionCo R\&D process begins }\end{array}$ & Information & Weak & None & $\begin{array}{l}\text { DesignCo in } \\
\text { Christchurch and } \\
\text { PaymentSolutionC } \\
\text { o in Auckland. }\end{array}$ \\
\hline $\begin{array}{l}\text { DesignCo and } \\
\text { PaymentSolutionCo }\end{array}$ & $\begin{array}{l}\text { In November } 2002 \text { PaymentSolutionCo and DesignCo sign a } \\
\text { contract for the design of the } 5^{\text {th }} \text { generation outdoor payment } \\
\text { terminal OPT. }\end{array}$ & Services & Weak & $\begin{array}{l}\text { Developed from } \\
\text { ad hoc and } \\
\text { informal } \\
\text { meeting. }\end{array}$ & $\begin{array}{l}\text { DesignCo in } \\
\text { Christchurch and } \\
\text { PaymentSolutionC } \\
\text { o in Auckland. }\end{array}$ \\
\hline $\begin{array}{l}\text { DesignCo, } \\
\text { GlobalPlasticCo, }\end{array}$ & & Information & Weak & $\begin{array}{l}\text { PlasticCo and } \\
\text { DesignCo had }\end{array}$ & $\begin{array}{l}\text { Two parties were } \\
\text { based in }\end{array}$ \\
\hline
\end{tabular}




\begin{tabular}{|c|c|c|c|c|c|}
\hline $\begin{array}{l}\text { PlasticCo and } \\
\text { PaymentSolutionCo }\end{array}$ & $\begin{array}{l}\text { Given that DesignCo were tasked to design the product, they set } \\
\text { out to understand the capability of the technology and also their } \\
\text { partners. } \\
\text { By mid-2003, DesignCo invites these partners to a meeting to } \\
\text { discuss the plastic technology }\end{array}$ & & & $\begin{array}{l}\text { prior } \\
\text { relationships. } \\
\text { The relationship } \\
\text { with } \\
\text { PaymentSolution } \\
\text { Co and } \\
\text { DesignCo was } \\
\text { developing. } \\
\text { GlobalPlasticCo } \\
\text { were new to the } \\
\text { group. }\end{array}$ & Christchurch. \\
\hline $\begin{array}{l}\text { DesignCo, } \\
\text { PaymentSolutionCo } \\
\text { and ManufactureCo }\end{array}$ & $\begin{array}{l}\text { Discussion on providing a quote for the manufacture. Very } \\
\text { tentative pricing }\end{array}$ & Information & $\begin{array}{l}\text { Strong with } \\
\text { DesignCo, } \\
\text { weak with } \\
\text { PaymentSoluti } \\
\text { onCo }\end{array}$ & $\begin{array}{l}\text { History with } \\
\text { DesignCo, none } \\
\text { with } \\
\text { PaymentSolution } \\
\text { Co. }\end{array}$ & $\begin{array}{l}\text { Christchurch and } \\
\text { Auckland. }\end{array}$ \\
\hline \multicolumn{6}{|c|}{ Over a period of time DesignCo developed a prototype that was taken to customer by December 2003} \\
\hline $\begin{array}{l}\text { DesignCo, } \\
\text { PaymentSolutionCo } \\
\text { and MalayOilCo } \\
\text { engineers }\end{array}$ & $\begin{array}{l}\text { Product discussions were driven by DesignCo and } \\
\text { PaymentSolutionCo as they refined their prototype. These } \\
\text { discussions covered integration and further information gathering } \\
\text { and this occurred between } 11 / 2003 \text { and } 02 / 2004 \text {. The process gave } \\
\text { MalayOilCo confidence and displayed their commitment to win } \\
\text { the tender. }\end{array}$ & $\begin{array}{l}\text { Information, } \\
\text { influence }\end{array}$ & Strong & $\begin{array}{l}\text { Little history } \\
\text { prior between } \\
\text { New Zealand } \\
\text { companies and } \\
\text { MalayOilCo. }\end{array}$ & $\begin{array}{l}\text { New Zealand to } \\
\text { Malaysia }\end{array}$ \\
\hline
\end{tabular}




\begin{tabular}{|c|c|c|c|c|c|}
\hline $\begin{array}{l}\text { PaymentSolutionCo } \\
\text { and MalayOilCo }\end{array}$ & $\begin{array}{l}\text { Using a prototype, PaymentSolutionCo wins the Malaysian } \\
\text { contract to provide 5,000 units of the G5 OPT product to } \\
\text { MalayOilCo. The first phase involves a pilot run of 50-100 units. }\end{array}$ & Product contract & Strong & $\begin{array}{l}1 \text { year of } \\
\text { interaction. }\end{array}$ & $\begin{array}{l}\text { New Zealand to } \\
\text { Malaysia }\end{array}$ \\
\hline $\begin{array}{l}\text { PaymentSolutionCo } \\
\text { and ManufactureCo }\end{array}$ & $\begin{array}{l}\text { DesignCo involved ManufactureCo into the process and } \\
\text { ManufactureCo sign a contract to manufacture with } \\
\text { PaymentSolutionCo. 06/2004 }\end{array}$ & $\begin{array}{l}\text { Product supply } \\
\text { and manufacture }\end{array}$ & Strong & $\begin{array}{l}\text { None but } \\
\text { facilitated } \\
\text { through } \\
\text { DesignCo. }\end{array}$ & $\begin{array}{l}\text { Product companies } \\
\text { in Christchurch }\end{array}$ \\
\hline $\begin{array}{l}\text { PaymentSolutionCo } \\
\text { and GovtGrant }\end{array}$ & $\begin{array}{l}\text { In } 2004 \text { Technology New Zealand, which promotes the } \\
\text { development and adoption of advanced technologies by business, } \\
\text { awarded PaymentSolutionCo financial assistance (R\&D grant of } \\
\$ 400,000) \text { for the development of the outdoor payment terminal. }\end{array}$ & Financial support & Weak & None. & Auckland \\
\hline $\begin{array}{l}\text { PlasticCo and } \\
\text { PrinterCutterCo }\end{array}$ & $\begin{array}{l}\text { PlasticCo develops the capability of three local companies to } \\
\text { support their work. }\end{array}$ & Suppliers & Strong & Little prior work. & $\begin{array}{l}\text { All Christchurch } \\
\text { located companies }\end{array}$ \\
\hline $\begin{array}{l}\text { ManufactureCo and } \\
\text { MalayOilCo }\end{array}$ & $\begin{array}{l}\text { ManufactureCo manufacture the product based on supply from } \\
\text { PlasticCo and design from DesignCo and their contract with } \\
\text { PaymentSolutionCo. The pilot run is shipped directly to } \\
\text { MalayOilCo. }\end{array}$ & Product & Strong & None. & $\begin{array}{l}\text { New Zealand to } \\
\text { Malaysia }\end{array}$ \\
\hline
\end{tabular}




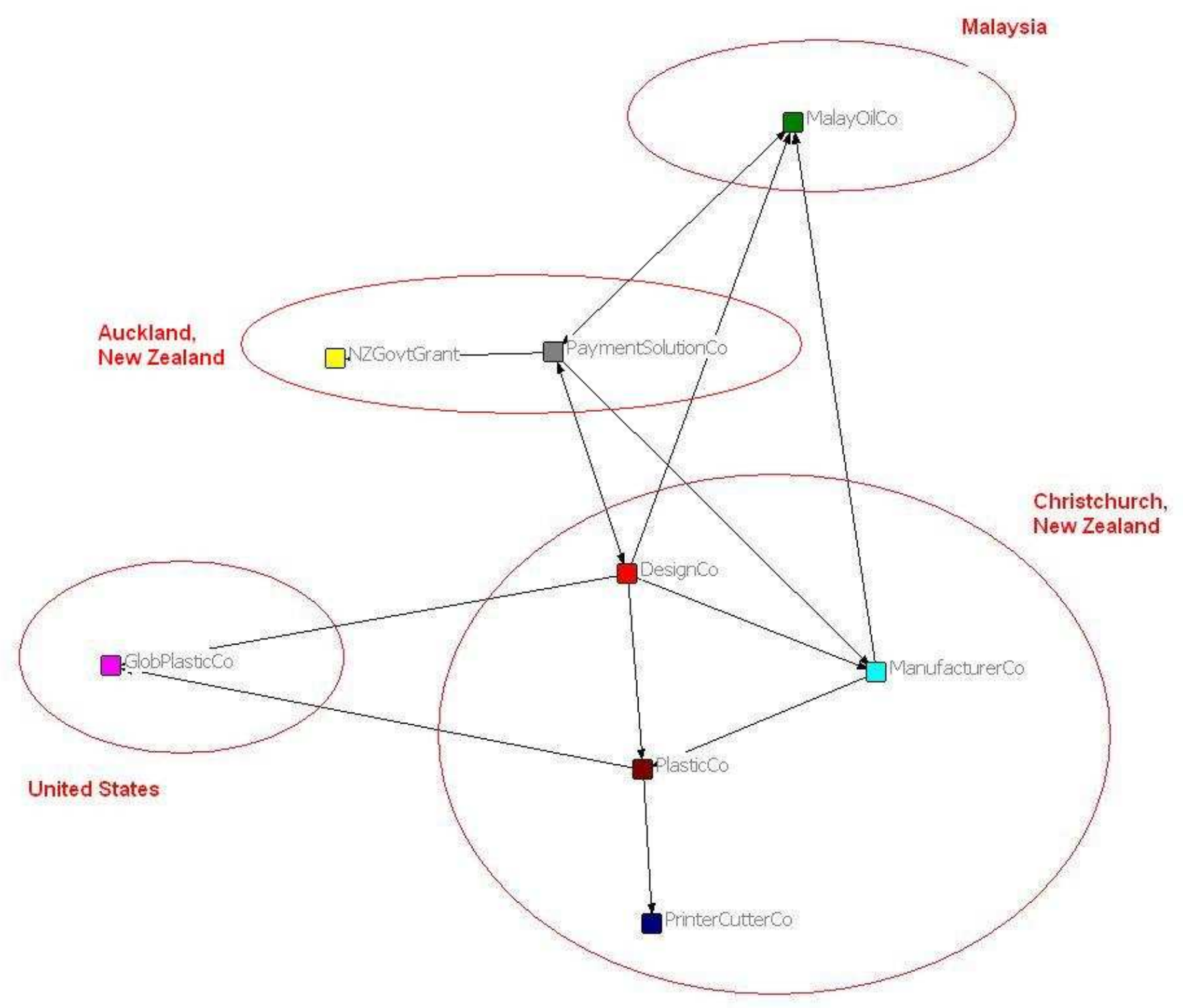

Figure 5: Phase 2 Network Map 


\subsection{Phase 3: Production and Future Opportunities}

Phase 3 describes the relationships involved in the production and delivery of the payment terminal to MalayOilCo. As a result of the product's success,

PaymentSolutionCo were also able to secure another multi-million dollar contract with an oil company in Malaysia. The new oil company relationships have been included here to capture the success of the product and also highlight new customer relationships that arose directly from the initial success.

The first relationship captured in Table 15 shows a new contractual agreement between PaymentSolutionCo and ManufactureCo for 5,000 units. This time the product is for a new customer in Malaysia. The production is facilitated by DesignCo who is responsible for ensuring the new product variations are delivered from each actor.

PlasticCo provide their new moulds directly to ManufactureCo for manufacturing. This relationship is captured in the second row of Table 15 and can also be visualised in Figure 6. At this point, PlasticCo and ManufactureCo have worked on several initiatives together over a number of years. The embeddedness and strength of their relationships are discussed in Chapter 6.

The third relationship captured in Table 15 conveys a shift in the relationship between PaymentSolutionCo and ManufactureCo. While the participant from PaymentSolutionCo was intimately involved in the development phases, as the development moved into production it meant their oversight role decreased greatly. As a result, the manager from PaymentSolutionCo (based in Auckland) decreased the number of their flights to ManufactureCo (based in Christchurch). To support the on-going production relationship, ManufactureCo assigned a fulltime account manager. The account manager would be responsible for production and also repairs that came back from the customer. This relationship is captured in the third row of Table 15. 
As mentioned above, gaining new customers for PaymentSolutionCo meant slight variations in the product. The last row in Table 15 shows the new contract from PaymentSolutionCo to GlobalOilCo2. This can also be visualised in Figure 6 .

In summary, the network in Phase 3 involved the core actors involved in the production and delivery of the payment terminal. The network map shows 2 relationships from PaymentSolutionCo to Malaysian customers, MalayOilCo and GlobalOilCo2. DesignCo, PlasticCo and ManufactureCo are involved in accommodating and manufacturing the product. 
Table 15: Phase 3 Network Features

\begin{tabular}{|c|c|c|c|c|c|}
\hline Actors & $\begin{array}{l}\text { Context } \\
\text { (Description of Relationship) }\end{array}$ & $\begin{array}{l}\text { Content } \\
\text { (power, } \\
\text { information, } \\
\text { goods \& services, } \\
\text { influence) }\end{array}$ & $\begin{array}{l}\text { Strength } \\
\text { (reciprocity, } \\
\text { intensity, } \\
\text { trust, time) }\end{array}$ & History & $\begin{array}{l}\text { Geographic } \\
\text { distance }\end{array}$ \\
\hline $\begin{array}{l}\text { PaymentSolutionCo to } \\
\text { ManufactureCo }\end{array}$ & $\begin{array}{l}\text { Contract between ManufactureCo and PaymentSolutionCo to } \\
\text { supply 5,000 units. DesignCo facilitates it all and PlasticCo are } \\
\text { involved in supplying their mould }\end{array}$ & Product & Strong & Pilot & $\begin{array}{l}\text { Auckland and } \\
\text { Christchurch }\end{array}$ \\
\hline $\begin{array}{l}\text { ManufactureCo and } \\
\text { PlasticCo }\end{array}$ & $\begin{array}{l}\text { PlasticCo supply ManufactureCo who ship to MalayOilCo 5,000 } \\
\text { units on behalf of PaymentSolutionCo. The product relies on input } \\
\text { from PlasticCo. }\end{array}$ & Product & Strong & Pilot & $\begin{array}{l}\text { Auckland and } \\
\text { Christchurch }\end{array}$ \\
\hline $\begin{array}{l}\text { PaymentSolutionCo } \\
\text { and ManufactureCo }\end{array}$ & $\begin{array}{l}\text { ManufactureCo assign a full-time staff member to manage and } \\
\text { maintain relationship with PaymentSolutionCo as they rely on } \\
\text { ManufactureCo to ship and manage repairs. PaymentSolutionCo } \\
\text { chargers per unit. ManufactureCo is responsible for ongoing } \\
\text { delivery and repair. }\end{array}$ & Services & Strong & Pilot & $\begin{array}{l}\text { Auckland and } \\
\text { Christchurch }\end{array}$ \\
\hline $\begin{array}{l}\text { PaymentSolutionCo } \\
\text { and GlobalOilCo1 }\end{array}$ & $\begin{array}{l}\text { PaymentSolutionCo then sell the product to GlobalOilCo1, } \\
\text { securing a new order for } 5,000 \text { units. This requires a new } \\
\text { evolution of the product. }\end{array}$ & Product & Strong & $\begin{array}{l}\text { Previous } \\
\text { customer }\end{array}$ & $\begin{array}{l}\text { Auckland and } \\
\text { Malaysia }\end{array}$ \\
\hline
\end{tabular}




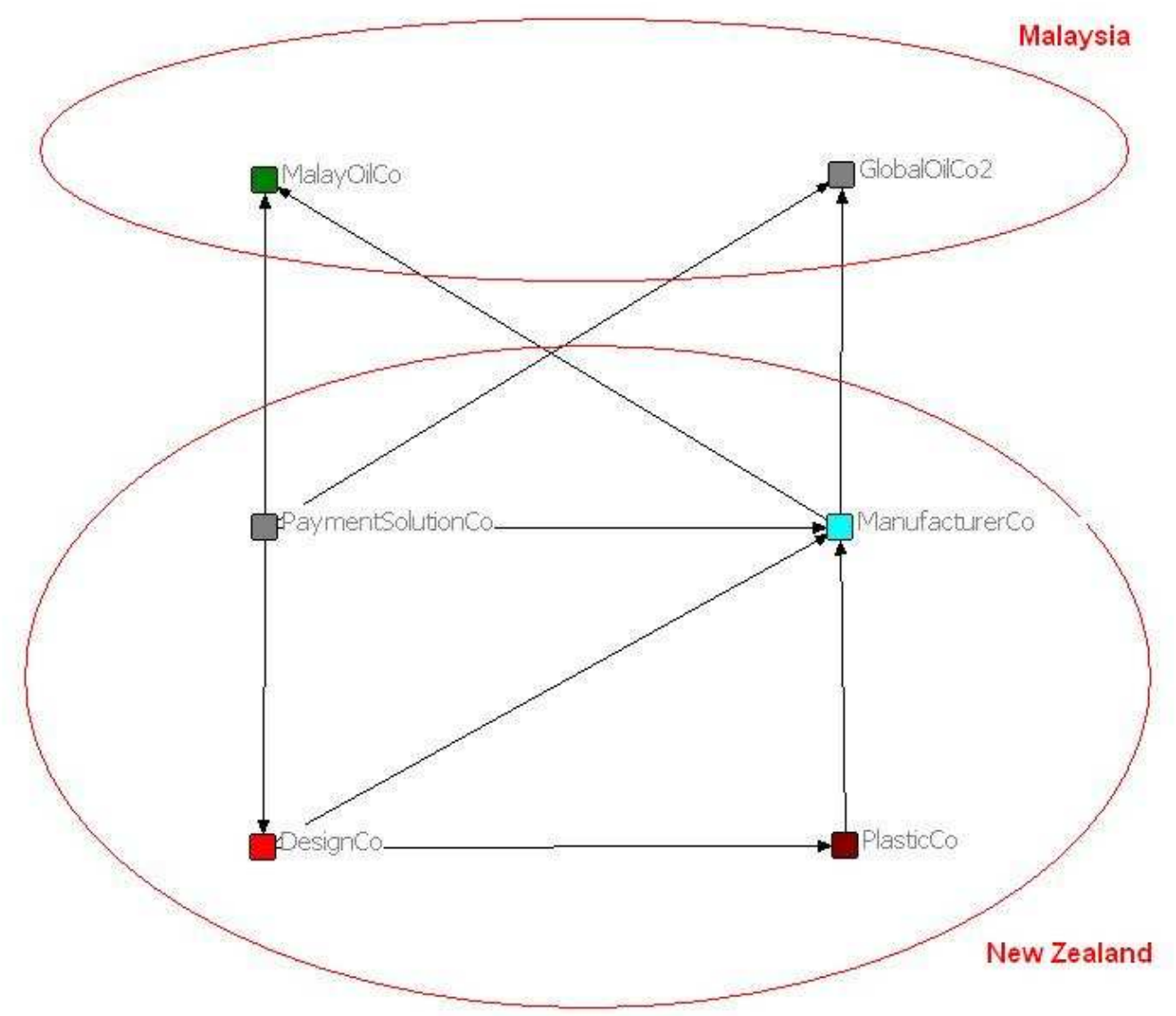

Figure 6: Phase 3 Network Map 


\subsection{Overall Network Statistics}

Table 16 captures structural data on the network over the 3 phases. Therefore, it provides insight into how the network evolves over time in terms of size, density and cohesion. The clique information allows for the identification of close groups. As discussed in Chapter 2 such groups tend to have strong ties, sharing information, trust and similar characteristics. Coupled with the qualitative data, clique identification helps explain dense groups in the network. A detailed account in each measure is provided in Table 11. A key observation from Table 16 is the reduction in the number of relationships, density and cohesion. Network size is discussed in Chapter 6, along with an explanation for the increase average distance in Phase 2, the design and development phase.

Table 16: Overall Network Analysis Statistics by each phase

\begin{tabular}{|l|l|l|l|}
\hline & Phase 1 & Phase 2 & Phase 3 \\
\hline Number of Ties & 19 & 14 & 9 \\
\hline Density & 0.0905 & 0.0667 & 0.0429 \\
\hline Average Distance & 1.269 & 1.767 & 1.357 \\
\hline $\begin{array}{l}\text { Cohesion } \\
\text { O to 1 where larger values } \\
\text { indicate greater cohesiveness }\end{array}$ & 0.107 & 0.1 & 0.055 \\
\hline Clique 1 & $\begin{array}{l}\text { WoodCo } \\
\text { ManufactureCo } \\
\text { DesignCo } \\
\text { SoftwareCo }\end{array}$ & $\begin{array}{l}\text { ManufactureCo } \\
\text { DesignCo } \\
\text { PalayOilCo }\end{array}$ & $\begin{array}{l}\text { ManufactSolutionCo } \\
\text { PalayOilCo }\end{array}$ \\
\hline Clique 2 & $\begin{array}{l}\text { SheetMetalCo } \\
\text { ManufactureCo } \\
\text { DesignCo } \\
\text { PlasticCo }\end{array}$ & $\begin{array}{l}\text { ManufactureCo } \\
\text { DesignCo PlasticCo }\end{array}$ & $\begin{array}{l}\text { MesignCo } \\
\text { PaymentSolutionCo }\end{array}$ \\
\hline Clique 3 & $\begin{array}{l}\text { ManufactureCo } \\
\text { DesignCo PlasticCo }\end{array}$ & $\begin{array}{l}\text { PaymentSolutionCo } \\
\text { GlobalOilCo2 }\end{array}$ \\
\hline
\end{tabular}




\subsection{Actor Specific Network Statistics}

The following tables (Tables 17-22) present the analysis for specific actors in the network across the 3 phases. This allows for analysis of individual network positions as the network evolves.

\subsubsection{Size and Brokerage Scores}

Table 17 captures the network size and brokerage scores of each actor. The network size shows the amount of relationships a particular actor has for the phase. The brokerage scores provide an indication of how an actor is positioned to broker relationships between actors that are not directly connected to each other. In examining Table 17, 4 actors maintain a high number of relationships across the phases. These are ManufactureCo, DesignCo, PaymentSolutionCo and PlasticCo. Another feature of these data are the high brokerage scores of ManufactureCo and DesignCo. This is consistent with the qualitative data that explains that DesignCo made a number of introductions, or new relationships, and ManufactureCo maintained relationships with all suppliers and the customer as they built and delivered the product. Finally, the reduction of ManufactureCo's brokerage score in Phase 2 emphasises that this network structure reflects the research and design and not manufacturing. Complementarily, DesignCo's brokerage score is high in Phase 2 because their role was to facilitate the research and development within the network. 
Table 17: Size and brokerage scores for each actor, across each phase

\begin{tabular}{|c|c|c|c|c|c|c|}
\hline \multicolumn{7}{|c|}{ Size and Brokerage Measures } \\
\hline \multirow[b]{2}{*}{ Actors } & \multicolumn{3}{|c|}{ Size of Actor Network } & \multicolumn{3}{|c|}{$\begin{array}{l}\text { Brokerage Score for each } \\
\text { Actor }\end{array}$} \\
\hline & Phase 1 & Phase 2 & Phase 3 & Phase 1 & Phase 2 & Phase 3 \\
\hline WoodCo & 3 & 0 & 0 & 1 & 0 & 0 \\
\hline SheetMetalCo & 3 & 0 & 0 & 0.5 & 0 & 0 \\
\hline GlobalPlasticCo & 0 & 2 & 0 & 0 & 0.5 & 0 \\
\hline ManufactureCo & 5 & 4 & 5 & 6.5 & 3 & 8 \\
\hline DesignCo & 5 & 5 & 3 & 5.5 & 7 & 2 \\
\hline SoftwareCo & 3 & 0 & 0 & 1 & 0 & 0 \\
\hline $\begin{array}{l}\text { Malaysian } \\
\text { Government }\end{array}$ & 1 & 0 & 0 & 0 & 0 & 0 \\
\hline GlobalOilCo1 & 1 & 0 & 0 & 0 & 0 & 0 \\
\hline FuelPumpCo & 1 & 0 & 0 & 0 & 0 & 0 \\
\hline MalayOilCo & 1 & 3 & 2 & 0 & 1 & 0.5 \\
\hline PaymentSolutionCo & 2 & 4 & 4 & 1 & 4.5 & 4.5 \\
\hline GlobalOilCo2 & 0 & 0 & 2 & 0 & 0 & 0.5 \\
\hline PlasticCo & 3 & 4 & 2 & 0.5 & 5 & 0.5 \\
\hline NZGovtGrant & 0 & 1 & 0 & 0 & 0 & 0 \\
\hline PrinterCutterCo & 0 & 1 & 0 & 0 & 0 & 0 \\
\hline
\end{tabular}

\subsubsection{Network Centrality Scores}

Chapter 4 described network centrality as the ability to control information flows between actors. Tables 18, 19 and 20 each correspond Phase 1 to 3 and capture the 
centrality scores for each actor. Actors with scores of 0 have been omitted to enhance readability. ManufactureCo stands out in Phase 1 and 3, while PaymentSolutionCo has high centrality in Phase 2. The network maps in Figures 4 to 6 reflect these characteristics from a visual perspective. The reason and implications of these structural traits are discussed in Chapter 6.

Table 18: Phase 1 Centrality Scores

\section{Phase 1 Centrality Scores}

\begin{tabular}{|l|l|}
\hline & Betweenness \\
\hline ManufactureCo & 5 \\
\hline DesignCo & 1 \\
\hline PaymentSolutionCo & 1 \\
\hline
\end{tabular}

Table 19: Phase 2 Centrality Scores

\section{Phase 2 Centrality Scores}

\begin{tabular}{|l|l|}
\hline & Betweenness \\
\hline PaymentSolutionCo & 9 \\
\hline PlasticCo & 5 \\
\hline DesignCo & 4 \\
\hline MalayOilCo & 3 \\
\hline ManufactureCo & 2 \\
\hline
\end{tabular}


Table 20: Phase 3 Centrality Scores

\begin{tabular}{|l|l|}
\hline Phase 3 Centrality Scores & Betweenness \\
\hline & 4 \\
\hline ManufactureCo & 1 \\
\hline DesignCo & \\
\hline
\end{tabular}

\subsubsection{Structural Holes}

The effective size and constraint scores in Tables 21 to 23 provide insight into the positioning of actors relative to structural holes. The effective size of an actors network takes into account their redundant ties, i.e. effective size is network size less redundant ties. From Chapter 2, structural holes separate non-redundant sources of information. Therefore, actors with a high effective size score will be more likely to be positioned next to a structural hole. Actors with high scores in their effective network size include, ManufactureCo, DesignCo and PaymentSolutionCo - all central actors in the product's development.

The constraint scores indicate how limited an actor's options are based on their surrounding network. The higher the constraint score the more constrained the actor is. Additionally, constraint scores are considered to be an inverse score of social capital, such that the higher the constraint scores the lower the actor's social capital. Once again, actors with the most amount of freedom or social capital across the 3 phases are DesignCo and PaymentSolutionCo. The social capital and positioning of DesignCo and PaymentSolutionCo on the edge of a structural hole is identified and discussed in the next chapter. 
Table 21: Phase 1 Structural Holes Measures

\section{Phase 1 Structural Holes Measures}

\begin{tabular}{|c|c|c|}
\hline & Effective Size & Constraint \\
\hline WoodCo & 1.333 & 0.997 \\
\hline SheetMetalCo & 1.3 & 0.947 \\
\hline GlobalPlasticCo & 0 & 0 \\
\hline ManufactureCo & 3.125 & 0.581 \\
\hline DesignCo & 2.5 & 0.674 \\
\hline SoftwareCo & 1.333 & 0.997 \\
\hline Malaysian Government & 1 & 1 \\
\hline GlobalOilCo1 & 1 & 1 \\
\hline FuelPumpCo & 1 & 1 \\
\hline MalayOilCo & 1 & 1 \\
\hline PaymentSolutionCo & 2 & 0.556 \\
\hline GlobalOilCo2 & 0 & 0 \\
\hline PlasticCo & 1.3 & 0.947 \\
\hline NZGovtGrant & 0 & 0 \\
\hline PrinterCutterCo & 0 & 0 \\
\hline
\end{tabular}


Table 22: Phase 2 Structural Holes Measures

\section{Phase 2 Structural Holes Measures}

\begin{tabular}{|c|c|c|}
\hline & Effective Size & Constraint \\
\hline WoodCo & 0 & 0 \\
\hline SheetMetalCo & 0 & 0 \\
\hline GlobalPlasticCo & 1 & 1.125 \\
\hline ManufactureCo & 2.375 & 0.765 \\
\hline DesignCo & 3.167 & 0.571 \\
\hline SoftwareCo & 0 & 0 \\
\hline Malaysian Government & 0 & 0 \\
\hline GlobalOilCo1 & 0 & 0 \\
\hline FuelPumpCo & 0 & 0 \\
\hline MalayOilCo & 1.25 & 0.956 \\
\hline PaymentSolutionCo & 2.833 & 0.585 \\
\hline GlobalOilCo2 & 0 & 0 \\
\hline PlasticCo & 3 & 0.535 \\
\hline NZGovtGrant & 1 & 1 \\
\hline PrinterCutterCo & 1 & 1 \\
\hline
\end{tabular}


Table 22: Phase 3 Structural Holes Measures

\section{Phase 3 Structural Holes Measures}

\begin{tabular}{|c|c|c|}
\hline & Effective Size & Constraint \\
\hline WoodCo & 0 & 0 \\
\hline SheetMetalCo & 0 & 0 \\
\hline GlobalPlasticCo & 0 & 0 \\
\hline ManufactureCo & 3.4 & 0.536 \\
\hline DesignCo & 1.667 & 0.84 \\
\hline SoftwareCo & 0 & 0 \\
\hline Malaysian Government & 0 & 0 \\
\hline GlobalOilCo1 & 0 & 0 \\
\hline FuelPumpCo & 0 & 0 \\
\hline MalayOilCo & 1 & 1.125 \\
\hline PaymentSolutionCo & 2.5 & 0.684 \\
\hline GlobalOilCo2 & 1 & 1.125 \\
\hline PlasticCo & 1 & 1.125 \\
\hline NZGovtGrant & 0 & 0 \\
\hline PrinterCutterCo & 0 & 0 \\
\hline
\end{tabular}

Together with the relationship tables and network maps, the quantitative network data provides insight to the characteristics, structure and evolution of the overall network and individual networks over time. Linkages to the literature and further analysis of the data are discussed in Chapter 6. 


\section{Discussion}

This chapter provides a discussion on each phase of the network by drawing on the literature in Chapter 2 and the analysis of data presented in Chapter 5. Each phase is structured according to the themes that have emerged from the analysis. Each theme is then related back to the literature and research questions. For ease of reference the networks maps are presented for each phase.

\subsection{Phase 1}

As highlighted in Table 13, Phase 1 of the case includes activities prior to the initiation of the product development process. The first section, within Phase 1, explores the motivation for collaboration amongst SheetMetalCo, PlasticCo and ManufactureCo and goes further to explain how their cooperation developed. This clique involved frequent interaction over time that embedded their relationships and the implications of their embeddedness are discussed in section 6.1.2. Section 6.1.3 discusses the network closure and constraint and how this clique structure influences their individual actions.

Section 6.1.4 and 6.1.5 both address social capital. First, section 6.1.4 explores social capital arising from the successful delivery of a product for WoodCo (network capability). Together with the first clique this discussion collectively covers the group of actors in the bottom left of Figure 7. The second source of social capital stems from the network that spans the international boundary, from New Zealand to Malaysia (Figure 7). The impact of this international relationship is discussed in section 6.1.5. The last section in Phase 1 discusses how participation in foreign markets influences PaymentSolutionCo, specifically in terms of resource acquisition. 


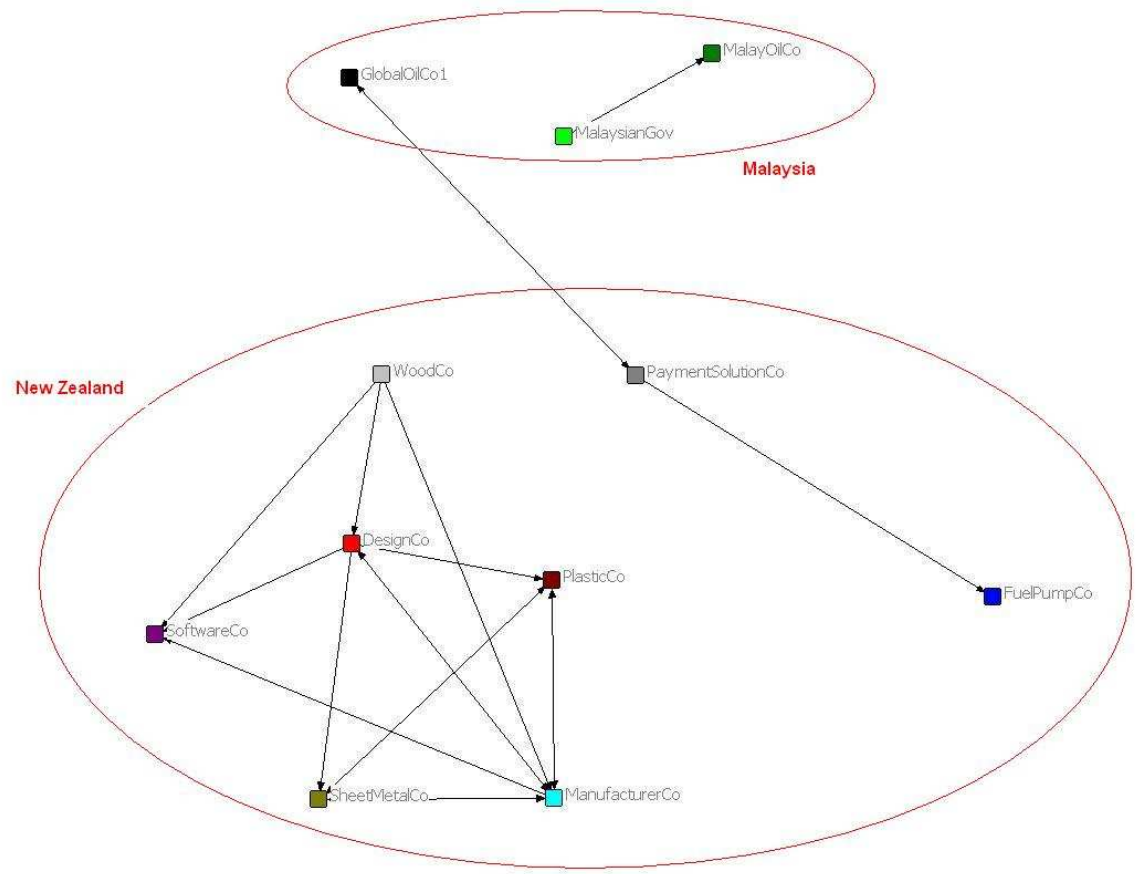

Figure 7: Phase 1 Network Map

\subsubsection{Clique 1: A complete manufacturing solution}

In 1999 the three CEO's of SheetMetalCo, PlasticCo and ManufactureCo decided to meet on a monthly basis to identify opportunities that required a 'complete manufacturing solution' based on each of their complimentary specialities. As such, this group of three had a complete set of relationships to each other; identified as a clique from the UCINET data in Table 16.

The motivation, or reason, to collaborate as a group was based on developing new sales leads based on a broader solution set:

"Three companies got together and we spent a lot of time talking to each about joint ventures, joint customers and did a lot of market development work together...trying to create a situation where we came in and said leave all your manufacturing solutions to us, we've got between us 
electronics, plastics and metal work... And it seemed to have quite an appeal to the people we targeted" (PlasticCo)

As a result, their cooperation as a group has been ongoing, spanning six years and several 'pockets' of formal working arrangements. How did their cooperation develop? Holm, Eriksson and Johanson (1996) develop a structural model of cooperation where they discuss 'relationship understanding' leading to increased levels of relationship commitment as part of their model. The term 'relationship understanding' refers to the ability to handle unforeseen circumstances (Holm, Eriksson and Johanson, 1996), which is clearly acknowledged by the participants as follows:

"Yes, we came together informally, we just started meeting once a month, 3 executives from 3 companies, and just over a lunch once a month...Yes it did [work quite well]. It's created certain pockets of work all around the place...each of you is risking their own company's reputation on the basis of others so you've got to be pretty sure you know they can do the job" (PlasticCo)

In the excerpt above, we see the participants acknowledge and convey a sense of understanding with regard to the risks that may arise in their projects. This aligns to their 'relationship understanding' (Holm, Eriksson and Johanson, 1996).

Commitment to these relationships can be evidenced from their investments into previous projects, such as the product development for WoodCo. As such, the findings support the idea that understanding how to work with a particular set of partners will increase commitment to those relationships (Holm, Eriksson and Johanson, 1996). Further evidence supporting their business network and cooperation model (Holm, Eriksson and Johanson, 1996) is discussed in Phase 2.

Captured in the qualitative data above, the relationships between the three CEO's were strong, based on Granovetter's (1979) definition of time, reciprocity, emotional intensity and intimacy. The benefit of strong ties within this group that aims to represent a 'total manufacturing solution,' is that if information about an 
opportunity becomes available to a single actor they are more likely to share it with their strong ties, in this case shared amongst the other actors in the group (Granovetter, 1983).

\title{
6.1.2 Embeddedness of Ties
}

The strength of the relationships between the three CEO's described in 6.1.1, points to their business relationships being embedded within a socially constructed relationship (Granovetter, 1985, Hite, 2003, Uzzi, 1997). Evidence of this social layer is their informal monthly lunches and also high levels of trust, particularly in relation to high-risk projects.

The trust of the relationships between PlasticCo, ManufactureCo and SheetMetalCo, became evident when their relationships were under pressure in terms of meeting deadlines and developing solutions. When asked if the challenges put a strain on the relationships the owner and CEO of PlasticCo commented:

\begin{abstract}
"No and that's a credit to all those companies involved, in the fact that everyone treated it like a true partnership and treated it very much as a joint development and I think everyone understood that we were pioneering and pioneering comes with a price..." (PlasticCo)
\end{abstract}

The continual interaction and delivery of services between these three actors further embeds these organisational relationships, bringing each relationship closer. However, as Uzzi (1997) points out, there are risks of over-embeddedness ('the paradox of embeddedness') where in one case, a sudden structural network change can leave the network vulnerable and at risk due to interdependencies (Uzzi, 1997). Hite (2005) also confirms what he terms the disadvantage of relationally embedded ties.

This case provides evidence of sudden structural changes where senior management in ManufactureCo left the network but relationships between organizations were maintained and continued to be effective: 
"The management of ManufactureCo changed in late 2003 or 2004 and that's changed the chemistry and dynamics a bit but it hasn't changed the way we work together, and we work together very well. And this morning for instance [the] ManufactureCo Chief Executive [was] talking about joint prospects and talking how we target them..." (PlasticCo)

This provides an example where over-embeddedness has been avoided, whether intentionally or not. On one hand, actors work to reap the benefits of a close strong relationship such as timely, fine-grained information, trust and joint problems solving (Uzzi, 1997; Hite, 2003). On the other hand, the actors have to avoid over-reliance on the benefits of embedded relations. How was this managed?

A potential explanation for this balance is the dependence on the transactional content. To reap benefits of their relationships, ManufactureCo, PlasticCo and SheetMetalCo have to rely on teams of engineers and analysts for delivery. This itself pulls the emphasis away from singular relationships and forces relationships to occur at all levels of the organizations, thereby influencing or limiting the nature of the CEO level relationships. This is aligned to Hite's (2005) comment on relational governance:

"Emerging firms must be aware of the potential for overembeddedness... and may need to adapt governance measure to fit both the transaction and relational characteristic of network ties" (Hite 2003, 2005)

The case data provide evidence for governance of the transactional relations primarily through the manufacturing process and as such, may mitigate the risk of over-embeddedness. In this case, by avoiding over-embeddedness, the network mitigated the risk of project failure caused by the change of key actors. Relying on transactional process for relational governance provides a partial answer to the research question on how the network governs itself. 


\subsubsection{Network Closure and Constraint}

The clique described in 6.1.1 and 6.1.2 is part of the network that has a small number of actors with a high level of connectedness, where everyone is connected (Granovetter, 1985, 1992). Coleman calls this network closure where the benefits take the form of greater information access and high levels of trust, which we have observed above (Coleman, 1990).

Burt (2000) finds that small networks with high density are highly constrained meaning their "network is directly or indirectly concentrated in a single contact" (Burt, 2000:10). In closed networks, each actor has visibility of each other's actions. To avoid the negative stigma attached to pursuing opportunities without a particular actor, the network here has purposefully catered for this flexibility, allowing actors to enter and exit commercial arrangements with members in the group:

“Quite often it ended for work for two but that didn't matter. My feeling of clustering is that an awful lot of clustering fails because people were too rigid about the structure of them... a loose cluster often works a lot better than a hard-wired cluster...you're stopping as you get all your hard wires...you stop when you get a project that suits everyone... where as a loosely formed cluster like we've had, the objective is to get more business if it happens it doesn't involve one of us it doesn't matter..." (PlasticCo)

This fluid arrangement was an explicit strategic decision and meant that actors were not constrained by their relationships to each other. This finding is also aligned to Burt's (2000) proposition regarding the integration of network closure and structural holes, as each actor was empowered to develop positions next to structural holes where they could bring in new manufacturing opportunities. The key observation here is that actors were encouraged to do so even if the opportunities only benefited a select few of the whole network. 
The constraint on actors based on the network structure can be clearly seen in their constraint scores of 0.947 in Table 21, which is very high. However, without the qualitative data the actors would appear to be constrained, thus highlighting the advantages of a mixed methodology in understanding network dynamics.

\subsubsection{Proven network capabilities as social capital}

The second clique identified in Table 21 in Phase 1 is between WoodCo, ManufactureCo, DesignCo, SoftwareCo, PlasticCo and SheetMetalCo. These actors collaborated to develop an electronic product for WoodCo that identifies the density of a log. The product was designed by DesignCo, manufactured from ManufactureCo and received components from SoftwareCo and PlasticCo.

This product development is significant to the overall network development as it proved the capability of the network working together. Therefore, the network is high in social capital based on their successful delivery, established norms, trust, coordination and efficiency (Putnam, 1993, Burt, 2000). DesignCo was aware of how their previous achievements contributed to their social capital in relation to the other actors:

"I mean [we] already had some credentials, we already delivered some products at that stage..." (DesignCo)

The following quote describes the networking working together for WoodCo:

"Similar type of model to the one we were using, the end customer, in that case [WoodCo], and DesignCo was doing the design, there was another design company involved in the electronics...but it was a similar process where by a certain amount of product design was done and the manufacturing was done here" (ManufactureCo) 
"DesignCo have shown that [capability]...doing work for WoodCo and some military stuff as well...so it's a similar environment...very harsh very hardy...from an industrial design...” (PlasticCo)

Their social capital is a sum of the resources possessed by the group based on their relationships (Burt, 2000). As the network evolves, the social capital of this group provides a competitive advantage and this is explored in Phase 2.

\subsubsection{Participation in foreign markets as social capital}

The other two networks in Phase 1 are disconnected and separate to each other resulting in three distinct sub-networks. Firstly, the two-actor network comprising of the Malaysian Government and MalayOilCo represents the announcement by the Malaysian government to adopt the new EMV standard in credit card technology. The new chip-based card system meant lower fraud rates. The Malaysian Government announced its intention to adopt it early with a goal of becoming the world's first nation to adopt the standards. At this stage, MalayOilCo, a Malaysian oil company with retail outlets across the country, set out to investigate adopting EMV terminals in the outdoor petrol stations. These are country specific activities removed from the New Zealand actors.

However, in saying that, PaymentSolutionCo did maintain relationships to its existing customer base in Malaysia, which that included other large multinational oil companies.

“...they [PaymentSolutionCo] did have GlobalOilCol and they did have GlobalOilCo2 in Malaysia as well...” (DesignCo)

In exploring the role of social capital in the internationalisation process, Chetty and Agndal (2006) identify 'the serendipity role of social capital' where unexpected events arising from social capital, can trigger internationalisation activities. This proposition is supported by the case data. 
PaymentSolutionCo's social capital stemmed from being involved in the Malaysian market. Chetty and Agndal (2006) state that a government agency may introduce an opportunity - in this case the Malaysian Government. The relationship was based on providing an older generation payment terminal, for the fuel service environment, and spanned from Auckland, New Zealand to Malaysia, highlighting PaymentSolutionCo's expertise and experience in the industry.

So, on one hand the Malaysian Government made a market announcement and on the other hand, we have a New Zealand company that maintains its customer relationship in the same market. While the relationships are two separate actors, they share a mutual geographic space: the Malaysian oil industry. The relationship was more than transactional in nature because it implicitly provided industry knowledge and continued to provide a link to the market.

"We took some of the knowledge ...there's obviously stuff you learn when you build things, you take that through...then there's that knowledge around the oil industry" (PaymentSolutionCo)

Using the social network approach, we have viewed the market participation as social capital (Burt, 2000) and applied it as a trigger to internationalisation using one of the propositions developed by Chetty and Agndal (2006).

Although not captured by the data explicitly, it is assumed that PaymentSolutionCo provided commitment and resources to maintain and further develop relationships to these customers and markets. Evidence of this is their market intelligence:

“...they [PaymentSolutionCo] knew the competition...they knew MalayOilCo was having a lot of difficulty with...their existing supplier was not servicing them very well at all...they had a lot of reliability problems and that's the thing..." (DesignCo) 
Finally, Chetty and Agndal (2006) note that firms who do access unexpected market knowledge, may or may not, have the social capital to enable them to act on the opportunity. This comment will be explored in Phase 2 as PaymentSolutionCo further investigate the opportunity with MalayOilCo.

\subsubsection{Relationally embedded ties and resource acquisition}

The last sub-network in Phase 1 shows PaymentSolutionCo with relationships with both a local New Zealand company and also the Malaysian oil companies mentioned in the previous section. Following Hite's (2005) research, PaymentSolutionCo is relationally embedded in to the Malaysian market via its relationships to Malaysian oil companies. Hite (2005) states that a strategic implication of relationally embedded ties is that it can influence the benefits arising from resources acquisition. Therefore, an organization can better understand what it is searching for through their embedded relations (Hite, 2005).

The case data provide evidence for an acquisition of technology in New Zealand that directly aligns to the PaymentSolutionCo's embedded relations in Malaysia. In this phase, PaymentSolutionCo purchased software from FuelPumpCo that controls the fuel pump mechanism. This was outdated technology but provided PaymentSolutionCo with a resource that aligned to its target industry and current product range, namely, the oil industry and retail automation solutions. One of PaymentSolutionCo's specialities is in the technology that controls the fuel systems and payment:

"We bought the retail automation side and they retained the pump manufacturing side and that business is still running... retail automation is product back office for controlling [the] payment terminal for our business..." (PaymentSolutionCo)

While our focus has not been explicitly on the evolution of the relational ties as Hite (2005) calls for, it does provide case evidence for the hypothesis. If relationally embedded ties can influence resource acquisition for a growing 
organization, can the acquisition also be used influence the embedded ties? For example, in this case could the resource acquisition be used as a signal of commitment to the Malaysian market?

In conclusion, we can see that the networks located in Christchurch in Phase 1 represent a trusted and proven manufacturing solution with design capabilities. In addition the network map shows activities that span international borders from supplier to customer. And finally, the announcement from the Malaysian Government is what would normally be captured as an environmental trigger, can be identified here as a particular actor to actor relationship, based on the impact it has on MalayOilCo. The network structure that represents a manufacturing solution provided by DesignCo, PlasticCo, ManufactureCo and SheetMetalCo, provides one component of the overall network structure. This corresponds to the second research question on network structure "How is the network organised and structured?"

\subsection{Phase 2}

In Phase 2 the network becomes aware of the opportunity in Malaysia and, as a result of significant research and development, wins the international contract. The discussion in Phase 2 Section 6.2 .1 begins by addressing the new international relationships from PaymentSolutionCo to MalayOilCo, and as a result, draws in and integrates the internationalisation literature. Structural autonomy is found to be a core mechanism underlying how the network formed. This is explored in section 6.2.2 and this section highlights how the network structures in Phase 1 contribute to the Phase 2 map (see Figure 8 below). In examining actors in central network positions, section 6.2.3 provides insight to the impact that DesignCo on the network given their centrality and influence (in Figure 8). Understanding how DesignCo were able to leverage their social capital and network position to develop international relationship is explored in section 6.2.4. Lastly, understanding how and why the network of PlasticCo developed is discussed which includes a focus on the search and development of social capital through network learning. 


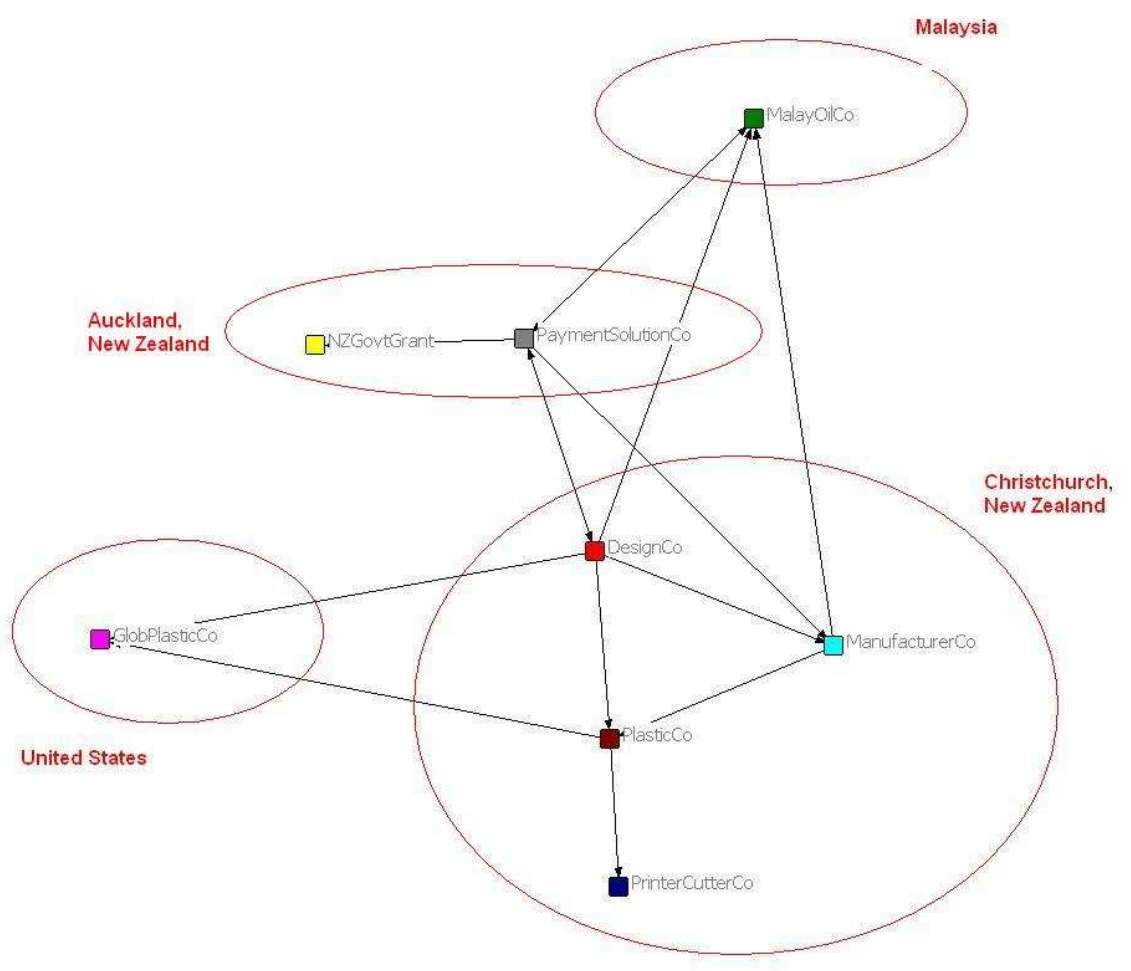

Figure 8: Phase 2 Network Map

\subsubsection{Integrating Network and Internationalisation Research Themes}

The transition from Phase 1 to Phase 2 is dramatic and can be visualised from the network map in Figure 5. The first dramatic change is a merger of the previously separate networks. These were linked by a new relationship between PaymentSolutionCo and MalayOilCo. The first row in Table 14 captures the new relationship between PaymentSolutionCo and MalayOilCo.

The content of this relationship is the information that new credit card technology standards will require MalayOilCo to replace all of its payment terminals in the Malaysian market:

“PaymentSolutionCo didn't know and we didn't know [about the opportunity]... I think the real tipping point on the project is when Malaysia announced that the EMV requirements and then it became clear that the old terminals would have to be replaced. And so that drove the whole product development” (DesignCo) 
As mentioned in the Phase 1, PaymentSolutionCo were positioned in this market by having social capital provided by prior relationships with other oil industry players. Relating this to the Stage model of internationalisation (Johanson and Vahlne, 1977), we can see that PaymentSolutionCo leveraged its prior experiences and familiarity of the market to increase its awareness initially and then consequently, increase their commitment to the market.

"we service all oil companies in Malaysia...with the previous terminal we had...I think its about 17,000 in the field...I think that is throughout the southern hemisphere..."

"no the EMV side we started from ground zero...we took some of the knowledge ...there's obviously stuff you learn when you build things, you take that through...then there's that knowledge around the oil industry but in terms of design that was from ground zero...but you take all your learning from other products and incorporate those...into the design" (PaymentSolutionCo)

Each stage of PaymentSolutionCo's internationalisation appears to model each generation of their retail automation product. As such, the prior stages based on the fourth generation product allowed PaymentSolutionCo to learn about the Malaysian market and reduce their 'psychic' distance in terms of the product requirements, customers and also provide indication of the size of opportunities. All of these factors support the Stage model of internationalisation (Johanson and Vahlne, 1977) providing direct managerial experience and knowledge about market entry mechanisms (Coviello and McAuley, 1999). In contrast to the Stage model, PaymentSolutionCo has not pursued developing in-country operations (Coviello and Munro, 1999). This is most likely to be because the business model is structured on the revenues from initial export sales where contractors manage installation and servicing.

From our discussion in Phase 1, we identified that PaymentSolutionCo's social capital provided unexpected information about a new market opportunity with 
MalayOilCo (Chetty and Agndal, 2006). After becoming aware of the opportunity in Malaysia, PaymentSolutionCo did not internalise the product development process and, instead PaymentSolutionCo actively sought new partners to support the development of a product:

\footnotetext{
"We were looking for some one who was good at industrial design...we were wanting a terminal designed by engineers. We looked at a number of [manufacturing] operations around the country" (PaymentSolutionCo)
}

Therefore, we observe that PaymentSolutionCo used their existing social capital to discover an opportunity but required further social capital to explore and exploit it. This supports Chetty and Agndal's (2006) internationalisation model of social capital.

This also aligns to the Network model of internationalisation (Johanson and Mattson, 1988). Specifically in this case PaymentSolutionCo sought a local network to develop a capability to meet the needs of an international customer resulting in externalisation rather than internalisation of capability. As such, the international success of PaymentSolutionCo depends on its ability to manage its network effectively (Coviello and McAuley, 1999).

After identifying an appropriate set of relationships, PaymentSolutionCo was still exploring the costs of development and the size of the opportunity. Their commitment, or decision to commit, was based on clear investment criteria and a robust research and development process. Therefore, commitment to the new contract supports the FDI model of internationalisation (Coviello and McAuley, 1999) where PaymentSolutionCo manager's made a clear investment decision based on cost benefit analysis:

“Well its $R \& D$ and we've always got $R \& D$ projecting going in what we call pre-production phase, you play a fine line between going into full production...pre-production always gives us a full working model... 
Yes. We have to you know, it part of IP and its part of how you grow a business keep investing in R\&D going." (PaymentSolutionCo)

This case appears to be an example where all three internationalisation theories are present. Highlighting multiple internationalisation theories to a single case follows Coviello and McAuley's (1999) guidance and call for a dynamic and integrated approach to researching internationalisation processes.

\subsubsection{Social Capital and Structural Autonomy}

The relationship between DesignCo and PaymentSolutionCo started with no prior history at all. However, as discussed earlier both actors have high levels of social capital. DesignCo has high social capital for the effective and successful relationships with the companies in Christchurch in delivering a product for WoodCo. PaymentSolutionCo has high social capital based on their participation in international markets and specifically awareness of an opportunity with MalayOilCo.

The high levels of social capital meant both actors had clear motivation to establish relationships with each other:

"It was one of the key drivers for us in terms of...was to have all the parties involved as much as possible...obviously we are not based in Christchurch but all those parties are based in Christchurch... DesignCo have shown that and certain point doing work for WoodCo and some military stuff as well...” (PlasticCo)

This is reinforced by the following comment from DesignCo emphasising their social capital with the companies based in Christchurch: 
“A more holistic approach...making sure relationships are always maintained and people are talking to each other...” (DesignCo)

As highlighted in the network map in Figure 8, both actors, DesignCo and PaymentSolutionCo, sit on either side of a structural hole as described by Burt (2000) and these positions create a competitive advantage for individuals who span this hole. This is consistent with their high social capital in the respective networks that circulates different flows of information (Granovetter, 1973, Burt, 2000, 2004).

The development of the relationship between DesignCo and PaymentSolutionCo, means each actor is in a position to selectively broker information and resources (Burt, 2000). The relationship was formalised with a contract for design in November 2002. Comparing Phase 1 and 2, we can see that PaymentSolutionCo in Auckland has used DesignCo to create a bridge to the network of companies in Christchurch. This was an explicit and deliberate strategy by PaymentSolutionCo as they sought a complete product development solution that had previously worked together. The benefits of this strategy is articulated by a participant as follows:

"We wanted basically everyone who was involved in the manufacturing to be within distance of each other... and then also...prefer to have relationships already in place...we didn't want to go through that learning process... and you know have them in disparate regions throughout the country...because that's extra risk and cost to the project...so that's one of the reasons why we chose the guys down in Christchurch..." (PaymentSolutionCo)

Linking to the discussion on Phase 1, we are now in a position to observe the integration between the closed network in Christchurch and the structural hole to PaymentSolutionCo. This is consistent with the intentions of actors in the closed network who were actively seeking new opportunities via new relationships. 
This phenomenon is called structural autonomy, where structural holes and network closure are brought together in a productive way (Burt, 2000, 2004). The brokerage across the hole introduces new opportunities, in this case from MalayOilCo. This opportunity is combined with the value buried in the 'total manufacturing solution' represented by the Christchurch companies (Burt, 2000). This discussion is also consistent with Hite and Hesterly's (2001) commentary on network evolution:

"The central implication of our model of network evolution is that perspectives emphasising the advantages of cohesive network and those extolling the superiority of networks that bridge structural holes are actually complimentary” (Hite and Hesterly, 2001:275)

However, the context of Hite and Hesterly's (2001) research is vastly different: the entrepreneurial firm and the transition from identity based to calculative networks (Hite and Hesterly, 2001). This finding reinforces the applicability of structural autonomy to the growth of international manufacturing networks. This discussion begins to address the first research question by providing insight into how the network formed and its evolution over time.

\subsubsection{Centrality and Influence}

According to Freeman (1979), positions of high centrality in the network are in positions of influence. Both the qualitative and quantitative data show the central position that DesignCo held and also their influence on the network. The qualitative data highlight the role that DesignCo played as project managers of the product development process.

"Yes, that was their role. They were really employed by and still are employed by PaymentSolutionCo in as much as Project Managers as well as designers" (PlasticCo) 
“[We] just keep asking questions just keep people talking...there's a lot of iteration in terms of the design like we had pretty much weekly design meetings with [PaymentSolutionCo]... there's steady flow of information from people” (DesignCo)

As facilitators, DesignCo controlled what actors were introduced to the network such as GlobalPlasticCo:

"It was really driven by DesignCo...DesignCo were the driver because they were tasked by PaymentSolutionCo to do the design and they brought ourselves and GlobalPlastic Co in ...” (PlasticCo)

This is further reinforced by DesignCo's broker score of 7 in Phase 2 (Table 17) by far the highest in the network. Although DesignCo's centrality score is the third highest, we have previously discussed their role as brokers on the edge of the manufacturing companies in Christchurch, thus highlighting their position for this sub network.

So what effect did this position of high centrality have on the network?

In this particular case, although not a plastics expert, DesignCo made crucial supplier decisions on behalf of other actors, exercising their influence in the network. Upon appointment to design the new product, DesignCo initiated a meeting with plastic experts GlobalPlasticCo. DesignCo made the decision to bring GlobalPlasticCo into the opportunity and as a result, facilitated the relationship between GlobalPlasticCo and PlasticCo. GlobalPlasticCo provided raw material to PlasticCo who then applied innovative moulding and printing techniques.

Additionally, DesignCo influenced the network by controlling when new actors entered the network and contributed to specific collaborative activities. For example, when developing a prototype and identifying the capabilities of the plastic materials, DesignCo called a meeting with PlasticCo, PaymentSolutionCo and GlobalPlasticCo. With information from this meeting, DesignCo was able to 
build a prototype with limited further interaction with this group. As such the other actors were isolated from the design process. In taking such a lead role, DesignCo limited the input from other actors:

"DesignCo sort of disappeared of our radar and things for quite a long time and then came back and finished the design, so there was very little we could influence ... but because they...already designed ... liquid crystal displays ... we were very restricted at what we could change." (PlasticCo)

This example supports Freeman's (1979) betweenness centrality theory and shows the influence that DesignCo had on other actors and the process itself. Freeman finds that persons in this position can influence a group based on their control of information and goes further to talk about their potential as coordinator of group processes (Freeman, 221:1979).

While the end results of the overall project were very positive, it did have some negative impact on the actors involved. For example, PlasticCo felt they could have had more constructive input in the development if they had been involved at an earlier stage:

[So from that stage you were working quite closely with them?]

"No, well we should have been but because so much of the design was around the electronics and the software and the electronic hardware design and things... which is really quite a pity because that's the one thing I would have loved to have changed about the project because it would of made the task a lot easier." (PlasticCo)

The observation here is that DesignCo took a lead in the decision-making for the overall product development, not just their domain. More explicitly, they exercised their influence on the product development processes (Freeman, 1979). This example provides observation of the economic action that resulted from an actor's position within the network. 
Exercising their influence amongst other network members requires high levels of trust for them not to react destructively in terms of the network goals. How was this managed? How is the influence on the network governed? There are two existing theoretical propositions that may offer an explanation. The first comes from Holm, Eriksson and Johansson's' (1996) model on cooperation. In essence it explains that an actor will remain committed to a project if there is 'relationship understanding' (Holm, Eriksson and Johanson, 1996). Relationship understanding for PlasticCo, in this instance, may materialise as acknowledging DesignCo's role as project managers. The second explanation, as to why significant influence has not upset network relations here, was that the relationships were increasingly becoming embedded and as a result, trust was also increasing between actors (Uzzi, 1996, Hite 2005). The embedded argument is also supported by Jones, Hesterly and Borgatti (1997) who find that structural embeddedness diffuses social norms and values and also enables information diffusion, constraining actor's activities. However, based on this experience would PlasticCo do things differently in future relationships? While not within the scope of this thesis it is an interesting point to consider.

\subsubsection{Social Capital, Structural Holes and New International Relationships}

As shown in Figure 8, DesignCo provides access for PaymentSolutionCo to reach the manufacturing capability of firms in Christchurch and as such manage or facilitate those relationships on behalf of PaymentSolutionCo. To fulfil their roles as designers, DesignCo requires rich, contextual and technical knowledge from the customer, MalayOilCo. As such, DesignCo sit on the edge of two structural holes (Burt, 2000). While we have already examined the role and benefits of structural holes with these actors, it is of interest here that the social capital or role that DesignCo maintains has enabled them to span a structural hole into a foreign market.

While DesignCo may state that this interaction is crucial to successful design, it shows a high level of trust between PaymentSolutionCo and DesignCo and also the social capital that DesignCo maintains. This is further evidence in their roles 
as brokers of information, and in this case, specific product requirements from the product environment and the customer.

"Yes, during that year, there were a number of trips where... a number of visits to [MalayOilCo] where [PaymentSolutionCo] actually took specifications and drawings and costs models and all that sort of thing and had discussions and then they went back with a bit more information and then they went back with some preliminary rendering of what the product might look like and how it was assembled...I provided component cost information and manufacturing cost information and looked at reliability and all those things and obviously all the aesthetic and styling..."

(DesignCo)

This supports Chetty and Agndal's (2006) 'efficacy role of social capital.' This idea refers to how the frequent interaction of DesignCo, strong ties, reciprocity, mutual commitment creates a foundation to increase social capital (Chetty and Agndal, 2006). The authors argue that this social capital can be used to trigger a mode change in the internationalisation. This fits with our evidence of DesignCo developing a new international relation with MalayOilCo. Even though the relationship is not formalised by contractual mechanisms it is of significance given their scope of customer interaction and influence (Chetty and Agndal, 2006).

\subsubsection{PlasticCo and Network Learning}

A critical success factor of this project was the plastic technology developed in Phase 2. The required product had to be scratch free, solvent resistant, tamperproof and withstand the harsh outdoor environment in Malaysia.

From the initial meeting set up by DesignCo, GlobalPlasticCo offered a raw material product and identified processes that PlasticCo could undertake to achieve their intended outcome. However, there were several unforeseen hurdles in developing this technology: 
“It proved to be quite a task, because we were pioneering it and we hadn't done it before."

"We ended up pioneering it and journeying through endless trial runs and a huge amount of prototyping and trial and error and learning and involved a massive amount of research and things like and thermoforming and printing and distortion printing and you know there was so many physical barriers to overcome that there was tremendous amount of development work involved in it. And long hours... and long hours...I can remember a period, probably about 4 months were I wasn't home on the weekends." (PlasticCo)

Additionally, the complexity of the product required new capability that PlasticCo had to source externally. PlasticCo had to seek out social capital that could provide specific product capabilities (Burt, 1992, 2000).

The network maps shows the result: PlasticCo developed new relationships with PrinterCutterCo (3 individual sub-contractors). Their embedded relationship provided the means to go beyond contractual obligations (Uzzi, 1997) and we have evidence here that the relationship is not simply transactional in nature and, instead required careful partner selection followed by intensive capability development:

"We knew of them, we weren't doing work with them, we had to seek them out. And we had to go and assess capability and pick the right companies. We've had to be the glue I guess or the coordinator for the processes. We had to learn as much about inks and printing as our printer, we've had to learn as much about thermoforming as our thermoformer and as much about cutting as our subcontractor there because everything is new and there wasn't anyone around to go find this sort of thing out from. So we had to ... and that was our necks on the line... and our business at risk..." (PlasticCo) 
Uzzi (1997) goes further to state that these joint learning processes replace the simplistic exit or stay market response that would have stopped this particular product development because it was innovative and required intensive learning. The result was a similar arrangement to the first network established between ManufactureCo, PlasticCo and SheetMetalCo, where each actor shared opportunities and leads within a flexible structure. This fits with Uzzi's (1997) description of how embedded ties support joint problem solving arrangements.

"These arrangements typically consist of routines of negotiation and mutual adjustment that flexibly resolve problems.” (Uzzi, 1997:47)

As such, PlasticCo facilitated the learning of their own network that developed their respective capabilities. This was required to meet the customers' needs and but also to overcome their own commitments and development hurdles.

\subsection{Phase 3}

Phase 3 is about the production, delivery and success of the product developed in New Zealand. Section 6.3.1 begins with a discussion on how the overall network size reduces from Phase 2 to 3 . The information flows, centrality and power of two central actors, PaymentSolutionCo and ManufactureCo, is then explored in Section 6.3.2. This section examines how their role relates to the manufacturing industry and also discusses the impact on information flows and influence. 


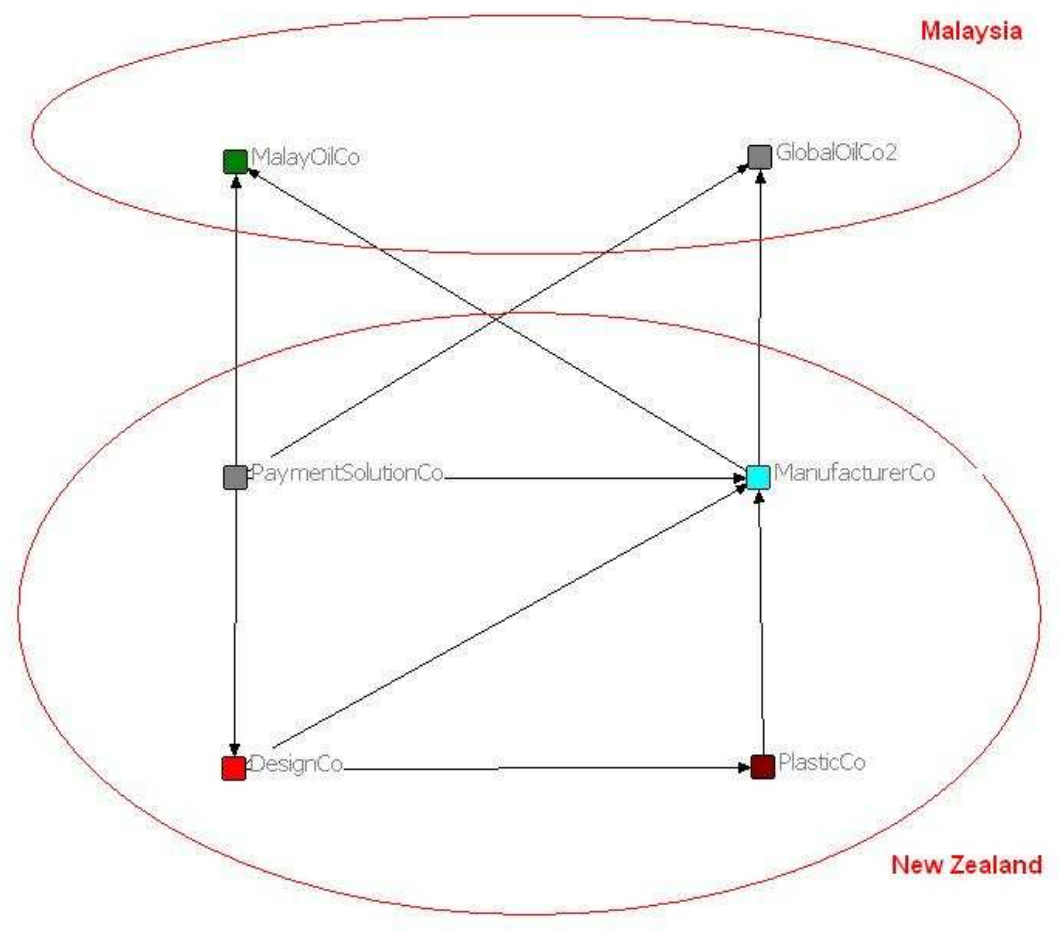

Figure 9: Phase 3 Network Map

\subsubsection{Reduction in Network Size}

The most dramatic network change in Phase 3 is the reduction in the number of actors or the size of the network. This can be seen in the network map in Figure 6 and also Table 17 that shows network size.

The reduction in the network size appears to be because the production process has been simplified. As such actors, such as GlobalPlasticCo and PrinterCutterCo, are no longer seen in the network map in Figure 6. They may be involved but have not been mentioned as active relationships in this Phase.

On completion of the development Phase 3 we now see that these sub-contractors are not involved and, instead the network map now shows the core production actors; PlasticCo, ManufactureCo and DesignCo. Additionally, the senior management of PaymentSolutionCo reduced their frequency of travel to Christchurch and replaced this oversight function with a full-time relationship manager from ManufactureCo. 
"Yes, he works for [ManufactureCo] and he is the programme manager for PaymentSolutionCo" (ManufactureCo)

This is evidenced in a reduction of network complexity and reflects a reduction in risk as the network transitioned from development to production phases.

\subsubsection{Information Flows, Centrality and Power}

The network shows that both ManufactureCo and PaymentSolutionCo share relationships with both customers GlobalOilCo1 and MalayOilCo.

PaymentSolutionCo's primary role is a single point of contact as a supplier, whereas, ManufactureCo's role is the delivery mechanism for the product.

As previously discussed, ManufactureCo's role as a contract manufacturer places them in a central role within the network and this evident in the Phase 3 maps. ManufactureCo has the highest centrality scores shown in Table 20. This means that ManufactureCo is positioned in the network to be in between most information flows throughout the network (Freeman, 1979).

"The centre of activity is centred around ManufactureCo in terms of manufacturing because the product development, there's lots of improvements [that] come from ManufactureCo in terms of the observations, they'll be fed in from what the customer wants and feeds in from the design house will want to change..." (ManufactureCo)

This reflects a shift in power from PaymentSolutionCo to ManufactureCo. This transition was anticipated based on the business model and servicing of the payment terminals.

\footnotetext{
"It was typical contract manufacturing... that means the product they charge with manufacturing...they ship it...they also do any repairs that come back through the system also...” (PaymentSolutionCo)
} 
If the relationship between PaymentSolutionCo and MalayOilCo is no longer operational, how does PaymentSolutionCo ensure an ongoing relationship to this actor?

\subsection{Performance Consequences of the Network}

The following section discusses the outcome of the network in terms of their success. GlobalOilCo1, the new actor in the network is representative of the success of the product in the market and PaymentSolutionCo's position in the market. Following the successful win by MalayOilCo, PaymentSolutionCo were then able to customise the product for GlobalOilCo1 in Malaysia. The original value of the contract with MalayOilCo was \$21 NZD million dollars in revenue for PaymentSolutionCo. It also provided new social capital to support market expansion and increase their competitiveness.

"The yellow unit is for GlobalOilCol and this one is MalayOilCo is silver...Different colour, different style of card reader but essentially the same product. And that initially was an order from 3000 units and appears, I don't know if there is any confirmation, but it appears to have possibly escalate to about 5,000 so... and then there potential on top of that for PaymentSolutionCo's technology to be sold into Australia, to Europe and the States so right now looking forward there is quite good prospects. Very good prospects and numbers for us aren't huge in terms of turnover but it's still attractive... really its gone incredibly well, if you knew some of the obstacles, its gone incredibly well." (PlasticCo)

Furthermore, as a result of their collaboration over these three phases, the network greatly increased their social capital by spanning structural holes in Phase 2, increased by trust, frequent interaction, reciprocal services and positive returns (Granovetter, 1979, Burt, 1992, 2000). As such each company could then potentially leverage this social capital and gain future contracts independent of this network. This is a positive spill-over effect that effects all actors in the network. 
Commenting on their increasing impact on the global market, PaymentSolutionCo states:

\footnotetext{
"We are starting to gain in significance...we are certainly got the intention to become a major contender in this space...we are a major player in this part of the world... a very successful product for us." (PaymentSolutionCo)
}

Since the initial product launch, PaymentSolutionCo have sold their product to an Indian oil company and also Shell in Belgium in April 2006, representing a strategic move into the European market.

\subsection{Links to the Research Questions}

Based on the discussion across the 3 phases (section 6.1 to 6.4 ), this section reviews and addresses the research questions set out in Chapter 1.

\subsubsection{How does the network form?}

Our discussion of Phase 2 highlights the structural autonomy (Burt, 2000) that involved the complimentary roles of network closure from the manufacturing network in Christchurch and structural holes from relationships between DesignCo, PaymentSolutionCo and MalayOilCo.

Following Granovetter (1985) and Burt (2000), actors on each side of the structural hole had developed high social capital which provided an impetus for developing the bridge. Therefore, the network formed by the bridging of two distinct networks, the manufacturing network in Christchurch and PaymentSolutionCo's relationships to Malaysia. Although the actors met accidentally, both were clearly in positions of high social capital as discussed previously (Burt, 2000). The development of their social capital is therefore a critical pre-cursor to the network forming. A common element from both the 
qualitative and quantitative data, is the inclination for actors to source social capital from other actors by either searching out new partners, or developing social capital with existing actors or both. From the interview evidence, it appears that the management of these companies enjoyed their respective specialisations or niches.

"We were all keen to be at the leading edge in our particular fields. We are all keen to be innovators, risk takers... you know high risk high return opportunists and so that could work...so we all had those common goals. Not that we all get on really well together as you have to go through what we've gone through. But that's no the glue, it's the common approach to business that we have." (PlasticCo)

These specialisations seem to form strong identities in the network, displayed through social capital such as reputation, trust and key relationships.

“And DesignCo is up there, as there isn't any design consultancy that can do as broader range of things as they do, and are as innovative and creative as they are... And hopefully they would say the same thing about us in plastics.”

"Its sort of exclusive to a client it made us the only party that can do this and certainly in the southern hemisphere and probably very few in the companies in the world that would try and tackles this. So it gives us an international product." (PlasticCo)

"ABC believes that the key to a successful economy in New Zealand is for small companies to develop products they're passionate about." (Founder, DesignCo)

This sense of pride and world-class ability is shared amongst the actors. Relating this back to the network approach, it appears that the actors actively and purposely sought partners with similar characteristics and values. As discussed in the 
literature, this is a fundamental characteristic of networks (Granovetter, 1982; Burt, 1992).

\subsubsection{How is the network organised and structured?}

There are a few distinct network characteristics that define the structure of the network studied here. First, there is the highly cohesive group of companies based in Christchurch (see clique 1 in Table 16). Their cohesion, or strong relationships (Granovetter, 1973), are based on previous projects and collaborations which resulted in a highly embedded relationships as discussed in Phase 1 (Uzzi, 1997).

The second important characteristic, in the overall network structure, is the international relationship that PaymentSolutionCo maintained to its previous customers in Malaysia. This was a key source of PaymentSolutionCo's high social capital (Burt, 1992; Coleman, 1988; Chetty and Agndal, 2006). Their social capital provided access to the market opportunities in Malaysia, a critical success factor in this project. Once again this occurred in Phase 1, before the opportunity was identified.

The last structural characteristic of critical significance is the structural hole between the network structures discussed above (Burt, 1992). On each side of the hole are two actors with high social capital, DesignCo and PaymentSolutionCo (Burt, 2000, 2005). This hole was subsequently bridged triggering the product development process.

There is evidence by DesignCo and PaymentSolutionCo intentionally managing their network and, as a result, their social capital. As previously discussed, DesignCo's reason to exist as a company was about facilitating innovation amongst a range of stakeholders. This shows their attitude and approach to using networks to reach an outcome. As the founder of DesignCo has stated: 
"My idea is simple, I want to facilitate the development and innovation of new products and machinery. This is how the name [DesignCo] came about - representing Innovation and Facilitation.” (Founder, DesignCo)

The first evidence of PaymentSolutionCo intentionally managing their network is their acquisition of FuelPumpCo, a result of their embedded ties to oil companies in Malaysia (Chetty and Agndal, 2006). Their action is a result of their network structure. Second, we have discussed earlier how PaymentSolutionCo took a network approach to support their internationalisation (see section 6.2.1).

Together, these two actors positioned themselves within their respective networks, both with high social capital, and a propensity to broker across networks. This provides an explanation for their positions as brokers across the structural holes.

\subsubsection{How does the network change and evolve over time?}

Looking at the three network maps across the different phases, several observations can be made on the how the network evolves (refer to Figures 4 to 6). Between Phase 1 and 2 we observe that two networks merge into one group. Additionally, as the network size increases so too does the average distance in Table 16. This aligns to opportunity identification and research processes where actors actively searched out new social capital. Qualitative data describes the frequency of interactions increasing, reinforcing the embeddedness of the relationships and increasing their social capital and trust.

Transitioning from Phase 2 to 3 saw a sharp reduction in the number of actors. This highlighted how core actors delivered products to MalayOilCo but also the identification of a new customer as a result of their success. Therefore, a key change in the network structure in Phase 3 is the two international relationships. DesignCo, ManufactureCo, PlasticCo and PaymentCo dominate all three phases and remain in significant, but distinct, positions through the networks' evolution. 
In terms of power, the centrality scores in Tables 18 and 20 show that in Phase 1 and 3 ManufactureCo has the highest centrality scores. These phases represent networks in a 'production' mode, where the manufacturing role has been relatively central. Phase 2 is distinguished because the network is in "research and design' mode where PaymentSolutionCo, PlasticCo and DesignCo have high centrality scores within a wider network. This pattern is also identified in the brokerage scores in Table 17.

\subsubsection{How distinctive are the firm roles within these relationships?}

The overall network largely follows the functions of a manufacturing network except for the role of DesignCo. While PlasticCo developed its own sub-network that built social capital, embedded ties and new relationships, this can also be expected in a tiered supplier network such as those found in automotive networks.

The role of DesignCo was distinct as they facilitated network interactions and brokered new relationships. This is evident in the qualitative data where they specifically introduce GlobalPlasticsCo to PlasticCo and choose to limit actor involvement in the design process. This highlighted their influence on the network but also showed that other network actors shared an understanding of DesignCo's role. This explains the lack of negative reactions or diminishing of trust. The role of DesignCo described here, reinforced their brokerage scores and involvement in all cliques.

The other role of significance is that of PaymentSolutionCo, who managed the relationship with MalayOilCo. This role is of importance because it spanned international boundaries and as such represented high social capital. Furthermore, PaymentSolutionCo highlighted aspects of the three internationalisation theories discussed in the literature review. This displayed learning through experience, using a structured decision-making process for foreign investment and also using a local network to meet international customers needs. 


\subsubsection{What are the performance consequences for companies in the network?}

The performance impact on the companies within the network were significant. However so were the costs involved, in terms of both monetary value, time and relationships. Overall, the collaboration resulted in a \$21 NZD million contract with MalayOilCo and several new contracts shortly after. Coupled with this success were dozens of publicity articles outlining the success of the companies and their collaboration. These have not been included due to confidentiality agreements.

The network perspective emphasises an increase in social capital through their trust, reciprocity of services, emotional intensity and intimacy. Actors who provided data directly have indicated strong and cohesive relationships.

In conclusion, the network developed on the basis of prior cohesive networks in Christchurch. Unlocking the social capital of this group required a bridge to span the structural hole between DesignCo and PaymentSolutionCo. As the other actor on the edge of the hole, PaymentSolutionCo also has high social capital based on their international relationships. Two key roles emerged based on a high level of a brokerage, DesignCo for brokering to the local network and ManufactureCo for brokering international relationships. The performance consequences for the companies involved have been both financial and strategic, due their increased social capital. While this section aligned the discussion findings back to the original research questions, the following Chapter will provide the overall conclusion of the research and highlight the contribution, implications and limitations of this thesis. 


\section{Conclusion}

International business relationships are especially critical to the economic prosperity of small, isolated countries such as New Zealand. However, internationalisation typically requires significant resources and investment and, in cases such as New Zealand, the majority of firms are small to medium enterprises (SME's) that tend to have limited resources (Oviatt and McDougall, 1999; Chetty and Holm, 2000).

This thesis set out to explore how collaboration amongst a network of companies can lead to successful internationalisation. Positioned between the network and internationalisation literature, this research focused on a successful case where a New Zealand company supported by a network local of companies won a $\$ 21$ NZD million export contract to supply retail payment terminals to a Malaysian oil company. The research focused on the network formation, structure and evolution over time. In addition, the roles and performance of the network were examined.

The research method focused on a successful case and involved in-depth interviews with senior management of four companies. This was coupled with social network analysis based on data extracted from the interview transcripts. Capturing chronological data was made possible by using a historical approach.

There are several points of interest that surfaced from the results. First, relationally embedded ties appear to have reinforcing network effects. For example, the discussion chapter explored how PaymentSolutionCo's embedded ties with Malaysian companies influenced their resource acquisitions. This acquisition then became a building block for network activities that led to further internationalisation success (Section 6.1.6). Another example is the strong relationships between the group of companies in Christchurch. These actors shared several similarities, such as wanting to be world leaders in their respective industries. As discussed in section 6.5.1, this level of embeddedness created a 
culture of shared norms, motivation and peer pressure to pursue network activities that were high-risk but aligned to internationalisation success.

The second point of interest relates to the research contribution of this thesis. In examining how the network evolved over time, the data captured shows how a closed network formed bridges across structural holes, leading to 'structural autonomy' (Burt, 2005). There are several complex network dynamics at play for this to occur; increasing social capital of a closed network through successful collaboration, efforts to avoid over-embeddedness and hence, search out new opportunities, maintaining information flows and commitment from international ties and the role of brokers in actively building and influence networks. While these have been discussed in detail in the previous chapter, of interest here is the active exploration and development of various sources of social capital. This appears to be a consistent factor amongst the actors which directly contributes to structural autonomy.

The third contribution of this research is the identification and integration of internationalisation theories within the case. In Chapter 6, the discussion on Phase 2 identifies elements of the Stages, FDI and Network models of internationalisation. Examining the network over time uncovered the different times the models were evidenced and used by the actors. For example, upon awareness of the opportunity PaymentSolutionCo used the Network model to develop their social capital. However, PaymentSolutionCo then adopted the FDI approach by following a structured and disciplined decision-making process for financial investment. This appears to support Coviello and McAuley's (1999) description of internationalisation as a dynamic, time-based process.

The combination of data from network analysis and the case study illuminate the network in different ways providing the third area of contribution. The network statistics identified particular actors who were in highly central positions, or were in positions of high brokerage, such as ManufactureCo in Phases 1 and 3. However, when overlayed with the interview data, the actor's power, or influence, on the network appeared to be diminish. A potential explanation is that the network structure aligned to a typical manufacturing operation, i.e. where the 
contract manufacturer plays a central role, taking input from all other actors. As such, it painted a generic picture that did not capture the more subtle influences from actors and also embeddedness affects. While the combination of quantitative and qualitative network data is not new, the case does capture the advantages of their combination especially in relation to the networks' evolution.

\subsection{Implications and Future Research}

The following section describes the research implications for managers, policy makers and researchers. It includes areas for future research.

\subsubsection{Implications for Researchers}

Given the breadth of issues discussed within this thesis there are several areas that may spark future research interests. Some of the areas below are not new research areas, however they would contribute to the literature in combination to the approach presented in this thesis. First, the active searching and developing of social capital points to a network 'orientation' for actors that would be interesting to further understand. As mentioned in the case, some actors have had experience with government-led network initiatives and others purposely sought network solutions. Future research may seek to understand the concept of network orientation and the potential impact of network orientation.

The second area for investigation is the analysis of the network at the individual level, which would complement the level of analysis presented here. While this may pose methodological issues, understanding the individual interaction, time and exchanges in relation to the organisational level data will provide much richer understanding as to how elements such as embeddedness and trust evolve over time.

The case study in this thesis shows the development of new international contracts to existing markets. An important and complimentary research area would be to 
examine a completely new international relationship forming without any preexisting links.

Finally, the sources of social capital throughout the case stem from varying areas and in addition, appear to be valued only if its recognised by actors in the network. This research would be complemented by the ability to track the levels, sources and awareness of social capital as the network develops.

\subsubsection{Implications for Managers}

One of the implications, which is highlighted by this thesis, stems from the work of Holm, Eriksson and Johanson, (1996). The idea of using 'relationship understanding' to enhance cooperation has been evidenced in the case and is more complex than it appears. The idea of acknowledging in advance what is expected in a relationship appears to be similar to an implicit 'memorandum of understanding' that sets out guiding principles. The understanding also relates to the aspiration of the organisations. The implication for managers is to develop a relationship understanding at the organisational level. For example, clearly communicating the principles of working together in relation to their goal may support developing that understanding. Or, as was evidenced here, sharing growth aspirations in each actors' respective fields can also develop relationship understanding. The benefit of building this understanding is that when the network undergoes sudden changes, or an actor starts behaving erratically, the network is in a better position to continue functioning.

Another implication for managers is to recognise that current relationships will influence new relationships or resource acquisitions. This was displayed by both DesignCo and PaymentSolutionCo. As such, it may require a manager undertakes a systematic review of their network. By doing so they may have a better understanding of how to broker new relationships and how other actors view their social capital. For example, if a current network maintains a complete and proven manufacturing capability, they may seek to identify opportunities to exploit and grow that capability. 
Managers should also strategically commit to maintaining relationships to desired markets. This would provide social capital as shown by PaymentSolutionCo's participation in the Malaysian oil industry well after their transactions were made. Although maintaining these relationships come at some cost, it provides the ability to become aware of opportunities via existing or completely new ties.

\subsubsection{Implications for Policy Makers}

Based on this case, policy makers may attempt to replicate a similar network structure in the aim of building new international relationships. For example, they can actively seek out cohesive networks with high social capital based on successful collaboration and identify actors on the edge of structural holes. The benefit arises when these holes are bridged. While policy makers may not explicitly broker relationships, they can continue to scan for environmental triggers that may provide the appropriate prompt for new relationships.

\subsection{Limitations}

There are several limitations to acknowledge. By using a single positive case the research is not able make comparisons to contrast or compliment these findings. Second, by capturing a wide breadth of network data, the research has not been able to explore in depth any one particular area.

In relation to data collection, not having access to the end customer provides some limitation to understanding their perspective; the risks involved and their awareness of a network in New Zealand.

The commercial sensitivity also limited the source and range of data, specifically the contractual arrangements between actors. This information would have provided insight into the compensation for risks undertaken and also shed light on the incentives and commitments required. 
Finally, while this research has captured 3 time-bound phases of the network's development it does not provide detailed accounts of specific activities over time. For example, in Phase 1 a number of companies worked together to develop a solution for WoodCo that involved significant amount of activity over 18 months. Capturing this information proved difficult based on participants recall even when prompted based on factual data. However, if available it would provide deeper insight into the impact of their interaction, e.g. how relationship strength developed for specific activities.

In conclusion, this thesis has successfully provided analysis on a network of organisations in New Zealand who won a multi-million dollar export contract. As such, this thesis has made a series of contributions to the area of network dynamics that supports successful internationalisation. 


\section{References}

Acs, Z. and Vaga, A., 2002, Geography, endogenous growth, and innovation, International Regional Science Review, Vol. 25, No. 1, pp. 132-148.

Agndal, H. and Chetty, S., 2007, Social Capital and Its Influence on Changes in Internationalization Mode Among Small and Medium-Sized Enterprises, Journal of International Marketing, Vol. 15, Iss. 1, pp. 1.

Ahuja G., 2000, Collaboration networks, structural holes and innovation: a longitudinal study, Administrative Science Quarterly, Vol. 45, pp. 425-455

Albu, M. and Romijn, H., 2002, Innovation, networking, and proximity: Lessons from small high-technology firms in the United Kingdom, Regional Studies, Vol. 36, Iss. 1, pp. 81-86.

Aldrich, H.E., Reese, P.R., and Dubini, P., 1990, The Go-Between: Broker's Roles in Entrepreneurial Networks, Frontiers of Entrepreneurial Research, pp. 554.

Beamish, P. W., 1990, The Internationalisation process for smaller Ontario firms: a research agenda, in Research in global strategic managementinternational business research for the twenty-first century: Canada's new research agenda, (ed. A. M. Rugman), pp. 77-92, JAI Press Inc, Greenwich.

Blankenburg-Holm, D., Eriksson, K., \& Johansson, J., 1996, Business Networks and Cooperation in International Business Relationships, Journal of International Business Studies, Vol. 27, Iss. 5.

Blau, P., 1981, Introduction: Diverse views of social structure and their common denominator, in Blau and Merton (eds.) Continuities in structural inquiry, Sage, London.

Bohman, H., Boter, H. and Tesar, G., 2003, Beyond Networking: A Case Study of Rigorous Cooperation Among SMEs, Industrial Marketing \& Purchasing Group Conference, Lugano, September 4-7.

Borgatti, S.P., Everett, M.G. and Freeman, L.C., 2002, UCINET for Windows: Software for Social Network Analysis, Harvard, MA: Analytic Technologies.

Borgatti, S., and Foster, P., 2003, The Network Paradigm in Organizational Research, A Review and Typology, Journal of Management, Vol. 29, No. 6, pp. 991-1013.

Bourdieu, P., 1980, Le capital social, Actes de la Recherche en Sciences Sociales, Vol. 31, 2-3 
Brass, D., and Burkhardt, M., 1992, Centrality and Power in Organizations, in Nohria, N., and Eccles, R., 1992, Networks and Organizations: Structure, Form and action, Harvard Business School.

Bucklin, L. P., and Sengupta, S., 1993, Organizing successful co-marketing alliances, Journal of Marketing, Vol. 57, pp. 32-46

Burt, R., 1992, Structural Holes, Cambridge, MA: Harvard University Press, 1997, The Contingent Value of Social Capital," Administrative Science, Quarterly, Vol. 42, pp. 339-365.

Burt, R., 1992, The Social Structure of Competition, in Nohria, N., and Eccles, R., 1992, Networks and Organizations: Structure, Form and action, Harvard Business School.

Burt, R., 1997, The Contingent Value of Social Capital, Administrative Science Quarterly, Vol. 42, pp. 339-365.

Burt, R., 2000, Structural Holes versus Network Closure as Social Capital, in Social Capital: Theory and Research, edited by Lin, N., Cook, K. and Burt, R., 2001.

Burt, R., 2005, Brokerage and Closure: An Introduction to Social Capital, Oxford University Press.

Camagni, R., 1991, Local "Milieu”, Uncertainty and Innovation Networks: Towards a New Dynamic Theory of Economic Space, in Camagni, R., editor, Innovation Networks: Spatial Perspectives, Belhaven Stress. London, UK and New York, USA.

Campbell-Hunt, C. and Chetty, S., 2004, A Strategic Approach to Internationalization: A Traditional Versus a "Born-Global" Approach, Journal of International Marketing, Vol. 12, Iss. 1, pp. 57-81.

Campbell-Hunt, C., Chetty, S. and Mattear, S., 2005, Clustering at the edge: Growing businesses of global reach from thin soil, Otago Competitiveness Research Network Working Papers.

Cavana, R. Y., Delahaye, B. L. and Sekaran, U., 2001, Applied business research: qualitative and quantitative methods, John Wiley \& Sons: Brisbane, Australia.

Chetty, S. and Sadler, A., 2000, The impact of networks on New Zealand firms, Journal of Euro - Marketing, Vol. 9, Iss. 2, pp. 37.

Chetty, S. and Holm, D., 2000, Internationalisation of small to medium-sized manufacturing firms: a network approach, International Business Review, Vol. 9, Iss. 1, pp 77-93. 
Chetty, S. and Wilson, H.I.M., 2003, Collaborating with competitors to acquire Resources, International Business Review, Vol. 12, pp. 61-81.

Coleman, J. S., 1990, Foundations of social theory, Cambridge, Harvard University Press.

Coleman, J., 1988, Social Capital in the Creation of Human Capital, American Journal of Sociology, Vol. 94, pp. S95-S-120.

Coviello, N. E. and Munro, H. J., 1997, Network Relationships and the Internationalisation process of small software firms, International Business Review, Vol. 6, pp. 361-386.

Coviello, N.E. and McAuley, A., 1999, Internationalisation and the smaller firm: A Contemporary Empirical Research, Management International Review, Third Quarter, Wiesbaden.

Coviello, N.E. and Munro, H.J., 1995, Growing the entrepreneurial firm: networking for international market development, European Journal of Marketing, Vol. 29, Iss. 7, pp. 49-61.

Coviello, N.E., 2005, Integrating qualitative and quantitative techniques in network analysis, Qualitative Market Research: An International Journal, Vol. 8, Iss. 1, pp.39-60.

Coviello, N.E., 2006, The network dynamics of international new ventures, Journal of International Business Studies, Vol. 37, Iss. 5, pp. 713.

Crocombe, G. T., Enright, M. J. and Porter, M. E., 1991, Upgrading New Zealand's Competitive Advantage, Oxford University Press: Auckland.

Easterby-Smith, M. and Lyles, M., 2003, Handbook of Organizational Learning, Sage, New York.

Eisenhardt, K.M., 1989, Building theories from case study research, Academy of Management Review, Vol. 14, Iss. 4, pp.532-550.

Ellis, P., 2000, Social ties and Foreign market entry, Journal of International Business Studies, Vol. 31, Iss. 3, pp.443-469.

Emerson, R. M., 1981, Social Exchange Theory, in Social Psychology: Sociologital Perspectives, Morris Rosenberg and Ralph Tumer, eds. New York: Basic Books, pp. 30-65.

Etemad, H., 2004, Internationalization of small and medium-sized enterprises: A grounded theoretical framework and on overview, Canadian Journal of Administrative Sciences, Vol. 21, Iss. 1, pp. 1-21. 
Evangelista, R., Iammarino, S., Mastrostefano, V., Silvani, A., 2002, Looking for regional systems of innovation: evidence from the Italian innovation survey, Regional Studies, Vol. 36, Iss. 2, pp. 173-186.

Fletcher, R., 2008, The internationalisation from a network perspective: A longitudinal study, Industrial Marketing Management, Vol. 37, pp. 953-964.

Fombrun, C.J., 1982, Strategies for Network Research in Organizations, Academy of Management Review, Vol. 7, Iss. 2, pp. 280-291.

Freeman, L., 1979, Centrality in Social Networks Conceptual Clarification, Social Networks, 215-239.

Goodman, R. S. and Kruger, E. J., 1988,, Data Dredging or Legitimate Research Method? Historiography and Its Potential for Management Research, Academy of Management Review, Vol. 13, pp.315-325.

Grabher, G., 1993, The Weakness of Strong Ties. The Lock-in of Regional Development in the Ruhr Area, in The Embedded Firm, ed. G. Grabher. London: Routledge, 1993, pp. 255-277.

Granovetter, M., 1973, The Strength of Weak Ties, American Journal of Sociology, Vol. 78, pp. 1360-1380.

Granovetter, M., 1979, The Theory-Gap in Social Network Analysis, pp. 501-518 in Perspectives on Social Network Research, ed. by P.W. Holland and S. Leinhardt. New York: Academic Press.

Granovetter, M., 1982, The Strength of Weak Ties: A Network Theory Revisited, pp. 105-130 in Social Structure and Network Analysis, ed. by P. V. Marsden and N. Lin, Sage: Beverly Hills.

Granovetter, M., 1985, Economic Action and Social Structure: the Problem of Embeddedness, American Journal of Sociology, Vol. 91, pp. 481-510.

Granovetter, M., 1992, Problems of Explanation in Economic Sociology, in Nohria, N., and Eccles, R., 1992, Networks and Organizations: Structure, Form and action, Harvard Business School.

Gulati, R., 1998, Alliances and Networks, Strategic Management Journal, Vol. 19, Iss. 4, pp. 293-317.

Gulati, R., and Gargiulo, M., 1999, Where Do Interorganizational Networks Come from?, American Journal of Sociology, Vol. 104, Iss. 5, pp. 1439-93.

Gulati, R., Nohria, N. and Zaheer, A., 2000, Strategic networks, Strategic Management Journal, Vol. 21, pp. 203-215.

Gulati, R., 1995, Social structure and alliance formation patterns: A longitudinal analysis, Administrative Science Quarterly, Vol. 40, Iss. 4, pp. 619-652. 
Gummesson, E., 1988, Qualitative Methods in management research, Lund, Norway: Studentlitteratur, Chartwell-Bratt.

Håkansson, H. and Snehota, I., 1995, Developing Relationships in Business Networks, Thompson, London.

Håkansson, H., Johanson, J., 1993, Network as a Governance Structure, in Grabher, G., The Embedded Firm. The Socio-Economics of Industrial Networks, Routledge, London.

Hendry, C., Brown, J., \& DeFillippi, R., 2000, Regional clustering of high technology based firms: Opto-electronics in three countries, Regional Studies, Vol. 34, Iss. 2, pp. 129-144.

Hickson, D., Hinings, R., Lee, A., Schneck, R. \& Pennings, J., 1971, A strategic contingencies' theory of intraorganizational power, Administrative Science Quarterly, Vol. 16, pp. 216-219.

Hite, J. M. and Hesterly, W., 2001, The evolution of firm networks: From emergence to early growth of the firm, Strategic Management Journal, Vol. 22, pp.275-286.

Hite, J. M., 2003, Patterns of multidimensionality in embedded network ties: A typology of relational embeddedness in emerging entrepreneurial firms, Strategic Organization, Vol. 1, Iss. 1, pp. 11-52.

Hite, J. M., 2005, The evolution of relationally-embedded network ties, Entrepreneurship Theory and Practice, Vol. 29, Iss. 1, pp. 113-144.

Holm, D. and Johanson, J., 1997, Business Network Connections and the Atmosphere of International Business Relationships,. In Ingmar Bjorkman and Mats Forsgren (eds.) The Nature of the International Firm, Copenhagen: Mumkgaard Int. Publ. Ltd.

Human, S.E. and Provan, K.G., 2000, Legitimacy building in the evolution of smallfirm networks: A comparative study of success and demise, Administrative Science Quarterly, Vol. 45, pp.327-365.

Johanson, J. and Mattsson, L., 1988, Internationalization in Industrial Systems - A Network Approach, in Hood and Vahlne, eds., Strategies in Global Competition, New York: Croom Helm.

Johanson, J. and Mattsson, L.-G., 1992, Network positions and strategic action - an analytical framework, in Axelsson, B. \& Easton, G. (eds.), Industrial networks. A new view of reality, Routledge, London.

Johanson, J. and Vahlne, J.-E., 1977, The Internationalization Process of the Firm: A Model of Knowledge Development and Increasing Foreign Market 
Commitments, Journal of International Business, Vol. 8, Iss. Spring/Summer, pp. 23-32.

Johanson, J. and Vahlne, J.-E.,1990, The mechanism of internationalisation, International Marketing Review, Vol. 7, Iss. 4, pp. 11-24.

Johanson, J. and Wiedersheim-Paul, F., 1975, The Internationalization of the Firm Four Swedish Cases, Journal of Management Studies, Vol. 12, Iss. 3, pp.305-22.

Johansson, B. and Karlsson, C., 2001, Geographic Transaction Costs and Specialisation Opportunities of Small and Medium- Sized Regions: Scale Economies and Market Extension, in R.R. Stough, (Eds.) Theories of Regional Development: Lessons for Regional Policies, Springer-Verlag, Berlin, pp.150-180.

Jones, C., Hesterly, W. S., and Borgatti, S. P., 1997, A general theory of network governance: Exchange conditions and social mechanisms, Academy of Management Journal, Vol. 22, Iss. 4, pp. 911-945.

Kieser, A., 1994, Why organization theory needs historical analyses and how this should be performed, Organisational Science, Vol. 5, Iss. 4, pp. 608-620.

Kogut, B., Shan, W., and Walker, G., 1992, The Make-or-Cooperate Decision in the Context of an Industry Network, In N. Nohria and R. Eccles (eds.), Networks and Organizations: Structure, Form, and Action, Harvard Business School Press, Boston.

Kosa, M., and Lewin, A., 2000, Managing partnerships and strategic alliances: Raising the odds of success, European Journal of Management, Vol. 18, Iss.2, pp.146-151.

Krackhardt, D. and R. Stern., 1988, Informal Networks and Organizational Crisis: An Experimental Simulation, Social Psychology Quarterly, Vol. 51, pp. 23140.

Krackhardt, D., 1992, The strength of strong ties: The importance of philos in organizations, in N. Nohria, R. Eccles, eds. Networks and Organizations: Structures, Form and Action, Harvard Business School Press, Boston, pp. 216-239.

Larson, A. and Starr, J.A., 1993, A network model of organization formation. Entrepreneurial Theory and Practice, Vol. 17, Iss. 2, pp. 5-15.

Laumann, E. O. and Pappi, F. U., 1976, Networks of Collective Action: A Perspective on Community Influence Systems. New York: Academic Press.

Lin, N., 2001, Social Capital: A Theory of Social Structure and Action, Cambridge University Press. 
Lin, N., 2003, Job Search in Urban China: Gender, Network Chains, and Embedded Resources, in: H. Flap \& B. Volker (Eds) Creation and Return to Social Capital, pp. 145-171.

Lin, N., Dayton, P., and Greenwald, P., 1978, Analyzing the Instrumental Use of Relations in the Context of Social Structure" Sociological Methods and Research Vol. 7, Iss. 2, pp.49-166.

Lin, K, and Chaney, I, 2007, The Influence of Domestic Interfirm Networks on the Internationalization Process of Taiwanese SMEs, Asia Pacific Business Review, Vol. 13, Iss. 4, pp. 565-583.

Marsden, P. and Hurlbert, J., 1988, Social resources and mobility outcomes: A replication and extension, Social Forces, Vol. 66, pp. 1038-1059.

Marsden, P., and Campbell, K. E., 1984, Measuring tie strength, Social Forces, Vol. 63, pp. 482-501.

Mason, R., J., McKenney and D., Copeland G., 1997, Developing an Historical Tradition in MIS Research, MIS Quarterly, Vol. 21, Iss. 3, pp 257-276.

McCann, P., 2003, Geography, trade and growth: Problems and possibilities for the New Zealand economy, New Zealand Treasury Working Paper, 03/03, pp. 1-28.

Meyer, C., 2001, A Case in Case Study Methodology, Field Methods, Vol. 13, Iss. 4, pp. 329-352.

Milgram, S.,1967, The Small World Problem, Psychology Today, Vol.1, Iss. 1, pp. 60-67.

Ministry of Economic Development, 2008, New Zealand Trade and Enterprise, New Zealand's Economic and Trade Development Agency, Available: http://www.med.govt.nz/templates/Page_16234.aspx, Accessed: 18 December 2008.

Mitchell, J., C., 1969, The concept and use of social networks, in Social Networks in Urban Situations, ed. Mitchell, J., C., Manchester University Press, Manchester.

Nohria, N., and Robert G. Eccles Jr., eds. Networks and Organizations: Structure, Form, and Action, Boston: Harvard Business School Press, 1992.

O'Donnell, A., Gilmore, A., D. Cummins, (2001), The Network Construct in Entrepreneurship Research: A Review and Critique, Management Decision, Vol. 39, Iss. 9, pp. 749-760.

Oviatt, B. M. and McDougall, P. P., 1994, Toward a theory of international new ventures, Journal of International Business Studies, Vol. 25, pp. 45-64. 
Oviatt, B. M. and McDougall, P. P., 1999, Accelerated internationalization: why are new and small ventures internationalizing in greater numbers and with increasing speed?, in: A. M. Rugman \& R. Wright (Eds) Research in Global Strategic Management: International Entrepreneurship, pp. 23-40, JAI Press: Stamford, CT.

Powell, W. W., Koput, K. IV., and Smith-Doerr, L., 1996, Interorganizational collaboration and the locus of innovation: Networks of learning in biotechnology. Administrative Science Quarterly, Vol. 41, pp. 116-145.

Putnam, R. D., 1993, The prosperous community: Social capital and public life, American Prospect, Vol. 13, pp. 35-42.

Roelandt, T. J. A., and Den Hertog, P., 1998, Cluster Analysis and Cluster-based Policy in OECD countries. Various approaches, early results and policy implications, Draft synthesis report, OECD-focus group on cluster analysis and cluster-based policy, The Hague.

Sasi, V. and Arenius, P., 2008, International new ventures and social networks: Advantage or liability?, European Management Journal, Vol. 26, pp. 400- 411 .

Scholl, D., 2006, A Review of Internationalization and Network Concepts: Implications for the Role of Personal Relationships, Helsinki University of Technology, Seminar in Business Strategy and International Business.

Simmel, G., 1922, Conflict and the Web of Group Affiliations, Free Press, Glencoe, IL.

Simmons, G., 2001, The Impact of Size and Distance on New Zealand Firm Size, Behaviour and Performance, Draft Paper, Economic Transformation Project, New Zealand Treasury, Wellington.

Solberg C. A. and Durrieu, F., 2004, Access to networks and Commitment to internationalization as precursors to marketing strategies in international markets, Management International Review, Vol 46., no 1, pp. 57-83.

Solberg, C. and Durrieu, F., 2004, Access to networks and internationalisation commitment as precursors to marketing strategies in international markets, Paper submitted to the IMP Conference Copenhagen, September 2004.

Staber, U., 2001, Spatial proximity and firm survival in a declining industrial district: the case of knitwear firms in Baden-Württemberg, Regional Studies, Vol. 35, Iss. 4, pp. 329-341.

The Office of the Prime Minister, 2002, Growing an Innovative New Zealand, The Office of the Prime Minister, Parliament Buildings, Wellington, New Zealand 
Tichy, N. M., Tushman, M. L. and Fombrun, C., 1979, Social Network Analysis for Organizations, The Academy of Management Review, Vol. 4, Iss. 4, pp. 507-519.

Todeva, E., 2001, The explanatory power of network theory and its application to multinational business relationships, Conference APROS 2001, Organization Theory in Transition: Transitional Societies; Transitional Theories, 3-5 December, Hong Kong.

Turnbull, P. and Valla, J., 1987, Strategies for International Industrial Marketing, London: Groom Helm.

Uzzi B., 1996, The sources and consequences of embeddedness for the economic performance of organizations, American Sociological Review, Vol. 61, pp. 674-698.

Uzzi B., 1997, Social structure and competition in interfirm networks: the paradox of embeddedness, Administrative Science Quarterly, Vol. 42, pp. 35-67.

Van Wijk, et al 2003 in Handbook of Org learning and KM, Easterby-Smith and Lyles

Wikipedia, 2008, New Zealand, From Wikipedia, the free encyclopedia, http://en.wikipedia.org/wiki/New_Zealand, accessed $14^{\text {th }}$ November 2008.

Yin, R., 1994, Case Study Research: Design and Methods, $2^{\text {nd }}$ edn. Sage Publications, Newbury Park, CA.

Yin, R.,1989, Case study research: Design and methods, Newbury Park, Sage, CA.

Yin, R., 1993, Applications of case study research, Beverly Hills, Sage Publishing, CA. 